\title{
FY 1985 Status Report on Feasibility Assessment of Copper-Base Waste Package Container Materials in a Tuff Repository
}

\author{
R. D. McCright \\ Lawrence Livermore \\ National Laboratory
}

September 30, 1985

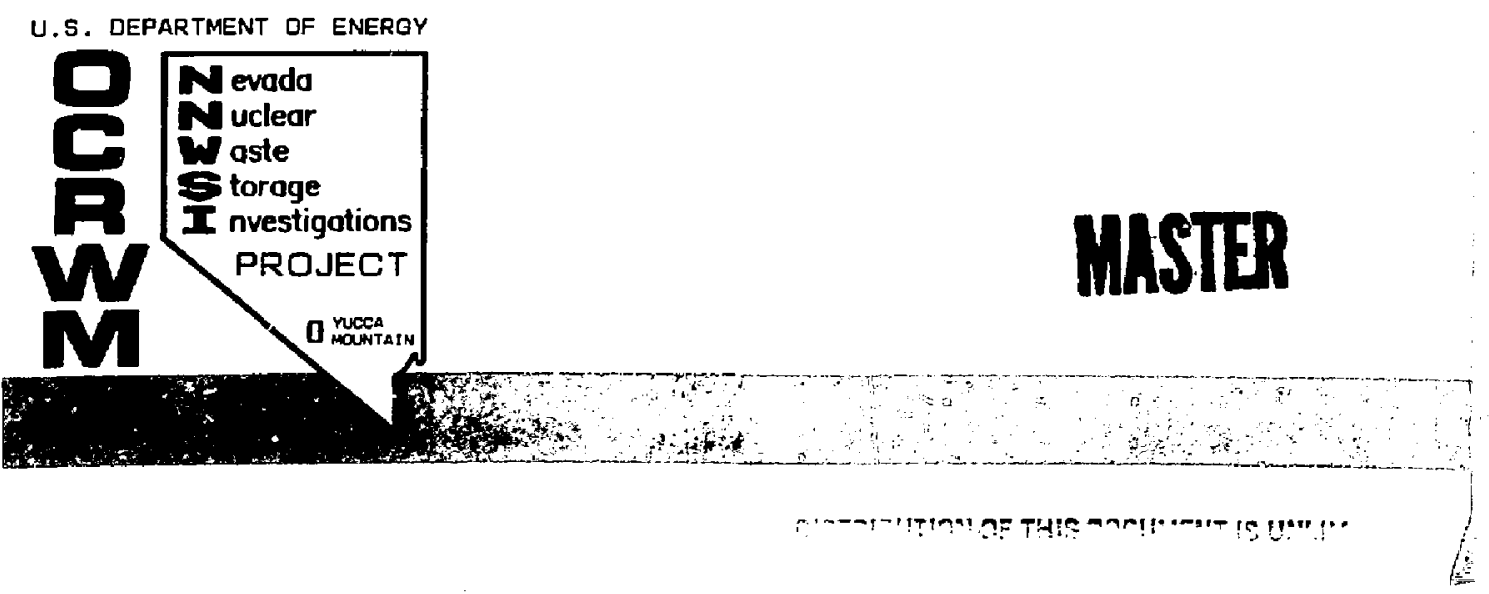




\title{
FY 1985 STAUUS REPDRT ON FEASIBILITY ASSESSMENT \\ OF COPPER-BASE WASTE PACKAGE CONTALNER MATERLALS \\ IN A IUFF REPOSITORY
}

\author{
R. D. McCrighí \\ Laurence Livermore National Laboratory \\ Septenber 301985
}

\section{DISCLAIMER}

\begin{abstract}
This report was prepared as an account of work sponsored by an agency of the United States Government. Neiltier the United States Government nor any agency thereof, nor any of their employes, makes any warranly, express or implied, or assumes any legal jisbility or respoasibility for the accuracy, completeness, or usefulness of any information, appasatus, product, or process disclowed, or represents that its use would not infringe privately owned tights. Reference herein to any specilic commercial product, process, or service by trade name, trademart. masuratures, of olberwise does not necesanily constitute or imply its endorsement, recommendation, or favoring by the United States Government or any azency tbercof. The yiews and opinions of authors expressed berein do not necessarify state or reflect thowe of the United Sutes Government or any atency iberoof.
\end{abstract}

*Work performed under the auspices of the U.S. Department of Energy by the
Lawrence Livermore National Laboratory under contract number $W-7405-E N G-48$. 


\section{FY 1985 STATUS REPORT ON FEASIBIL ITY ASSESSHENT \\ OF COPPER-BASE WASTE PACKAGE CONTAINER MATERIALS \\ IH A TUFF REPOSITORY}

\section{CONTENTS}

\section{Abstract}

1. Purpose and site 8ackground. .................... 1

2. Selecting Waste Package Container Materials........... 7

3. NMWSI Reference Waste Package Container Designs. . . . . . . . 11

4. Tesi Progran to Evaluate Copper and Copper A1loys as Container Materlals....................... 19

5. Possible Forms of Corrosion and 0xidation of Candidate Copper-Base Materials Under Tuff Repository Conditions . . . . . . . . . . 30

6. Corrosion Test Results to Date ............... 50

7. Fabrication and Welding of Copper and Copper Alloy Containers... . A7

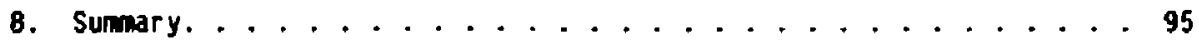

9. Acknowledgments. . . . . . . . . . . . . . . . 97

References........................ 99

$$
\text { Appendix } A
$$

Appendix $B$ 


\section{PURPOSE AND SITE BACKGROUND}

The purpose of this document is to detail the activitfes of the Nevada Nuclear Waste Storage Investigations (NWWSI) Project in FY 1985 to assess the feasibilty of using copper and copper-base alloys as container materials for disposal of high-level nuclear waste in a proposed repository at Yucca Mountain in Nye County. Nevada. The host rock at the Yucca Mountain site is tuff. This work is sponsored by the HWWSI as part of the United States Department of Energy (DOE) Office of Civilian Radioactive Waste Management (OCRWH) program. Ihe NNWS1 Project is managed by the Waste Management Project Office at the U.S. DOE Nevada Operations Office. Within the NNWSI Project, major tasks are performed by principal contractors. Lawrence Livermore National Laboratory (LLNL) is responsible for designing and evaluating the performance of the waste package, which consists of the metal container, waste form, and other components.

A two-year test plan for evaluating copper and copper-base alloys as alternative container materials to the reference austenitic stainless steel/high-nickel austentilic alloy system was developed by NWWI at the end of FY 1984. The plan was designed to evaluate copper and copper-base matertals for potential waste containers that would meet the regulatory requirements for containment, controlled release, and retrlevability set forth in

10 CFR Part 60 (NRC, 1983). The present document detalls the first-year results from the test plan. At the end of FY 1986. NNWSI will report its two-year feasibility assessment of copper-base materials.

\subsection{Characteristics of Yucca Mountain Site}

The host rock at the Yucca Mountain site is tuff. Specifically, the proposed repository is located in the lopopah Spring Member of the Paintorush luff. which is a welded, devitrifled, ash-flow layer. The major phases in the rock are a fine-gratned assemblage of alkali feldspar, quartz, and cristobalitite. Several minor phases are present. The elemental composition of the reference welded tuff is given in Table 1 (Johnstone and Wolfberg, 1981). It is of significance to the performance of containment materials that the rock composition is dominated by the presence of alkall and alkaline earth elements that will tend to give a basic reaction with water. Most elements 
1able 1. Major species bulk composition for reference welded tuff.

\begin{tabular}{|c|c|}
\hline Spectes & $\begin{array}{l}\text { Typical } \\
\text { range } \\
\text { (wt) }\end{array}$ \\
\hline \multirow{6}{*}{$\begin{array}{l}\mathrm{S}_{10} \\
\mathrm{~A}_{2} \mathrm{O}_{3} \\
\mathrm{~K}_{2} \mathrm{O} \\
\mathrm{Na}_{2} \mathrm{O} \\
\mathrm{H}_{2} \mathrm{O} \\
\mathrm{CaO}\end{array}$} & $68-75$ \\
\hline & $10-17$ \\
\hline & $2.0-7.0$ \\
\hline & $1.0-6.0$ \\
\hline & $1.0-5.0$ \\
\hline & $0.5-2.5$ \\
\hline \multirow{2}{*}{$\begin{array}{l}\mathrm{Fe}_{2} \mathrm{O}_{3} \\
\mathrm{FeO}\end{array}$} & $0.7-2.0$ \\
\hline & $0.1-2.0$ \\
\hline$S$ & $0.0-2.0$ \\
\hline MgO & $0.7-3.5$ \\
\hline $\mathrm{T}^{1} \mathrm{O}_{2}$ & $0.0-0.4$ \\
\hline $\operatorname{Mno}$ & $0.0-0.2$ \\
\hline$P_{2}{ }^{O_{5}}$ & $0.0-0.2$ \\
\hline
\end{tabular}


are present in their highest oxidation states, so that the prevailing redox condition is oxidizing. The investigations that led to the choice of this specific site are documented in the report of Johnstone et a1. (1984). The reference horizon for the repository 11 es some $350 \mathrm{~m}$ below the ground surface and at least $200 \mathrm{~m}$ above the static water table.

Locating the repository above the water table in the unsaturated zone influences the design of waste packages and provides limits on the conditions to which the waste packages will be subjected. Sone of the important features of the Yucca Mountain site are:

- The waste containers w111 not be submerged in a continuum of water. Rather, they w111 be subjected to constant contact with a mixture of water vapor and air and to intermittent contast with a limited amount of liquid water.

- Only small amounts of water are avallable in the repository location. Annual precipitation at Yucca Mountain is low (arid climate), and most of this water does not percolate downward but evaporates at the surface. Cracks and other structural features in the rock allow a small amount of water to infiltrate downward. Montazer and Wilson (1984) give a $11 \mathrm{mit}$ of $0.2 \mathrm{~mm} / \mathrm{y}$ of downward flux for the matrix of the Topopah Spring welded unit.

o The pressure exerted on the containers by the environment w111 be approximately $1 \mathrm{~atm}$. There will be no hydrostatic pressure because of the location above the water table. The containers will not bear 1jthostatic loads because the host rock should not creep under the post-emplacement thermal conditions. The load-bearing requtrements are limited to pressures caused by sloughing of rock from emplacement boreholes. Thus, thick-walled containers are not required to withstand significant external pressures from the environment.

- The waste packages will be exposed predominantly to a mixture of water vapor and air with a pressure of about 1 atm when the temperature is above the unconfined bolling point of water, which is $95^{\circ} \mathrm{C}$ at the elevation of the repository. Because of the heat generated by radioactive decay of the waste, the container surface temperatures will not cool to $95^{\circ} \mathrm{C}$ for many years. The container surfaces of those packages containing spent fue 1 waste are estimated to remain abcve the bolling point for the entire containment period. 
- The vadose water (water infiltrating the rock from atmospheric precipitation) and repository atmosphere are expected to be mildiy oxidizing.

The composition of the transient water that is characteristically assaclated with the Yucca Mountain site is derived from an analysis of water from producing we $11 \mathrm{~J}-13$ (7able 2), approximately $10 \mathrm{~km}$ east of the Yucca Mountain site. The water-producing formation at the well is an extension of the Inclined Topopah Spring member where it is present below the static water table. Water from this well has been condtioned by prolonged contact with the rock during its descent from higher elevations. From the point of view of metal corrosion, the J-13 water is mildy alkaline (pH 7-8); dominant anionic species are in their highest oxidized forms (nttrate, sulfate, bicarbonate). The content of halide ions is quite small (7 ppm chloride, 2-3 ppm fluoride). Heavy metal tonic spectes, ff present, are below detectable limits.

Although more detalled and more representative samples of the rock and vadose water will be taken when the exploratory shaft is sunk at Yucca Mountain, the analyses given in Tables 1 and 2 represent the current "reference" analyses and have been used in the research and development work for testing copper. Testing is performed in water taken directiy from the J-13 well and in some modifled forms of the water to account for devtations from this composition that will result from waste package emplacement.

\subsection{Emplacement Effects on Repository Environment}

The physical and chemical features of the repository environment that affect metallic corrasion have been discussed (HcCright et a1., 1983; Juhas et a)., 1984), particularly with respect to austenitic stainiess steels (such as A1SI 304L and 316L and the stab11ized grades 321 and 347) and the high-nickel austenitic alloy 825 . Emplacement of waste packages in the Yucca Mountain repository will increase the temperature around the waste package from the amblent $\left(29^{\circ} \mathrm{C}\right)$ to a peak temperature that depends on the type of waste form and the waste package and repository design (see $\mathrm{Sec} .3$ ). As the pressure at the repository location is essentially atmospheric, any water present in the environment wtll be vaporized because of the elevated temperature. Communication with the atmosphere through reck fractires will ensure aeration 
Table 2. Reference groundwater composition for tuff repositorles (based on composition of Jackass Flats Well J-13

at the Nevada lest Site). The pH is slightly alkaline (7.1).

\section{Element}

Sitica

Sodium

Calcium

Potassium

Magnestum

Lithium

Strontium

Iron

Aluminum

Barfum

Bicarbonate

Sulfate

Chloride

Nitrate

Fluoride

Phosphate

\section{Concentration}

(mg/l)

61.0

51.0

14.0

4.9

2.1

0.05

0.05

0.04

0.03

0.003

120.0

22.0

7.5

5.6

2.2

0.12 
of the vapor phase. Hater percolating downward w111 be vaporized as it crosses the $95^{\circ} \mathrm{C} 1$ sotherm. Gamma radiation emanating from the waste package may create chemical changes in the repository environment. The gamma field will decrease with time; 100 years after emplacement the gamma dose rate will have decreased by a factor of 10. After the container surface has cooled to $95^{\circ} \mathrm{C}$. I1quid water may re-enter the environment around the waste package. The composition of this water is expected to be similar to that of 3-13 well water, described above. There is the possibility of concentrating ionic spectes in the aqueous environment at levels above those in the 3-13 water. One process by which tonic species can concentrate is re-solution of spectes that were initially deposited in the rock formation when the downward percolating water evaporated. Another process for concentrating ionic species is deposition of "salts" by repeated dripping of water onto a hot container surface, evaporation of the water, and subsequent re-solution of the salt deposits when the container has cooled below the bolling point.

When discussing resaturation of the environment with ifquid water, it is important to remember the overali low water flux that will eventually find its way to the repository horizon (estimated at $0.2 \mathrm{~mm} / \mathrm{y}$ ). Thus, immersion of the container surfaces is expected to be confined to a small area of a small number of the total population of containers for a limited period of time. However, the "wet" environments are likely to be the most limiting ones for selecting materials that will withstand all of the environmental conditions that may develop over the 300-1000 year contalnment perlod, because many localized and stress-assisted forms of corrosion occur only in aqueous media. for this reason, the "wet" conditions receive more emphasis in the testing program than would be merited by apportioning the times during which the different environmental conditions would actually occur.

As evidenced by the previous discussion, several aspects of the thermal and radiation components of the waste package environment can at present be specified only as a range. 1hus, testing efforts for candidate materials must include representative conditions over this range. 


\section{SELECTING haSte PACKage CONTAINER hateriaLS}

The selection of container materials is guided by the regulatory requirements governing containment and retrlevability of waste packages. From the point of view of materials selection, certain practical considerations must be addressed. These include the corrosion-and oxidation-resistance of container materials, their strength and toughness, their fabricability and weldability, their cost and availability, and the compatibility of the container with other package components, including borehole liners. General aspects of these considerations are discussed in the section below and in greater detal1 in subsequent sections.

\subsection{Containment of Radioactive Wastes}

The paramount consideration in selecting a container material is whether the material is sufficiently corrosion-and oxidation-resistant to withstano the environment and provide "substantially complete" containment for a 300-1000 year period. The Nuciear Regulatory Commission (NRC) containment requirement is as follows:

60.113 Performance of particular barriers after permanent closure.... the engineered barrier system shall be designed, assuming anticipated processes and events, so that: (A) Containment of HLW within the waste packages $w 117$ be substantially complete for a period determined by the Commission taking into account the factors specified in 60.113(b) provided, that such perlod shall be not less than 300 years nor more than 1000 years after permanent closure of the geologic repository...(NRC, 1983)

The emphasis here is on using the metal container as the barrier for at least the first 300 years. Pending a quantitative definition of "substantially complete," containment is considered to mean demonstration that a very large fraction of the containers is unbreached in this time period. The thickness of the metal needed to meet the contalnment requirement will depend on corrosion rates and mechanisms in the expected envirsonment. The corrosion rates and mechanisms witi depend on a number of parameters including the type of stress that the container must withstand, the type of metal and its microstructure, the number and characteristics of defects in the metal, the temperature history, radiolys is effects, galvantc effects. and the groundwater characteristics. Thus, design and environmental factors enter into the corrasion performance. 
The container material must also be "compatible" with the waste form in the sense that degradation of the metal barrier should not compromise the performance of the waste form by hastening release of radioactive species.

In addition to the parameters affecting the corrosion performance, the waste package container must be strong enough that it will not be crushed by exterial hydrostatic and lithostatic pressures. Because there will be only a small amount of "free" liquid inside the waste package (water logged spent-fuel elements should be the primary source), internal pressures should be minimal. Since the NNWSI repository will be above the water table, no hydrostatic head exists, but there may be some stress from the sloughing of rock onto the packages. Potential dynamic loads must also be considered.

The most inportant factors determining the mechanical strength of the candidate container matertals are the staitc and dynamic loads during emplacement or retrieval of the waste package. The emplacement and external stresses have not been defined in terms of a minimum yield strength or other mechanical material property, but a preliminary ana?ysis of the maximum dynamic loads (conditions corresponding to a "drop test" of about three times the container height onto an unyielding surface) during an emplacement operation of a 1-cm-thick reference NNWSI container indicates that a maximum stress of 30,000 psi would occur just belaw the pintle of the container $\left(0^{\prime}\right.$ Neal et $\left.a 1,1984\right)$. The room-temperature yield 5 trengths of all the candidate stainless steels, high-nickel stainless alloys, and principal copper-base alloys of interest in the fully annealed condition (approximately 20-30 ksi) are of this same magnitude. Furthermore, the maximum stress under these "accidental" conditions is substantially delow the ultimate tensile strength, even allowing for the decrease in mechanical propertles with increasing temperature, so that no rupture and release of contents woutd be expected. On mechanical considerations alone, the relatively thin-wajled NNWSI containers could be fabricated from either stainless steels or a copper-base alloy. However, for a waste package container made of high-purity copper, some compensation for the low strength of this material would be required by using a container thickness greater than $1 \mathrm{~cm}$.

Toughness is perhaps a better index of the mechanical strength requirement given the steady-state external stresses, emplacement loads, and potential dynamic loads. However, the various requirements have not been translated into a minimum Sharpy impact strength for other measure of fracture toughness 
in materlais). These requirements are not ilkely to impose severe limitations on copper-base materials because of their excellent ductility. The potential exisis in some alloys for certain grain-boundary active elements to concenirate and create embrittled regions and loss of fracture toughness.

Discussion of the mechanical properties is continued in Sec. 3 of this report, and metallurgical effects on alloy embrittlement are discussed in Sec. 4.

\subsection{Retrieval of Waste Packages}

The other NRC standard that influences contatner selection is the one that describes retrlevability requirements for waste packages:

60.11l Performance of the geologic repository operations area through permanent closure. (b) Retrievability of waste. (1) The geologic repository operations area shall be designed to preserve the option of waste retrieval throughout the perlod during which wastes are being emplaced and, thereafter, urit $\{1$ the complet ion of a performance conftrmation program and Commission review of the information obtalined from such a program. To satisfy this objective, the geologic repository operations area shall be designed so that any or all of the emplaced waste could be retrieved on a reasonable schedule starting at any time up to 50 years after waste emplacement operations are initiated, unless a different time pertod is approved or specified by the Commission... (NRC, 1983)

To meet this requirement, the waste container, pint le assembly, pintle attachment welds, and waste package emplacement configuration are designed to be compatible with the initial emplacement operations and any subsequent retrieval operattons.

\subsection{Practical Considerations}

Other considerations that influence container selection include the desirable attributes of using commerclally avaliable materials and processes for fabricating and closing the containers. Some latitude is presumed in specifying the compositions, with more stringent control of some elements (particularly the "tramp" elements, which are "mpurities in the make-up materials) if testing and performance analysis indicate that this additional specification 15 desirable and feasible. The relationship between the fabrication and welding (or other ciosure process) and subsequent corrosion performance is factored into the matertal selection, and provistons are made 
to consider the range of process variables in the testing activities. furthermore, the "fabricability" and "weldability" of the candidate materials are considerations in the selection and eventual winnowing of the candidate 1ist. These terms relate to the ease with which these operations can be performed and the amount of process control that must be exercised to successfully accomplish the operation. These are somewhat vague terms, and in some instances the "ease" of operation means that there are fewer technical probiems to deal with (tendency to crack, requirements to heat treat, pretective atmospheres, degree of temperature control, etcl; in other cases, the terms relate to economic penalties associated with more involved or mare carefully rontrolied operations and need for spectalized and costly equipment. The economic and technical aspects obviously overlap.

The materlal selected for the container and the processes specified for fabricating the containers should be cost effective. This term is meant to incorporate more than just a comparison of the basic cust of one alloy with that of another. The waste package is one component of a much larger system. The design, construction, and operation cosis of the repository are likely to overwhelm the container costs. Furthermore, to demonstrate that the waste package and repository design will successfully meet the NRC requirements will involve a major expenditure of effort, so that container materlals with few fallure mechanisms that may occur in the geologic environment of interest receive more favorable traatment in the selection process. Cost/benefit analyses wili have to be done for the variojs candidate materials and designs as part of the process of material selection.

Borehole liners are included in reposttory designs to facilitate retrleval of waste packages. Two general emplacement configurations are under consideration: vertical emplacement of single waste packages in drilled boreholes spaced along a mined drift and horizontal emplacemerit of multiple waste packages in ?ong, dr 1 lled boreholes ( $60 \mathrm{~m}$ or more in length) botween mined drifts. In the case of horizontat emplacement, liners will be required along the length of the borehole. At least a partial lining of vertical boreholes will be needed. Because the lining must survive only the retrievability pertod, carbon steel is the prime candidate fiaterial for liners. Copper or a copper-base alloy may be considered for fabricating borehole liners if one of these materials is selected for the waste package container and carbon steel proves to be incompatible with copper. 
The compatibility of the carbon steel liner with the candidate container material must be considered when testing and selecting container materia1s. In most instances, the liner would be the "sacrificlal" member in any galvanic coupling of dissimilar metals. However, consideration must be given to whether the corrosion products (mainly ferric iron) procuced by the disintegrating liner would affect the corrosion rates and mechanisms of the contalner material.

\section{NKMSI REFERENCE WASTE PACKAGE CONTAINER DESIGNS}

NWWSI reference conceptual designs were developed for the two gener ic types of waste package: spent fuel and vitrified waste. The criteria for these designs are based on the gaometric configurations of the waste forms, thermal limitations on both the host rock and the waste forms, and the structural requirements associated with handing and emplacement operations. These designs were developed for a container made of austenitic stainless steel and are described in $0^{\prime}$ Neal et al. (1984).

The waste package containers emplaced in the tuff repository will heat the host rock. Because of the lower thermal conductivity of tuff, the container surface temperature will rise. Peak temperatures of $120-275^{\circ} \mathrm{C}$ are expected, and these will be sustained for several years before the temperature decays. The peak temperature and characteristics of the temperature-time decay curve depend on the nature of the waste, the quantity and age of waste in the container, the "areal power loading" in the repository (w/acre), and the geometric spacing of the packages in the repository. Spent-fuel packages will generally have the highest power and therefore will $\mathrm{F}^{-3}$.duce the highest temperatures. Packages containing reprocessed waste (defense or commercial) in a vitrified form (borosilicate glass) will generally have lower power and therefore lower peak temperatures. Present designs are constrained largely by the maximum permissible power load to maintain the internal temperatures below certain critical values $1350^{\circ} \mathrm{C}$ for spent fuel and $500^{\circ} \mathrm{C}$ centerline temperature for borosilicate glass). 


\subsection{Waste Package Descriptions}

The shape of the waste package is a right circular cylinder with a pintle mounted on the top cap for handing during emplacement and retrieval operations. The containers possess common outside diameters $(70 \mathrm{~cm})$. The height of the contalner varies in the different designs to accommodate different lengths of spent-fuel elements from both pressurized water reactors (PWR) and boiling water reactors (BWR). The range is 400-475 $\mathrm{cm}$ (without pintle); the pintle height is $16 \mathrm{~cm}$. The wall thickness is $1 \mathrm{~cm}$ except at the top and bottom end caps, where it is $3.8 \mathrm{~cm}$. Figure 1 shows an example of a spent-fuel container. The internai configurations will vary to accommodate different sizes and arrays of fuel elements and different arrangements of intact or consolldated fuel-element assemblles.

The internal configurations consist of compartments holding the fuel-element assemblies. Several different internal arrangements have been developed, and more will likely cantinue to be developed. In the reference designs, the compartments are separated by " "space frame" of 304 stainless stee1. The purpose of the space frame is to hold the elements in place and conduct heat away from them. An important design criterton is to prevent temperatures in excess of $350^{\circ} \mathrm{C}$ from developing on the Zircaloy-clad surfaces of the fuel elements. The waste package containers may be filled with an inert gas (most likely argon) after the spent-fuel rods are emplaced inside and before the top lid is welded onto the container. If copper or a copper-base alloy is used for the spent-fuel waste package container, the internal space frame may also be constructed of the same or comparable material.

Waste packages containing vitrified waste forms are effectively a can-1nside-a-can design. The waste-form producer will provide the defense or commercial waste inside a pour canister $(61 \mathrm{~cm} \mathrm{0D)}$ that will fit inside the 70-cm-0D $\times 1-\mathrm{cm}$-thick outside container, as shown in Fig. 2. The outside contalner is $308 \mathrm{~cm}$ long (without pintle), which will accomodate the 300-cm-long pour cantster. The pintle design and height are the same as those for the spent-fuel waste packages. The designs for the vitrifted waste packages are based on plans largely developed by the Defense Waste Process Facility (DWPF) under construction at the Savannah River Plant in South Carolina. The pour canister material for the Savannah River DHLW is AISI 304L 


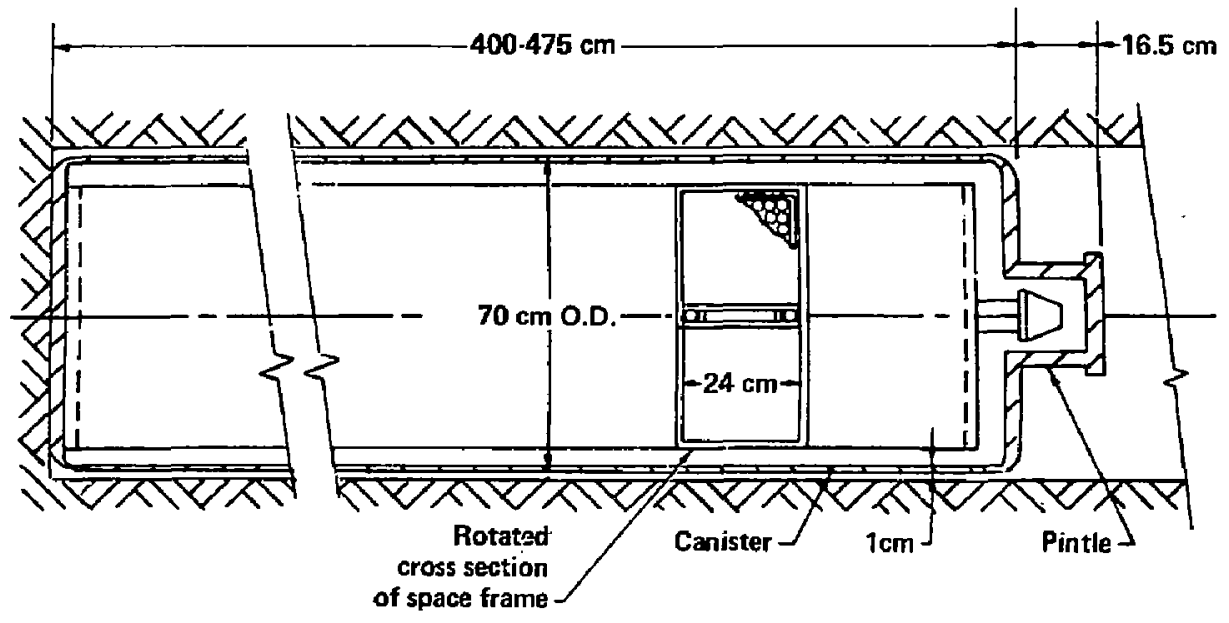

Accepts:

Consolidated, $10 y$, HBU, 4 assems $X 846 w=3384 w$

Consolidated, 5 y. ABU, 4 assems $X \quad 846 w=3384 w$ intact,

5 y, HBU, 2 assems $\times 1316 w=2632 w$

Fig. 1 NNWSI conceptual design for a spent-fuel waste package containing PWR fuel. (Design for BWR fuel waste packages is similar and contains 7 to 14 assembiles). 


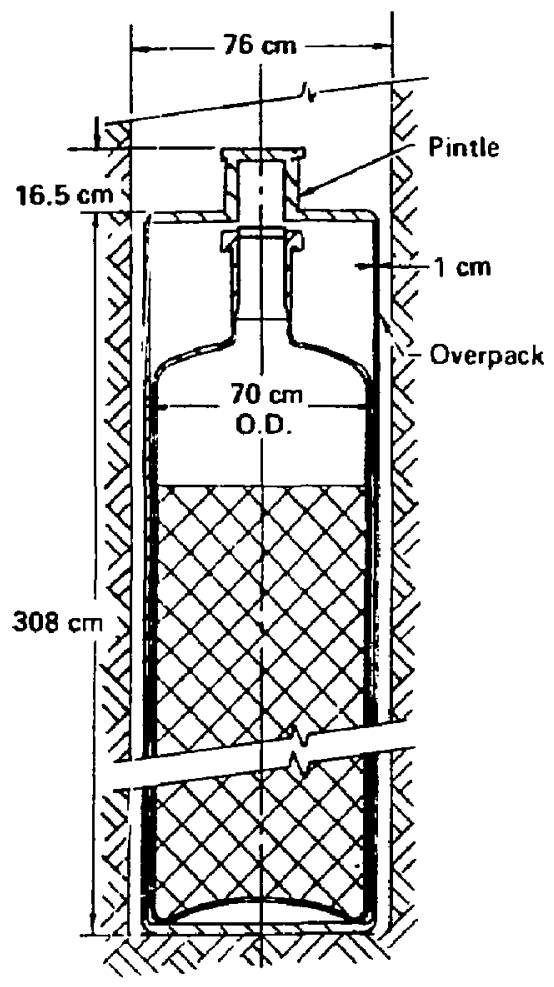

Fig 2. NNWSI conceptual design for waste packages containing vitrified wastes. 
stainless steel. Other defense waste producers (at the DoE Hanford, WA, and Idaho Falls, 10, sites) and commercial waste producers (Westinghouse at Hest Valley, Ny) have not yet developed all of the detalls of their process streams and canister designs.

\subsection{Thermal output}

During container loading and handing operations, surface temperatures of $70^{\circ} \mathrm{C}$ and less are expected. However, when the containers are emplaced in the repository, the container surface temperatures w111 rise considerably because of the relatively low thermal conductivity of the host rock. Typical

time-temperature projections have been calculated from heat-transfer computer codes and are 1 llustrated in $\mathrm{Fig} .3$ (spent-fuel waste package) and $\mathrm{fig} .4$ (OHLW waste package). The thermal conductivity of the container, space frame, and pour canister materials does not significantly influence the thermal decay curve; thus, the higher thermal conductivity of a copper container will not greatly alter these projections. The copper alloys have thermal conductivities comparable to those of the stainless steels. Although the detalled calculations have not been performed, the surface temperature is not expected to vary by more than $10-15^{\circ} \mathrm{C}$ at different locations in the container. Thermal conductivity data for candidate copper and copper-base a)loys are given in Appendix $A$.

The time-temperature projections in figs. 3 and 4 serve to indicate the approximate range of thermal environments expected in the repository. The projections will depend on the thermal outputs of surrounding waste packages; it would be possible, for example, to surrourid the low-thermally-loaded vitrified waste packages with high-thermally-loaded spent-fuel packages to keep the thermal environments more uniform. Additional factors that influence the temperature are whether the packages are at the perfphery or center of the repository and whether they are horizontally or vertically emplaced. Some of these factors have been discussed in a report by Hockman and 0 'Neal (1983).

\subsection{Radiation Output}

The thermal decay is related to the radiation decay; packages with the highest power generally have the highest radioactivity content, with the result that the radiation field around these packages is the highest. The 


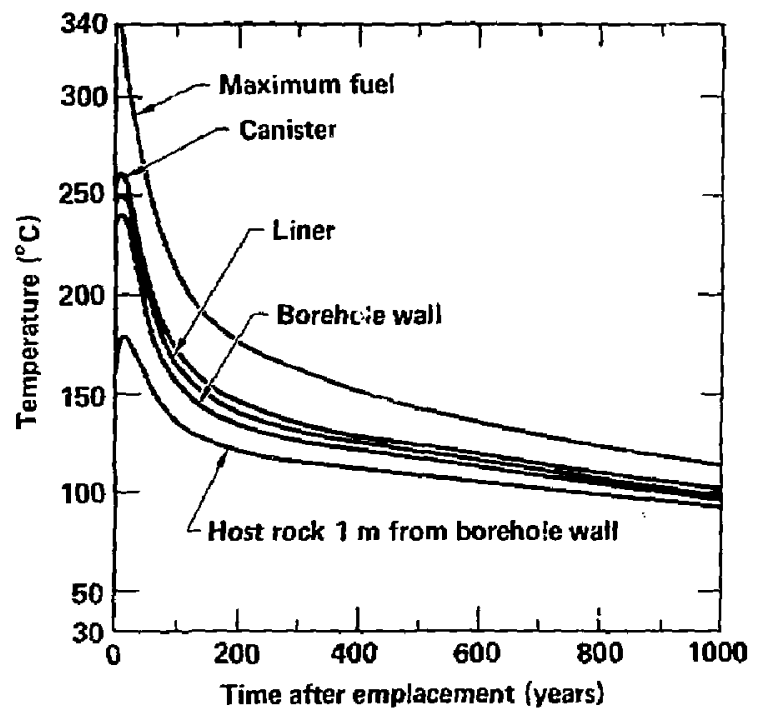

Fig. 3 Representative time-temperature projections for spent-fuel waste packages in a tuff repository. 


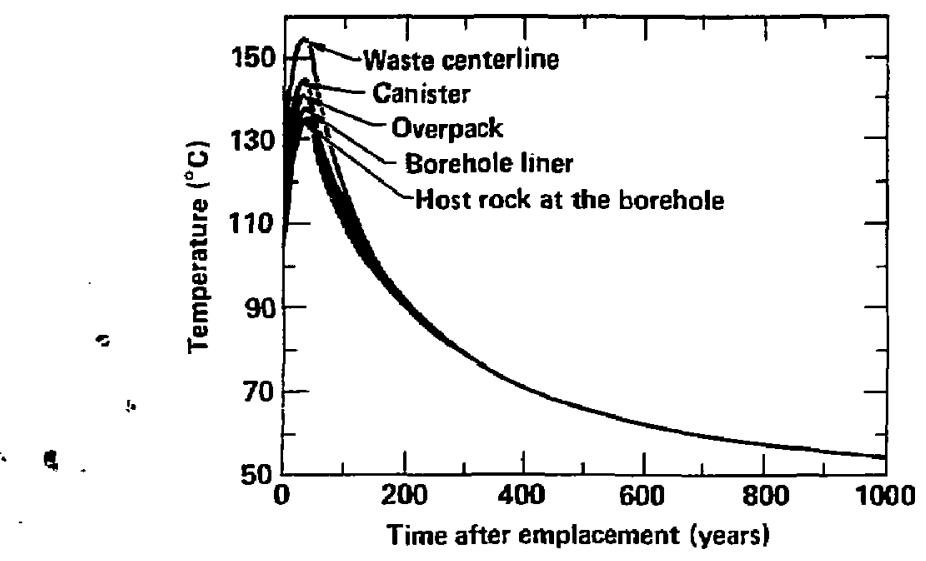

Fig. 4 Representative time-temperature projections for vitrified waste packages in a tuff repository. 
estimated ranges (expressed as a dose rate) for waste packages is $10^{3} \mathrm{rad} / \mathrm{h}$ for defense waste and $10^{5} \mathrm{rad} / \mathrm{h}$ for spent fuel for present NNWS1 reference designs based on 1 -cm-thick containers. At levels above $10^{3} \mathrm{rad} / \mathrm{h}$, the gamma radiation transmitted through the container wall can activate chemical reactions in the environment. Increasing the container wall thickness attenuates the gamma radiation field. The efficienc $y$ of the attenuation depends on the metal density and atomic number but is approximately the same for iron-base and copper-base container materials. The radiation field decays with $t$ ime, the rate of decay being more rapid for the vitrifted wastes than for spent fuel, owing to the presence of long-lived actinides in the latter. The age and burn-up of the spent fuel are important factors in determining the radiation field.

\subsection{Modifications to Haste Package Designs for Copper Containers}

The lower strength of high-purity copper will likely require the use of a thicker container wall than the 1-cm-thick walls used for the conceptual designs involving austenitic stainless steels. A preliminary estimate of the minimum thickness is about $2.5 \mathrm{~cm}$, based on the extent to which fully annealed copper yields during a drop-test simulation. From the point of view of mechanical properties, the present conceptual designs for austenitic stainless steel can be used for aluminum bronze and cupronickel. One favorable consequence of using thicker sections of copper (or any other metal) is that it reduces the gamma field intensity penetrating the container wall, which consequently reduces the amount of radiolysis-induced changes in the environment. Particularly in the case of copper, radiolysis products will make the environment more aggressive. We estimate that a 5-cm-thick copper section will attenuate the radiation dose rate by a factor of 10 .

The design of a copper or copper-base alloy container is further influenced by the form of corrosion that is expected in the repository environment. Container materials can be categorized as corrosion allowance (design for the expected amount of metal loss due to corrosion by increasing the thickness above tha: required for mectanical strength considerations alone) and corrosion resistant (design for mechanical strength considerations alone as the total amount of metal loss is negligible). To a large extent, 
general corrosion degradation problems are solved by increasing the thickness of tha contalner wa11, whereas localized and stress corrcsion problems are best avoided by using materials highiy resistant to these forms of corrosion. Increasing the container wall thickness usualiy does not provide much in the way of additional containment lifetime becuase of the rapid propagation of localized attack paths and stress corrosion cracks. Of the principal candidate copper-base moterlais descrtbed in Sec. 4, unalloyed copper possesses some of the attributes of a corrosion allowance materlal and a corrosion resistant material; aluminum bronze and copper-nickel are primarily considered as corrosion resistant materials.

As discussed above, the low yield strength of unalloyed copper w17l 11keiy necessitate an increase in the minimum container wall thickness (over the present reference NNWSI waste package design thickness of $1 \mathrm{~cm}$ ) to resist the maximum dynamic loads that can develop in the handing, emplacement, and retrleval operations. As the "extra" thickness for strength is needed during the early part of the containment period, the additional wall thickness can function as the corrosion al lowance in later years. The extra wall thickness attenuates the radiation field with the further advantage of decreasing the potential aggressivity of the environment. Copper-base alloys do not have to be used in the thicker sections on the basis of mechanical strength considerations; their general corrosion resistance is greater than that of copper in many environments so that much less of a corrosion-allowance thickness is needed. These considerations form the bases for modifications to the present reference NNWSI designs for waste package contalners made from a copper or a copper-base alloy.

\section{TEST PROGRAM TO EVALUATE COPPER AND COPPER ALLOYS AS CONTAIMER MAJERIALS}

Beginning in JuTy 1984, NWWS1 developed a test progran for evaluating copper and copper alloys for a potentlal repository in Yucca Mountain. The program was reviewed at DOE/NV and at DOE/HO with subsequent modifications to its current version (December 1984). The NNwSI strategy was to view copper and its alloys as an alternative alloy system to the austenitic stainiess steels and high-nickel austenitic alloys which are the present reference materiais. In order to proceed as rapidiy as possible, NNWSI worked closely with the copper industry associations in the U.S., the Copper Development 
Association (CDA) and the International Copper Research Association (INCRA), to utllize their experience in the selection of materials and processes for fabricating waste package containers.

As discussed in Sec. 1., the prevaliing environmental conditions at Yucca Mountain are moderately oxidyzing, and gamma radiation emanating from the waste form may make the environmental conditions even more oxidizing. While the stainless materials would be expected to perform quite well under these conditions, copper may be corroded at an unacceptable rate. Copper alloys have been developed that are more resistant than the unalloyed metal. CDA and INCRA recommended the materials discussed in Sec. 4.1. The interpretive 1iterature survey in Sec. 5 indicates the corrosion behavior of these materials in environments approaching the conditions expected in Yucca Mountain. Because the greatest uncertainty centers around radiation effects on the environment with possible production of species corrosive to copper (nitrate, nitrite, ammonia, hydrogen peroxide), corrosion testing in irradiated environments receives emphasis.

Copper, alone among the engineering metals, can thermodynamically -uexist with aqueous environments under certain conditions. Thermodynamic stability may be an important factor in demonstrating that the selected waste-package container material can attain the long-term service performance objectives. The fact that copper and bronze artifacts have survived from earlier civilizations demonstrates that the thermodynamic nobility of copper and the protective quality of initial corrosion products (tarnish layers) combine to provide a lang-lasting metalic structure.

The copper-base alloys of interest as container materlals possess relatively simple microstructural features. The principal solute elements are soluble ov:r a wide temperature range, and copper does not have any phase transformations. Hever theless, long-term segregation of various chemical species (particularly at grain boundarles) will have to be considered, especially if the segregated specles provoke embrittlement. Phenomenon affecting some copper-base alloys (particularly brasses, but occasionally a luminum bronzes) is selective leaching of the less-noble constitutent in certain environments. The selective leaching leaves a "sponge" of brittle copper . 
4.1 Candidate Copper-Base Materials for Nuclear Waste Package Containers in Tuff

In May 1984, NWWSI contacted representatives of the copper industry to discuss with them which grades of copper and wich alloys of copper might be appropriate candidate materials to consider for waste package containers in the tuff geochemical environment at Yucca Mountain. Representatives from COA and INCRA met with HAWSI representatives several times in 1984 to discuss the viability of different candidate materials and the testing approach to indlcate their performance. Because the environmental conditions in a tuff reposttory are dominantly oxtdizing, certalin copper-base alloys are expected to show greater corroston resistance than high-purity copper. However, high-purity copper is a candidate material for the Swedish repository program in granite and for the Canadian repcsitory program, also in granite, and for the Basalt Haste Isolation Project (BWIP) in basalt. Since there is some value in sharing information on a comon candidate among the different profects, high-purity copper was recommended as a candidate container material for the NNWSI project. The copper industry recommended fiv z copper-base materials for NWWSI to test--one high-purity copper and four alloys. These materlals are described brtefly below. The CDA Standards Handbook data sheets for these materlals give the composition and detalled mechanical and physical properties; they are included in Appenof $x A$. The nomenclature in our report uses the simpler three-digit CDA number for the different grades of copper and its alloys. The longer Unified Numbering System (UNS) number is given below; the UNS system includes the CDA number with extra place holders to incorporate additional digits for small modifications to the alloy composition.

- CDA 102 (UNS C10200) (oxygen-free copper) was proposed for the Swedish disposal canisters and its use was reviewed by the U.S. Nattonal Academy of Sclences. CDA 102 is included to provide a link to that program and a baseline for comparing all the alloys.

- CDA 613 (UNS C61300) (aluminum bronze--6.0-8.0\% a luminum) offers excellent resistance to high-temperature oxidation. It is widely used commercially in mildiy oxidizing enviranments at elevated temperatures.

- COA 715 (UNS C71500) (70\% copper, 30\% nickel) is chosen for 1 ts excellent corrosion resistance in aggressive environments such as steam environments contaminated with ammonia and other corrosive noncondensible gases. 
- CDA 172 (UNS C17200) (bery111um copper--1.8-2.0x bery111um) is a precipitation-hardenable alloy that can achieve very high yield, creep, and fatigue strengths.

- CDA 18) (UNS C18)00) (MZC copper) is an oxygen-free material with smal1 additions (a)l less than $1 \%$ ) of magnesium, zircontum, and chromium to achleve high strength through cold work and aging. It has the same virtues as oxygen-free CDA 102 and contains yield strengths above 50,000 psi at elevated temperatures.

There are cast versions of the above wrought materials. Section 7 discusses fabrication of the containers; conventional methods use rolled and welded matertal. In some alternative container-fabrication processes, cast materlals may be used. in whtch case the proper nomenclature would be:

0 CDA 801 (UNS CBO100) for the oxygen-free copper.

o CDA 952 (UNS C95200) for the a7uminum bronze.

- CDA 964 (UNS C96400) for the 70/30 copper-nicke1.

The compositions and certain physical and mechanical properties of the cast versions differ silghtly from those of the wrought verstons. These are given in Appendix $A$.

When this list of candidate materials was being complled, NNHSI was considering the idea of using copper-base materlals for the pour canister as well as the outer container (sometimes called overpack) for the vitrified waste forms. For this use, the glass waste would have been poured directly into the copper or copper alloy canister, hence the concern with high strength at elevated temperatures. (The glass is typlcally poured at a temperature of $1000-1100^{\circ} \mathrm{C}$, and peak temperatures of $600-700^{\circ} \mathrm{C}$ develop on the canister surface). Since that time, 1t has become apparent that the waste-form producers will most 11 kely specify austenitic stainless steel (specificaily AisI 304L) for the pour canister because of 1 ts excellent resistance to scaling in the process environment and consequent small production of contaminated matter on the surface. The outer container of the packages containing vitrified waste forms will not experience these thermal conditions, and the strength-at-temperature property w11l not be required. For this reason, as well as high relative cost, the CDA 172 (beryllium copper) and CDA 181 (MZC copper) were not considered fur ther. 
The respective room-temperatire yield strengths for CDA 102, CDA 613, and CDA 715 are 10, 40, and $20 \mathrm{ks}$ in the soft (annealed) condition for each mater $1 a 1$ (plate stock). These yield-strength properties are based on a $0.5 x$ extension under load and are somewhat higher than comparable yield-strength values derivad from the more conventional $0.2 \%$ offset reported in other alloy systems. The corresponding respective tensile strengths are 32,80 , and 55 ks1, again in the soft condition. Respective elongations are 45, 40, and $45 x$. Copper and its alloys are readily hardened by cold work, with substantial increase in strength but concomitant loss in ductility. The properties for annealed materials are used here for comparison because the expected long times at moderately elevated temperatures will favor relaxation of the work hardening effects.

\subsection{NNWSI Evaluation Plan}

\subsubsection{Parallel Test Prograns}

The NNHSI plans to evaluate the three candidate materials recommended by CDA and INCRA under anticipated and episodic environmental conditions that may occur around a waste package emplaced in a repository in Yucca Mountain. The evaluation plan for copper effectively parallels the research on using stainless steels as nuclear-waste container materials. Except where specific galvanic effects are the object of investigatinn, copper and stainless steel specimens cannot be placed in the same test vessel because of potential cross-contamination of the test environment as a result of the production of corrosion products from the dissimilar metals. Copper and copper-base alloys have generally lower mechanical strengths than austenttic stain]ess steels, and the fabrication and welding processes for producing and closing the canister may vary from the processes proposed for statnless steel containers. Waste package designs based on copper or copper-base alloys may differ considerably from those proposed with austenitic stainless steels as the container material. In many of the corrosion tests (stress corrostion testing, in particular), specimens are worked and heat-treated to simulate the fabrication and welding process conditions. Because of all of these differences between copper and austentic stainless stee1s, parallel testing efforts are needed for the two alloy systems. 
The present NHWSI schedule, in conformance with the Mission Plan, calls for selection of container materials at the end of FY 1987. At this time, $a$ decision on which alloy system (copper or stainless steel) witl be made if the corrosion test programs on each have indicated that candidates in each alloy system are 1ikely to meet the containment service life of 300 - to 1000-years in the tuff repository. The evaluation plan and schedule were developed with this decision point in mind.

\subsubsection{Quality Assurance}

Because copper or a copper-base alloy may be selected for fabrication of nuclear waste containers, data generated in the testing and evaluation of these materials may ultimately be used in support of a repository 11cense application. Therefore, the pertinent elements of the NWWSI QA Project Plan will apply to these copper and copper-base alloy testing and evaluation activities.

\subsubsection{Peer Review of the Copper Test Plan}

A peer review group was established to review, evaluate, and critique the copper test plan and to assess the test results as they become avallable. The group consists of Professor Denny Jones, University of Nevada at Reno, and Mr. John Griess, Oak Ridge Hational Laboratory.

\subsubsection{Common Hork Areas between NNWSI and BWIP}

In November 1984, discussions between waste package task representatives from NWWSI and BWIP Identified common work areas in the two projects. An agreement was reached that these work areas were to be undertaken in a joint effort, with either NWHSI or BNIP taking the lead in organizing and initiating the work in FY 1985 and continuing into FY 1986. The common work areas are:

- Analysis of the effects of thickness of the container on reduction of the gamma radiation flux in the near-field package environment. BHIP has initiated the work in this area. 
Cost and avallability of candidate copper and copper-base alloys over the repository construction and operation pertod. NWWSI has initiated the work in this area. Development of fabrication processes to produce waste package containers. NWWSI has inttiated the work in this area. Development of welding processes and techniques, including welding thick (one to several inches) sections and remote welding operations. BHIP will initiate the work in this area in FY 1986. Formation of a peer review group to review and critique the copper test plan, particularly the corrosion-related parts of it, as noted in Sec. 4.2.3. NNWSI was responstble for forming the peer group.

\subsubsection{Evaluation Summary}

The evaluation plan therefore consists of three parts: (1) acquire a data base on which the long-term corrosion performance of the candidate copper and copper-base alloys can be assessed in the waste package environment;

(2) analyze waste package designs based on copper as the contalner material and evaluating the impacts on the site surface and sub-surface facilities of - packaging the waste and handling the filled waste packages; and (3) assess the economic situation associated with using copper as a nuclear-waste containment material. Because critfcal pieces of information from part 1 are needed as input information to parts 2 and 3 , it is logical that the currosion test program receive priority in terms of schedule and allocation of resources.

\subsection{Schedule for. Evaluation of Copper}

\subsubsection{Corrosion Survey Tests}

The principal activity inftiated in Fy 1985 was survey testing of the candidate materials in environments relevant to a repository in Yucca Mountain. The purpose of the survey test activity is to determine the specific forms of corrosion degradation that are likely to be encountered and that w11l decrease the container service $11 \mathrm{fe}$. Th1s will require the acquisition and preparation of test materials, fabrication of test suppor $t$ hardware, test monitoring, and periodic measurement of test effects under both 
irradiated and nonirradiated conditions. Because testing under irradiation conditions is expensive and $11 \mathrm{mited}$ by the number of available gamma irradiation facilities, a considerable amount of supportive testing is performed in unirradiated but repository-relevant environmental conditions. In the survey mode, testing under unirradiated conditions serves to indicate the most instructive environmental and metallurgical conditions (temperature, stress leyel, alloy microstructure) in which to conduct the more limited number of irradiated tests.

Measurement of the electrochemical corrosion potentials in both irradiated and unirradiated environments is a useful parameter for discerning differences between the two environmental cases. The appropriate electrochemical potentials can then be applied to specimens exposed to unirradiated environments to simulate the radiation effect and allow a greater number of tests to be performed and data points to be acquired in a relatively short period of time. Electrochemical polarization techniques can be used to predict the breakdown of protective films or layers on the metal surface where localized corrosion can initlate. Alternating current impedance techniques can be used to extend electrochemical polarization methods to molst atmospheres. Also, chemical analysis of the irradiated solutions may reveal the nature of the chemical changes, so that corrosion tests can be performed in modiffed environments to simulate radiation effects.

\subsubsection{Participation of the Copper Industry}

CDA and INCRA assembled a task group on nuclear waste containers that would be involved in the FY 1985 activities. Some of the members of that task group reviewed Sweden's KaS design for a copper canister. Other task group members are particularly knowledgeable about the corrosion, fabrication, and welding of copper and its alloys. NHWSI is working closely with this task group in reviewing test results and making recomilendations for future work.

\subsubsection{Planned Activities for Fy 1986}

The level of copper-container investigations is planned to increase substantially for $F Y 1986$. In general, the survey tests will continue to obtain additional exposure time in the appropriate environments. Hew tests 
for specific forms of corrosion will be started as the results from the survey tests indicate they are needed. For example, if the survey tests suggest that localized corrosion is likely to be a problem, then more spectific tests will be conducted. If stress corrosion cracking is an indicated fallure mechanism, then more quantitative stress-corrosion-cracking tests--such as crack propagation measurements on a precracked fracture-mechanics-test specimen--will be pursued. The behavior of the pure copper CDA 102 and the different candidate alloys, principally CDA 613 and 715 , will be investigated for these corrosion modes.

The fabrication and welding of copper-base nuclear waste containers wtll be addressed in work beginning in FY 1986. Alternative fabrication processes such as the hot isostatically pressing (HIPping) operation proposed in the KBS design will be studied for possible application in the NWWSI project. The technical and economic aspects of the process will be covered. other fabrication processes that may merit further study are centrifugal casting and closed-end extrusion (see Sec. 7). Helding processes for high-purity copper and the different candidate alloys wit be investigated for their application to clusing nuclear waste canisters. If thick canister sections are prescribed, the closure weld of this heavy wall in a remote faclitiy may present major technical challenges. NNASI plans to work closely with CDA and INCRA with regard to these fabrication and welding investigations.

Interaction between NHWSI and BWIP could foster a fruitful generic study of the fabrication and welding processes for nuclear waste containers, as the issues here are largely not site-specific.

He anticipate that localized and/or stress-assisted forms of corrosion will be the principal degradation modes limiting the use of copper and its alloys for nuclear waste containers. To a large extent, general corrosion degradation problems can be solved by increasing the thickness of the container wall, whereas the localized and stress corrosion problems can be avoided by using materials highiy resistant to these forms of corrosion. However, both localized and stress corrosion have statistical features, and a large data base is needed to adequately predict thetr occurrence. The large number of variables in stress corrosion testing--stress configurations, material variables, environmental variables (including irradiation)--require a sizeable number of individual tests. A large fraction of the Fy 1986 resources will be directed toward localized and stress corrosion testing. 
If the corrosion test program indicates that copper or copper-base containers may attain the 300- to 1000-year containment 1ife, then work should begin in FY 1986 and continue into FY 1987 on the posstble interaction between a copper or copper-base container and other components in the waste package. These other components incluje the 304L stainless steel inner container for pour canister) for defense and commercial high-level waste packages and the Zircaloy (or, occasionally, stainless steel) cladding on the spent-fuel rods. A premature breach in the outer copper container can allow water to transport copper corrosion products inward, and this modified environment could accelerate fallure (especially by pitting or stress corrosion) of the inner waste package components. The effect of copper corrosion products on the controlled release rates of radionuclides from the vitrified or spent-fuel waste forms would have to be addressed. A further potentially adverse metal-metal interaction could occur between a carbon steel borehole liner and a copper container (see Sec. 2). This interaction will be investigated.

\section{4,3.4 FY 1986 Feasibility Assessment Report}

At the end of FY 1986, a report will be issued that documents the completion of this feasibility assessment. It will sumarize the results of the copper container research and development work and will indicate if a copper-base material is a viable candidate for nuclear waste containers in a tuff repository. A decision can be made at this point on whether to continue efforts on copper into $F Y$ 1987. This report will also include an economic analysis of the promising materials con the basis of the corrosion testing program), including costs of special heat treatments or other process requirements to allow a full evaluation of the candidate materlals.

\section{4,4 Identification of Contractors}

In FY 1985. LLNL had primary responsibility for conducting the evaluation of copper as a nuclear-waste container materlal. This work was performed along with and paralle to the work with stainless steel. LLML also conducted the electrochemical corrosion evaluation of the candidate materials in and out of the presence of a gamma radiation source and initiated the package-design concept analysis to support the economic assessment effort. 
To complete the proposed work in a timely manner, subcontracts were placed with the following organizations (December 1984):

o COA and IMCRA: To support the copper-contafner task group ard expenses in gathering information on physical and mechanical properties, supply, availability, and economic projections, and to provide detalled planning of FY 1986 program activities. (This subcontract was placed in May 1985.)

- Hestinghouse Hanford: To perform exposure tests of copper and copper-base alloys in gamma-irradiated environments in order to survey corrosion performance of these materials in tuff geochemical environments; a1so, to conduct supporting metallographic and chemical anaiysis of the materials and environments. (This subcontract was placed in January 1985.)

- University of Minnesota: 1o conduct general and localized corrosion testing of candidate copper-base materials with electrochemfcal monitoring in a gamma-irradiated environment and to use impedance measurements to monitor the oxidation rates in moist environments. (This subcontract was placed in June 1985.)

- SRI-International: To continue with the corrosion modeling activities begun on stainless steel and extend these to include copper; the modeling approach is based on environmental changes in the corrosion potentials. (This work was begun on an existing subcontract.)

- COA: To investigate thermodynamic stability of candidate materials in tuff geochemical environments. This investigation may include the nature and pruperties of protective layers on the copper-base materlals under these environmental conditions. (This work was performed by a consultant to CDA under their subcontract.)

o Westinghouse Hanford: To conduct survey stress corrosion studies on the proposed candidate materials, using techniques that may include slow strain rate, bent beams, U-bends, and other configurations. (This work was begun in part by Westinghouse-Hanford as part of their exposure tests under irradiated conditions.)

In FY 1986, the corrosion test work will largely continue from Fy 1985, with possible additiona 1 contractors as the nature of the test results indicates they are needed. The close working relationship with CDA and INCRA wilt help to identify which organizations are qualified to perform the specific pieces of work. 


\subsection{Test Plan Results}

Results of work accomplished in FY 1985 are discussed in the next sections of the report. Section 5 presents an interpretive survey of the 11 terature on the performance of copper and copper-base alloys. The projections of this survey on the actual expected environmental conditions in a repository in Yucca Mountain are given. Section 6 presents the corrosion test results to date under the environmental conditions tested. Section 7 describes different processes that can be used to fabricate and we id copper and copper-base alloy containers and gives some of the advantages and disadvantages of each process.

\section{POSSIBLE FORHS OF CORROSION AND OXIDATION OF CANDIDATE COPPER-BASE MATERIALS UNDER TUFF REPOSITORY CONDITIONS}

This section surveys the published literature on the general corrosion performance of copper, aluminum bronze, and 70/30 copper-nickel in environments that have characteristics similar to those of a repository in tuff (see Sec. 1). This review summarizes the known oxidation and corrosion behavior of these materials when they are exposed to air, steam, and water at temperatures between amblent and $300^{\circ} \mathrm{C}$. Where required, higher and lower temperature information has been included when it was found to be useful in establishing a behavioral trend. Similarly, information on certain other alloys was included where there was reason to believe that the work was applicable to the alloys of interest.

\subsection{0xidation of Copper in Air from $100-300^{\circ} \mathrm{C}$}

\subsubsection{Effect of Time and Temperature}

Examination of the 11 terature on the oxidation of copper, especially the reviews by Tylecote (1950-51), Ronnquist and Fischmeister (1960-61), anc Kubaschewski and Hopkins (1962) reveais that the metal oxidizes in alr essentlally according to parabolic rate kinetics at temperatures above about $200-300^{\circ} \mathrm{C}$. At these temperatures, the oxidation of copper for a given temperature obeys the expression 
$m^{2}=k_{p} t$

where $m$ is the weight gain $\left(\mathrm{mg} / \mathrm{cm}^{2}\right), k_{p}$ is the parabolic rate constant $\left(\mathrm{mg}^{2} / \mathrm{cm}^{4} \cdot \mathrm{s}\right)$ and $\mathrm{t}$ is time (s). Since the oxidation rate at these temperatures is diffusion controlled, it follows that the effect of temperature on the oxidation of copper should obey the Arrhenius equation

$k_{p}=A \exp (-Q / R T)$.

Valens 1 (1948) reported the oxidation of copper in air at $300-550^{\circ} \mathrm{C}$ to follow the Arrhenius equation according to the expression

$k_{p}=1.5 \times 10^{-5} \exp (-20,140 / R T)$.

where the units of $k_{p}$ are $1 n g^{2} / \mathrm{cm}^{4} \cdot s$. Similar values for the activation energy and pre-exponential term in the Arrhenius-type equation have been derived by other researchers for this same temperature range and to a somewhat extended range to inciude lower temperatures $\left(200^{\circ} \mathrm{C}\right)$.

The oxidation kinetics for copper at temperatures lower than about $200^{\circ} \mathrm{C}$ are not so we 11 defined. Inverse logarithmic, logarithmic, and cublc rates have all been reported over the temperature range from -195 to $256^{\circ} \mathrm{C}$. Very likely, the oxide's thickness, porosity, crystallographic orientation. tendency to blister and crack, experimental conditions, and other factors are involved in the oxidation kinetics reported at these temperatures. Regardiess of the exart rate laws involved, Ronnquist and Fischmeister (1960-61) established that, for practical purposes, the oxidation of copper at a given temperature can be approximated reasonably well by the expression $m^{n}=k t$, where $m, k$, and $t$ havf: the usual meanings, and the exponent $n$ is obtained directly from the slope of the assoclated $\log m$ vs $\log t$ plot. Analysis of the values of $n$ indicates that quasi-logarithmic oxidation (high values of $n$ ) prevalis at lower temperatures $\left(<200^{\circ} \mathrm{C}\right)$ and that cublc-to-parabolic oxidation occurs over an extended intermediate temperature range; oxidation is essentially parabolic at temperatures above about $550^{\circ} \mathrm{C}$. 
(Note that if a parabolic rate law is used, the predicted equivalent penetration of copper [actually the copper w11] gain weight because of oxide formation] is about $500 \mu \mathrm{m}$ at $250^{\circ} \mathrm{C}$ for 10 years, $150 \mu \mathrm{m}$ at $350^{\circ} \mathrm{C}$ for 100 years, and $100 \mu \mathrm{m}$ at $100^{\circ} \mathrm{C}$ for 1000 years. A higher order rate law would really apply at these temperatures, so these projections are high but indicative of an effectlvely negligible amount of metal loss under strictly dry oxidizing conditions.)

\section{1 .2 Composition of the $0 x i d e F 11 m$}

Copper oxidizes in air at temperatures less than $260^{\circ} \mathrm{C}$ to form cuprous oxide $\left(\mathrm{Cu}_{2} \mathrm{O}\right)$ (Uhlig, 1971). Above this temperature the oxide is overlaid with a superficial film of cupric oxide (CuO). While some researchers have reported that the oxide formed at lower temperatures contains =ignificant amounts of $\mathrm{Cu} 0$, the preponderance of evidence obtained by a number of techniques (electron diffraction, coulometry, $x$-ray photoelectron spectroscopy) supports cuprous oxide as the dominant oxidation product in the temperature range of interest.

\subsubsection{Effect of 0xygen Concentration and Pressure}

The early stages of copper oxidation depend on the oxygen partial pressure. The progression of stages is invisible film (surface still bright), nuclei, and continuous oxide film (Gronlund, 1956; Benard et a 1., 1959). At low temperatures $\left(105-118^{\circ} \mathrm{C}\right)$, an increase in the oxygen partial pressure appears at first to increase the oxidation rate of copper and then to decrease the rate when the oxygen partial pressure exceeds $15 \mathrm{~mm}$ of mercury (Lustman: and Meh1, 1941). Other researchers have found that higher partial pressures are beneficial to the low-teinperature oxidation resistance of copper.

It appears that the primary role of oxygen partial pressure in the oxidation of copper is its effect on the species present in the outer oxide layer, as indicated in the stabtlity diagram in $\mathrm{Fig} .5$. At temperatures less than $250^{\circ} \mathrm{C}$ the oxide consists of cuprous oxide regardless of the oxygen partial pressure. The cuprous oxide appears to offer greater protection than cupric oxide. 


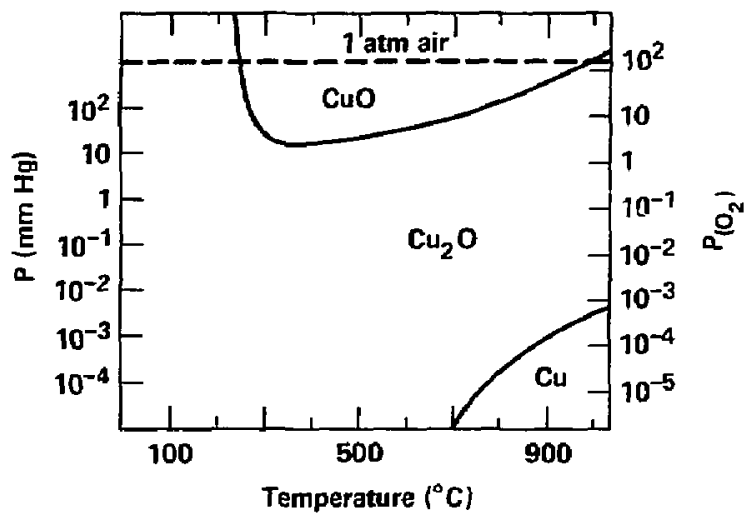

Fig. 5 Effect of temperature and oxygen partial pressure on the stability of copper, cuprous oxide $\left(\mathrm{Cu}_{2} \mathrm{O}\right)$, and cupric oxide (CuO). 


\subsubsection{Effect of Radiation}

The results of Tobin (1963) for high-purity copper wire oxidized over the temperature range 100 to $300^{\circ} \mathrm{C}$ reveal contrasting effects regarding the gamma irradiation of copper. Gamia radiation produced no significant effects where parabolic rate-law oxidation prevalled; in the logarithmic rate-law regions (presumably the lower temperatures), the presence of radiation increased the oxidation rate by about $12 \%$ without affecting the logarithmic rate law constant. Netther the detalls of the environmental conditions (whether wet or ory conditions) nor the radiolysis products were given.

\subsubsection{Effect of Moisture in Air and Oxygen}

The presence of moisture in oxygen has a somewhat beneficial effect on the oxidation resistance of copper in "dry" and "motst" oxygen at low temperatures $\left(100-256^{\circ} \mathrm{C}\right.$ ) (Campbe11 and Thomas, 1947). This effect has been noted by other researchers and at higher temperatures.

\subsubsection{Effect of Cold Working}

The general conclusion from several research efforts indicates that cold working has ittle effect on the oxidation rate of conper (in the temperature range of interest), and in some instances cold-worked material shows a lower oxidation rate than annealed material.

\subsubsection{Effect of Alloy Addttion}

The effect of alloying elements on the oxidation of copper has been summarlzed in some of the works previously cited (Tylecote, 1950-51; Kubaschewski and Hopkins, 1962). Most important, Campbe 11 and Thomas (1947) have shown that the low-temperature $\left(194-256^{\circ} \mathrm{C}\right)$ oxtdation resistance of copper is markedly improved by adding magnesium, berylilum, and aluminum. Reportedly, the oxidation rate of copper can be reduced to an insignificant ba lue by adding about 8 wty aluminum (Nishimura, 1938; Sanderson and Scully, ig73). An aluminum bronze containing 7 wt\% aluminum has an oxidation rate ios:ant of $1 \times 10^{-11} \mathrm{~g}^{2} / \mathrm{cm}^{4} / \mathrm{h}$ at $400^{\circ} \mathrm{C}$. 
The oxidation resistances of binary copper-nickel alloys containing up to about 30 wty nickel are about the same as those observed for unalloyed copper (Pilling and Bedworth, 1925). The oxidation rates for binary copper-nickel alloys are essentlally the same regardless of whether the oxidation occurs in dry air or in air containing 10\% water vapor (Hallowes and Voce, 1946).

\subsection{Corrosion of Copper in Aqueous Environments}

The important electrochenical degradation phenomena assoclated with copper exposed to steam and water environments are general corrosion (untform at tack) and stress corrosion cracking. Pitting of copper in these environments is extremely rare, especially in hot waters. The only known incldents of phosphorus-deoxidized copper pitting in hot waters have involved: (1) waters containing appreciable amounts of dissolved ranganese and, possibly, iron; (2) waters that were overly coagulated with aluminum sulfate; (3) slightly sub-neutral $\mathrm{pH}$ waters having relatively high sulfate contents where the sulfate-to-bicarbonate ratlos were greater than unity; and (4) waters contalning appreciable amounts of sulfide. The cold-water pitting of phosphorus-deoxidized copper has been limited to waters containing suifides and those containing apprectable amounts of dissolved $\mathrm{CO}_{2}$ in conjunction with dissolved oxygen and chloride.

Simllarly, galvanic corroston, intergranular attack, dealloying (selective leaching), corrosion fatigue, fretting, erosion corrosion, and concentration cell (crevice) corrosion are not serious concerns for copper exposed to steam and water, provided that reasonable consideration is given to these factors during system design, fabrication, installation, and operation.

\subsubsection{General Corroston}

In the following discussion, different units for corrosion rates are used. In many instances, figures were taken from original works and were not rescaled. The reader should keep the following conversion untts in mind:

$1 \mathrm{mt} 1 / \mathrm{y}(\mathrm{mpy})=25.4 \mu \mathrm{m} / \mathrm{y}$

$1 \mathrm{mil} / \mathrm{y}$ (mpy) $=6.3 \mathrm{mdd}\left(\mathrm{mg} / \mathrm{dm}^{2} / \mathrm{d}\right)$ for copper and copper-nicke 1 $=5.5$ mdd for a luminum bronze. 
Copper is resistant to attack by pure steam. The corrosion of copper by steam, however, is facilitated by the presence of oxygen. Figure 6 illustrates the corrosion rate of copper-nickel binary alloys in oxygen-containing water and steam at saturated pressure. A marked increase in the corrosion rates of copper and copper-nickel alloys occurs between 300 and $350^{\circ} \mathrm{C}$ (Sato, 1964). Noncondensible gases (e.g., $\mathrm{O}_{2}, \mathrm{CO}_{2}$, and $\mathrm{NH}_{3}$ ) in steam can produce a condensate that is aggressive to copper. For example, $67^{\circ} \mathrm{C}$ condensate containing $4.6 \mathrm{ppm}$ (weight bas 15 ) dissolved oxygen and $14 \mathrm{ppm}$ dissolved carbon dioxide at a pH of 5.5 reportedly corrodes phosphorus-deoxidized (PD) and arsenical copper at rates of 7 to 14 mpy (ASif, 1961). Copper has been reported to corrode at 1.4 mpy in steam condensate containing traces of hydrogen sulfide and hydrochioric acid at $32^{\circ}$. Condensates that are essentially free of noncondensible gases typically corrode copper at a rate of less than 0.1 mpy.

Low corrosion rates have been reported for copper exposed to botler feedwater. Copper corrodes at only 0.6 mdd when exposed to $198^{\circ} \mathrm{C}$ boller feedwater containing 0.03-0.06 ml/1iter dissolved oxygen and $0.02 \mathrm{ppm}$ ammonia (pH 8-8.5). No carbon dioxide was present in the water (Laque, 1954). Phosphorus-deoxidized copper is not appreciably corroded by industrial and domestic waters at lower temperatures. Results from a number of water environments are given in Table 3 (Laque, 1954) and Table 4 (Myers and Obrecht, 19731.

It is known but not widely appreclated that copper does not corrode catastrophically when exposed to dilute nitric acid. Provided that the nitric acid concentration does not exceed about $0.01 \%$, the corrosion rate for copper at ambient temperature 15 well below 60 mdd (McKay and Worthington, 1936).

Copper does exhibit relatively high corrosion rates in certain ammonia-containing environments. For example, when exposed to a continuously renewed atmosphere of $80 \%$ a1r. $16 \%$ ammonia, and $4 \%$ water vapor at $35^{\circ} \mathrm{C}$ (7.e.. above the dew point), high-purity copper (annealed) corrodes at a rate of 52 mpy. Additions of phosphorus reduce the corrosion rate in this environment. Copper containing $0.014,0.028$, and $0.056 \%$ phosphorus corrodes at rates of 38,27 , and $16 \mathrm{mpy}$, respectively (Thompson and 1racy, 1944). 


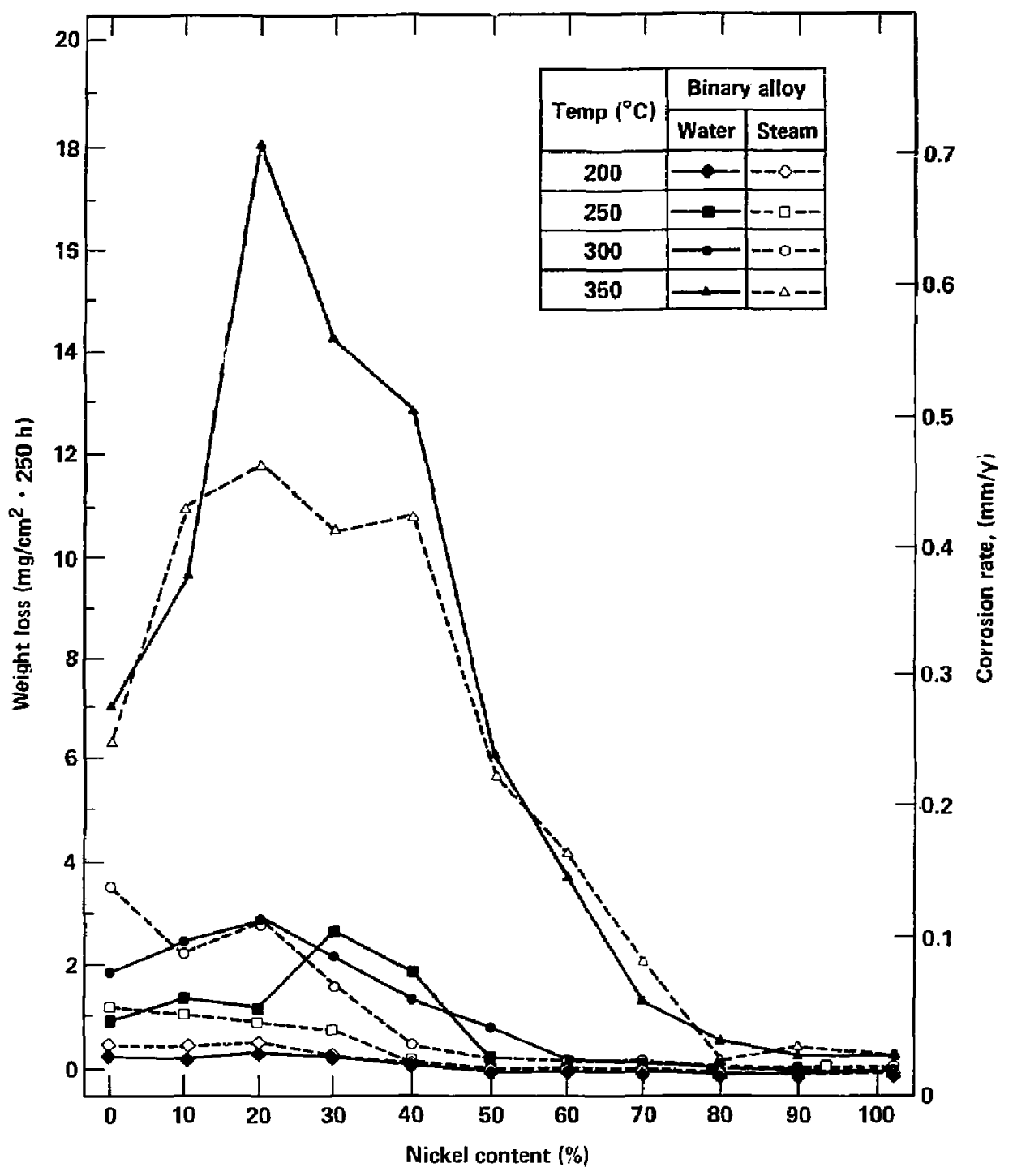

19. 6 Effect of nickel on the corrosion of binary copper-nickel alloys in oxygen-containing water and steam at saturated pressure. 
Table 3. Corrosion of copper by domestic and industrial waters (LaQue, 1954).

\section{Exposure condition}

Water side of tubular cooler: $\mathrm{pH}=7.8$, alkalinity $=165 \mathrm{ppm}$ as calcium carbonate, $66^{\circ} \mathrm{C}$

Outlet of condenser water box: acid water, $\mathrm{pH}=5$ (sometimes as low as 3 ), Monongahela River water

Cold well water high in dissolved carbon dioxide

Hot-water storage tank: $66^{\circ} \mathrm{C}$

Open tank containing well water: 85 ppm dissolved carbon dioxide, 65 ppm hydrogen sulfide, and $120 \mathrm{ppm}$ sodium chioride

Hot water heater: P1ttsburgh tap water, $60^{\circ} \mathrm{C}$

Hot water heater: well water containing free dissoived carbon dioxide, $71^{\circ} \mathrm{C}$
Corroston rate

$4.0 \quad(25)$

$4.0 \quad(25)$

$1.0(6)$

$0.3(2)$

$0.2(1)$

$0.2(7)$ 
Table 4. Corrosion of phosphorus-deoxidized copper by domestic waters at $93^{\circ} \mathrm{C}$ and a flow rate of $0.46 \mathrm{~m} / \mathrm{s}$. (Myers and Obrecht, 1973)

Hater condition ${ }^{3}$

Zeolite-sof tened

Zeolite-softened; blended to

hardness of $110 \mathrm{ppm}$ as $\mathrm{CaCO}_{3}$

Zeolite-sof tened; cold-vacuum

deaerated

Zeolite-sof tened; blended to

hardness of $60 \mathrm{ppm}$ as $\mathrm{CaCO}_{3}$

\section{Corrosion rate (mpy)}

2

1

$<2$

1

a

Unsoftened chemistry of well water: 6-8 ppm Cl, 14-24 ppm S0, 10-4 ppm $\mathrm{CO}_{2}$, 6-12 ppm $0_{2}$, 310-370 ppm total hardness as $\mathrm{CaCO}_{3}$, 300-325 ppm MO alkalinity as $\mathrm{CaCO}_{3} ; \mathrm{pH}=6.8-7.5$. 


\subsubsection{Stress Corrosion Cracking of Copper}

The susceptibtlity of certain grades of copper to stress corrosion cracking ( $S C C$ ) in amonia-containing environments is well known. Ammonia may be a transient radiolysis product in the container environment. Annealed copper containing the same phosphorus jevels as in the Thompson and Tracy work, cited above, and stressed in tension (10,000 psi constant load) fatled by SCC after from a few hours to a few days in the same alr/ammonia/ water-vapor environment at $35^{\circ} \mathrm{C}$. The shorter fallure times were noted for the copper grades containing the higher levels of phosphorus. Annealed tough-pitch (CDA 110) and oxygen-free, high-conductivity copper (CDA 102) exhibited no evidence of SCC after 40,000 minutes (28 days) in the same environment.

lough-pitch and 99.999\% pure copper have been reported to experience transgranular stress corrosion cracking (TGSCC) in a $0.05 \mathrm{M}$ ammonium hydroxide solution at $70^{\circ} \mathrm{C}$ when subjected to relatfvely high uniaxial tensile stresses. As expected, the time-to-fallure decreased with increasing tensile stress. Test results also indicated that the time-to-fallure decreased with increasing temperature (Suzuk1 et a1., 1974).

High-purity copper has also been reported to experfence TGSCC in sodium nitrite solutions. Slow strain-rate testing in aerated sodium nitrite solutions (up to $1 \mathrm{M} \mathrm{NaNO}_{2}$ ) at $40^{\circ} \mathrm{C}$ on $\mathrm{CDA} 122$ (phosphorus deoxidized copper) and 102 showed that the susceptibility was highest at the higher nitrite concentrations and did not occur below $0.001 \mathrm{M}$. Deaerating the solution decreased the susceptibility (Benjamin et a1., 1983).

\subsection{Corrasion of Copper-Base Alloys in Aqueous Environments}

The primary concerns regarding the use of copper-nickel and alpha aluminum bronze alloys in steam and water environments are general corrosion, stress corrosion cracking, and intergranular corrosion. Although these alloys are susceptible to pitting attack by waters containing suifides, this degradation phenomenon has been restricted primarily to polluted cooling waters, especially sea waters. 


\subsubsection{General Corrosion}

Copper-nickel alloys typically corrode in ory and good-quality wet steam at rates of less than $0.1 \mathrm{mpy}$. The corrosion rates reported by Sato (1964) for binary copper-nickel alloys exposed to steam at temperatures between 200 and $350^{\circ} \mathrm{C}$ at saturated pressure are presented in $\mathrm{Fig} .6$. Increasing the temperature from 300 to $350^{\circ} \mathrm{C}$ markedly increased the corroston rate for alloys containing up to about $70 \%$ nickel. These data suggest that the corrosion of copper-nickel alloys is somewhat factlitated by the presence of oxygen in the steam. This belief is supported by the results of Hopkinson (1964), who investigated conmerclaliy ayaflable and laboratory prepared 90\% copper-10x nickel (90Cu-10N1) and $70 \%$ copper-30\% nicke) (70Cu-30N1) alloys in oxygenated. distllled water vapor at $260^{\circ} \mathrm{C}$. In general, Hopkinson's data reyeal that, following an initial three-day period of high wetght loss per unit area, the weight lass for the $70-30$ alloy does nat significantiy increase with increasing exposure time.

Table 5 sumarizes weight loss data reported by Brush and Pearl (1969) for 90Cu-10N1 and 70Cu-30N1 alloys exposed to pressurized, high-purity, high-temperature, near-neutral pH water containing $10 \mathrm{ppb}$ dissolved oxygen. These data suggest that both alloys corrode at nearly the same very low rate; for a given temperature between 65 and $204^{\circ} \mathrm{C}$. It shou $3 d$ be noted that the highest weight lass recorded by the se investigators $149.6 \mathrm{mg} / \mathrm{dm}^{2}$ in 5093 hours, or $0.23 \mathrm{mdd}$ ) corresponds to a corrosion rate of less than $0.04 \mathrm{mpy}$.

Myers and Dbrecht (1973) reported that at lower temperatures the corrosion rate for alloy 706 (90Ca-10Ni) was less than 1 mpy when 1 t was exposed to $93^{\circ} \mathrm{C}$ sodium-zeolite-softened water flowing at $0.46 \mathrm{~m} / \mathrm{s}$. LaQue (1954) reported similarly low corrosion rates (about 0.9 mpy) for 70Cu-30N1 alloy when exposed to a varlety of domestic and industrial waters at temperatures up to $71^{\circ} \mathrm{C}$. The one exception to the low corrosion rates occurred in low-pH Monangahela River water ( $\mathrm{pH} 5$ and lower).

An aluminum bronze containing $10 \%$ a luminum has been reported to corrode at about 1 mpy when exposed to $104^{\circ} \mathrm{C}$ steam used to supply a deaerator (ASH, 1967). At $79^{\circ} \mathrm{C}$, the corrosion rate is about 2 mpy.

The corrosion resistance of $70 \mathrm{Cu}-30 \mathrm{Nt}, 90 \mathrm{Cu}-10 \mathrm{Ni}$ and of an aluminum bronze to aqueous environments containing relatively high concentrations of ammonia has been reparted by Tice and Venizelos (1963) and is shown in fig. 7 . Of the 
Table 5. Corrosion of copper-base alloys by high-temperature, high-purity, neutral pH water containing $10 \mathrm{ppb}$ dissolved oxygen. \{Brush and Pear?, 1969\}

\begin{tabular}{|c|c|c|c|c|c|c|}
\hline \multirow[b]{2}{*}{$\begin{array}{c}\text { Temperature } \\
\left({ }^{\circ} \mathrm{F}\right) \\
\end{array}$} & \multirow[b]{2}{*}{$\begin{array}{l}\text { Ttme } \\
\text { (h) }\end{array}$} & \multirow[b]{2}{*}{$\begin{array}{l}\text { Mone1 } \\
\text { al Joy }\end{array}$} & \multicolumn{4}{|c|}{ Average descaled weight $10 \mathrm{ss}\left(\mathrm{mg} / \mathrm{dm}^{2}\right)$} \\
\hline & & & $\begin{array}{l}\text { Admiralty } \\
\text { brass }\end{array}$ & gocu/ront & $70 \mathrm{Cu} / 30 \mathrm{N1}$ & 70Cu/30Ni+iron \\
\hline 150 & 5093 & $-^{\mathbf{a}}$ & 23.2 & 20.7 & $-\mathbf{b}$ & 11.7 \\
\hline 200 & 5093 & - & 29.9 & 18.6 & 21.5 & 11.0 \\
\hline \multirow[t]{2}{*}{250} & 2750 & 97 & - & - & - & - \\
\hline & 5093 & 302 & 19.5 & 20.5 & 14.1 & 18.3 \\
\hline \multirow[t]{2}{*}{300} & 2750 & 332 & - & - & - & - \\
\hline & 5093 & 373 & 24.4 & 19.3 & 17.6 & 36.4 \\
\hline \multirow[t]{2}{*}{350} & 2750 & 188 & - & - & - & - \\
\hline & 5093 & 365 & 40.6 & 28.6 & 22.5 & 37.4 \\
\hline \multirow[t]{2}{*}{400} & 2750 & 285 & - & - & - & - \\
\hline & 5093 & 452 & 73.3 & 41.9 & 49.6 & 45.8 \\
\hline
\end{tabular}

a The notation indicates that there was too little oxide present to warrant descaling.

b Specimens used for additional tests. 


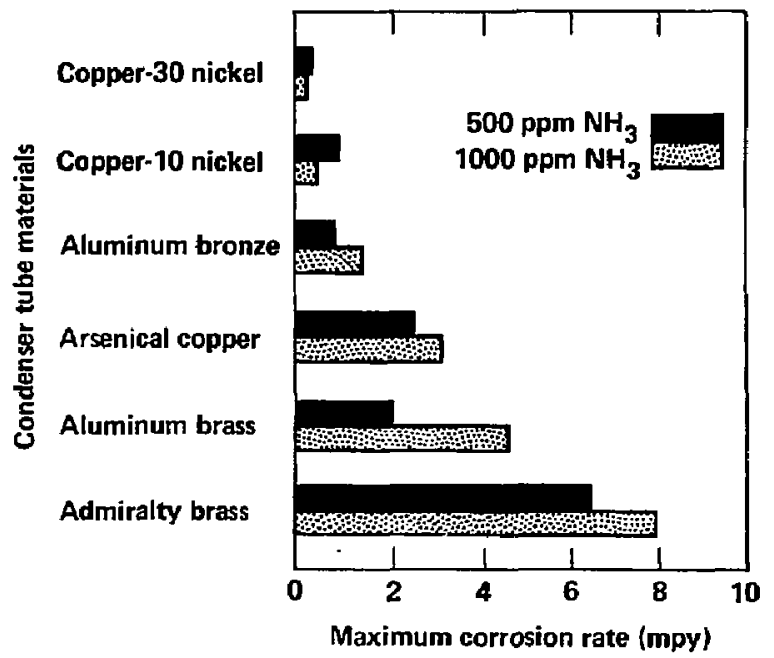

Fig. 7 Corrosion rates for copper-based alloys in ammonta "drip" tests conducted at ambient temperature. 
three alloys, 70Cu-30Ni has the best resistance to "dripping" aqueous ammonia solutions containing 500 and 1000 ppm ammonia. This observation regarding 70Cu-30N1 is supported by the results of Thompson and Tracy (1944), who reported the corrosion rate for 70Cu-30Ni alloy to be $0.6 \mathrm{mpy}$ when exposed to a continuously renewed atmosphere containing $80 x$ a1r, $16 \%$ ammonia, and $4 \%$ water vapor at $35^{\circ} \mathrm{C}$. In the same environment, $90 \mathrm{Cu}-10 \mathrm{~N} 1$ corroded at about 46 mpy. The excellent resistance of 70Cu-30Ni to ammonia-containing environments has also been reported by Rawdon and Groesbeck (1929), who found that the corrosion rates of this alloy in aerated and unaerated $3.5 \%$ ammonium hydroxide solutions at ambient temperature were 0.027 and 0.21 mpy, respectively. The corrosion rate of an $8 \%$ aluminum bronze is about 45 mpy in a moist ammoniacal environment (fig. 8) (Thompson and Tracy, 1944).

Corrosion rates for copper-nickel in dilute nitric acid solutions apparently have not been reported in the techntcal 11 terature. Very 1ikely, these alloys behave simflarly to copper.

\subsubsection{Stress Corrosion Cracking of Copper-Base Alloys}

Alpha aluminum bronzes (e.g., $\mathrm{Cu}-6.5 \mathrm{~A})-2.5 \mathrm{Fe})$ are susceptible to SCC in ammonta vapor, steam at $B 2-260^{\circ} \mathrm{C}$, and high-temperature aqueous environments. In ammonia, the crack morphology is predominately transgranular; intergranular cracking normally occurs in steam and in high-temperature aqueous environments.

The times-to-fatiure for a typical aluminum bronze in tests conducted in $176^{\circ} \mathrm{C}$ saturated steam where the material was stressed at 30,000 psi (constant load) in tension, are on the order of $150 \mathrm{~h}$ ( $K$ lement et al., 1959) (Table 6). The same investigators established that the SCC of alpha aluminum bronze in steam and high-temperature aqueous environments could be prevented by small additions (1.e., 0.2 to 0.3 wt $\%$ ) of either $t$ in or silver to the alloy. This observation led to the development of the commercially avallable Ampco Grade $B$ aluminum bronze. (Note, CDA 613 contains 0.2-0.5\% of $t$ in). Unfortunately, neither the $t$ in nor the silver additions effectively mitigated the alloy's susceptibility to SCC in ammonia vapor.

Thompson and Tracy (1944) reported that annealed binary alloys of copper and nickel stressed in tension at 10,000 psi are somewhat susceptible to SCC in a continuously renewed atmosphere containing air, ammonia, and water 


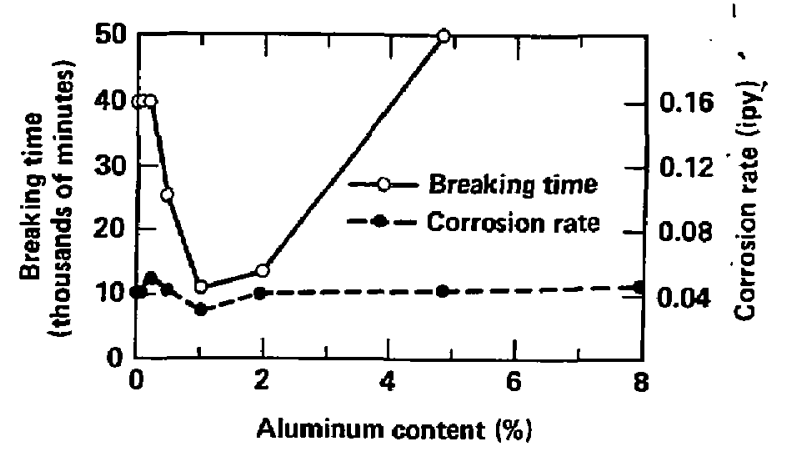

Fig. 8 Effect of aluminum on the zero-stress general corrosion rate and stress corrosion cracking behavior of annealed copper-aluminum alloys stressed in tension at 10,000 ps 1 and exposed to a molst ammontacal atmosphere at $35^{\circ} \mathrm{C}$. 
lable 6. Stress-corrosion cracking times-to-fallure for copper-base alloys exposed to saturated steam at $176^{\circ} \mathrm{C}$ and stressed at 30,000 ps 1 .

(Klenet, 1959)

Alloy

$5 \mathrm{~A} 1,95 \mathrm{Cu}$

$7 \mathrm{Al}, 2 \mathrm{Fe}, 91 \mathrm{Cu}$

$7 \mathrm{Al}, 2 \mathrm{Fe}, 91 \mathrm{Cu}, 0.35 \mathrm{Sn}$

$8 \mathrm{Al}, 92 \mathrm{Cu}$

$3 \mathrm{Si}, 1 \mathrm{Mn}, 95 \mathrm{Cu}$
Time to fail (h)

550

150

No fa1]ures after 3000

50

200 
vapor. Their results are shown in Fig. 9. The relative immunity to SCC of binary copper-aluminum alloys containing more than about $5 \%$ aluminum to the same environmental and stress conditions is evident in $\mathrm{Fig}$. 8 .

Sato and Nagata (1974) reported that 90Cu-10N1 and 70Cu-30N1 alloys are susceptible to IGSCC when exposed to pure water and steam at 300 and $350^{\circ} \mathrm{C}$. The IGSCC behavior of the two alloys appeared to be independent of the oxygen content ( 0.1 to $0.3 \mathrm{ppm})$ of the environment. The authors reported that these alloys experience intergranular corrosion in the absence of applied stress when exposed to steam/water in autoc laves at 300 and $350^{\circ} \mathrm{C}$ for $500 \mathrm{~h}$. Reportedly, the intergranular rate of attack was increased by stressing the specimens in tension; accelerated intergranular at tack occurred above a certain "threshold stress," the value of which appeared to depend on the chemical composition of the alloy and its metallurgical condition.

\subsection{Projections of Ljterature Review on Copper Container Performance}

Dxidation of copper and the candidate alloys in the air and relatively dry steam environments indicates that the amount of metal loss will be small even for several years of exposure to these environments in the $100-300^{\circ} \mathrm{C}$ range regardless of the exact kinetic law followed by the oxide growth. The protective character of the oxides will have to be investigated to determine whether a spalling or exfoliation phenomenon may substantially increase oxidation penetration into the metal. The oxidation rate of copper can be reduced to a very small value by alloying with aluminum laluminum bronzes, containing $7-8 \%$ a luminum).

Sparse information exists on the radiation effects in these environments, a matter of particular concern if ammonia or different oxides of nitrogen form in sufficient quantities to attack the metal. Condensed steam can provoke severe attack on copper if the steam contains carbon dioxide (from the atmosphere), ammonia, or $\mathrm{NO}_{x}$ (from radiolysis). In particular, aggressive effects of ammonia in increasing the general corrosion rate and intitiating transgranular stress corrosion cracking are noted. One of the important issues in copper container performance will be whether ammonia can form and remain stable for sufficient time in the near-package environment to provoke damage. The copper-nickel alloys are more resistant to corrosion effects in dilute armonia solutions. 


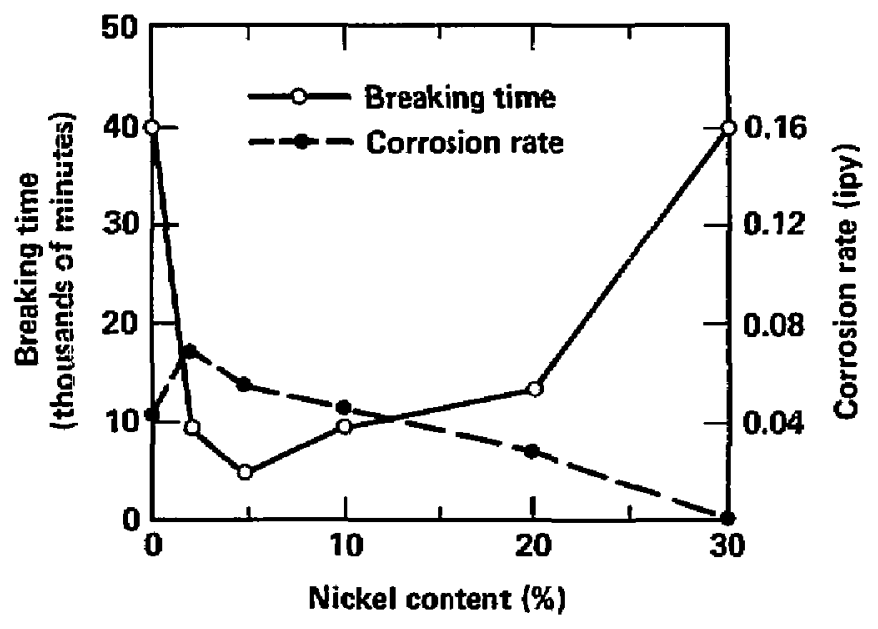

Fig. 9 Effect of nickel on the zero-stress general corrosion rate and stress corrosion cracking behavior of annealed copper-nickel alloys stressed in tension at 10,00 ps 1 and exposed to a molst ammontacal atmosphere at $35^{\circ} \mathrm{C}$. 
However, the intergranular corrosion phenomenon on copper-nickel alloys in unirradiated $\mathrm{h}$ igh-temperature $\left(300^{\circ} \mathrm{C}\right)$ water and steam is a possibly serious degradation mode in the repository enviranment. This phenomenon was observed in binary alloys; commercial copper-ntckel alloys contain iron as an intentional addition to improve the resistance to various forms of corrosion. Binary aluminum-copper alloys are also prone to intergranular stress corrosion in stmilar kinds of high-temperature aqueous environments, but the addition of small quantities of tin to the comercial aluminum bronzes prevents the attack.

An analysis of the performance of copper and copper-base alloys in many different kinds of natural and industrial waters indicates that water of the J-13 well composition should not be corrosive. The J-13 water should not contain significant quantities of $\mathrm{CO}_{2}$ because of the relatively high $\mathrm{pH}$. No significant corrosion of copper should occur over the higher temperature range because the water should be void of dissolved oxygen. The rat to of bicarbonate to sulfate ion in J-13 well water should not favor pitting attack; the absence of appreciable quantities of dissolved iron and manganese in the J-13 water is 11kewlse beneficlal in preventing localized corrosion. Sulfide ion is another potentially harmful species to copper and copper-base alloys. but the expected prevaling oxidizing conditions in the repository should preclude formation of this species. The general corrosion rates of copper-nickel alloys are expected to be much lower than that of unalloyed copper in most aqueous environment:.

Nitrogen-bearing radiolysis products when hydrolyzed are spectes whose formation can seriously limit the use of copper as a container material. Ammonia is probably the most damaging species because of the increase in general corrosion rate and tendency toward stress corrosion cracking. Hydrolysis of the various $\mathrm{NO}_{x}$ to form nitric acid, nitrite or nitrate salts can be damaging by an increase in the general corrosion rate (nitric dilute acid) or initiation of stress corrosion (salts). Copper may withstand very dilute nitric acid $(<0.07 \%$ ), but concentrating mechanisms (as in condensate on the container surface) will sharply increase the corrosion rate.

General corrosion rates as high as 0.1-0.2 mpy are of a magnitude that is tolerable for a waste package container 1-cm or 0.39-in thick in the NNWSI reference designs (Sec. 3). The published 11 terature indicates that the general corrosion rates of coriper (and its alloys) are of this magnitude in different waters and steam condensate. The rates are much lower in "dry" 
environments where condensed phases are not present. The use of copper in thicker sections (to compensate for the lower strength) means that higher general corrosion rates can be tolerated. One major advantage in increasing the container wa71 thickness is the concomftant decrease of the gamma dose rate penetrating the container. The amount of radiolysis in the near-package environment will be subsequentiy re-!uced, so that the formation of potentially harmful spectes will be decreased or eliminated.

\section{CORROSION TESI RESULTS TO DATE}

This section discusses work uno rtaken at LLNL and at Westinghouse Hanford. The work at LLNL is concerned with general and localized corrosion of the candidate copper inaterlals 1 , both irradiated and unirradiated environments. Much of this work involves electrochemical determinations of corrosion rates and behavior patterns. The work at Hanford is a survey of the general, localized, and stress corr ston susceptibility of the candidate matertals in irradiated environments.

\subsection{Electrochemical Corrosion Studies on Candidate Materials in Unirradiated} Environments

This section presents an overview of the electrochemical behavior of $\operatorname{COA} 102,613$, and 715 in $\mathrm{J}-13$ we $11 \mathrm{k}$ ter and in a botled-down verston of this water where the ionic spectes were concentrated approximately 100-fold. In this investigation, anodic polarization curves were used to determine the susceptiblitty of these candidate materials to unfform and localized carrosion in the temperature range from 23 to $30^{\circ} \mathrm{C}$. The anatysis of the materials used in this work is presented in Table 7. Before testing, the surfaces of all materials were prepared with the following polishing sequence: 600-grit SiC paper, 5-micron $\mathrm{Al}_{2} \mathrm{O}_{3}$ poltsh, 7 -micron $\mathrm{Al}_{2} \mathrm{O}_{3}$ polish, and rinse with DI water.

Either $\mathrm{J} . .13$ water or 100-times-C incentrated J-13 water was used as an electrolyte. The concentrated form las prepared by boli-down under atmospheric pressure. When the volune is reduced by a factor of $1: 100$, calctum and sodium silicates prectpttate from J-13 water, and the pH of tha supernatant, which was used in this work, rises to values of 10.1 to 10.3 . Soluble anions such as chloride, fluortde, and carbonate remain in solution. 
Table 7. Actual analyses of copper alloys used in corrosion tests.

\begin{tabular}{|c|c|c|c|c|c|c|c|c|}
\hline \multicolumn{9}{|c|}{ Elemental compositions (wtx) } \\
\hline A IToy & $\overline{C u}$ & NI & A1 & in & $\mathrm{Sn}$ & $\mathrm{Fe}$ & $2 n$ & Other \\
\hline \multirow[t]{3}{*}{ CDA 102} & 99.95 & - & - & - & - & - & $<0.001$ & $P b<0.001 ; C d<0.001$ \\
\hline & & & & & & & & $S<0.0018 ; H g<0.0001$ \\
\hline & & & & & & & & $P<0.003$ \\
\hline CDA 613 & 90.82 & 0.05 & 6.75 & 0.16 & 0.20 & 2.46 & 0.01 & $P b<0.01 ; \operatorname{Co}<0.01$ \\
\hline CDA 715 & 69.18 & 29.60 & - & 0.51 & - & 0.53 & 0.07 & Pb-0.01; P-0.002; \\
\hline & & & & & & & & $C-0.04 ; S-0.01$ \\
\hline
\end{tabular}


A three-electrode configuration was used in this work. This includes the sample, a platinum counter electrode, and a saturated calomel electrode (SCE) to which all potentials are referenced. Anodic polarization curves and corrosion potential measurements were obtained with a PAR Model 351 Corrosion Measurement Console or with a Model 173 Potentiostat. The anodic polarization curves were obtained potentiodynamically at a scan rate of $1 \mathrm{mV} / \mathrm{s}$ scan rate. Ihis scan rate was used to determine the following electrochemical parameters: $E_{\text {corr }}$ (the corrosion potential), $E_{p}$ (the pitting potential), 1pass (the passive-state current density), and $1_{\text {corr }}$ (the corrosion current). The corrosion rates were determined by means of a microprocessor-controlled, curve-fitting procedure around the corrosion potential. Here, an iterative procedure is used to fit solutions to the theoretical Butler-Volmer equation, from which the corrosion current is calcula:ed.

The corrosion rate (determined at the corrosion potential) and the passive-state current density are indicators of the susceptibility of the material to uniform corrosion, whereas the fitting potential and, in particular, the separation between the pitting and corroston patentials are indicative of the localized corrosion resistance. It should be mentioned that t..ere are other indices for determining the localized corrosion tendencies. other test methods and variations on the ciocice of test parameters used in this investigation. The particular method used here was chosen for its conventence in screening a number of candidate materials and environmental combinations.

Some of the electrochemical parameters of interest, as identified above, are shown in $\mathrm{Fig}$. 10, which represents the anodic polarization behavior of CDA 102 in 100-times-concentrated $\mathrm{J}-13$ water at $23^{\circ} \mathrm{C}$. In Fig. 11 and on succeeding polarization curves, one can abserve a second curve drawn in the vicinity of the corrosion potential. This secord curve is the computer-generated numerical fit to the actual data from which the corrosion rate was extracted. Several features relevant to corrosion processes are evident in Fig. 10. Among these are that CDA 102 is subject to pitting in this environment at high (oxidizing) potentials. An example of the pit morphology on CDA 102 by anodic polarization at potentials above the pitting potential is shown in Fig. 12. This represents a sample following completion of the anodic polarization experiment in fig. 10. The pits that form are 
broad but not very deep and are generally covered by blutsh-green deposits of corrosion products. The pitting behavior of copper in natural water has been discussed by Campbe11 (1974).

Another feature of the curve in $F 1 \mathrm{~g}$. 10 is the presence of a small active-passive type transition with a current maximum at approximately $15 \mathrm{mV}$. This region was always observed for CDA 102 and CDA 613 in 100-timesconcentrated $\mathrm{J}-13$ water at all temperatures $\left(23-80^{\circ} \mathrm{C}\right)$ but was not apparent in the unaltered J-13 water. For comparison, Fig. 11 gives an example of the behavior of CDA 102 in J-13 water at $23^{\circ} \mathrm{C}$. Like CDA 102 and COA 613, CDA 715 did not show an active-passive region in $\mathrm{J}-13$ water. In the more concentrated electrolyte, coA 715 usually did not show the active-passive behavior (although in a few cases it did). In any case, for all the alloys in the concentrated electrolyte at all temperatures investigated the magnitudes of the currents in this regton are small enough that this effect (with regard to implications for uniform corrosion) is rather insignificant.

Representative anodic polarization curves for each of the alloys in $\mathrm{J}-13$ water and concentrated J-13 water at $80^{\circ} \mathrm{C}$ are shown in Figs. 13 through 18. Data from curves such as these have been used to tabulate the data given in the following plots. Values for the corrosion potentials for the three materials in J-13 water and concentrated J-13 water are presented in Fig. 19 as a function of the test temperature. In this and succeeding figures, the range of values obtalned for replicate tests (three in most cases) are shown. Average values obtained are indicated as crosses on the bars. To differentiate the data obtained for J-13 water and its concentrated form, the values obtained in the concentrated electrolyte are indicated by an asterisk above the range bars. The values for the concentrated electrolyte are to the right of the temperature lines in each case.

It is readily apparent in Fig. 19 that for all alloys at each temperature, the more concentrated elect olyte leads to more negative corrosion potentials. Also, there appears to be no apparent strong temperature dependence for the corrosion potentials for any of the materials in J-13 water over the temperature range investigated. However, a stronger correlation between the corrosion potential and the test temperature is exhibited in the more concentrated electrolyte. The values of $E_{\text {corr become more negative }}$ with increasing temperature. This is particularly apparent for CDA 102 and 
715. Also, in this plot and the following plots the experimental range of values obtained for the concentrated $3-13$ water is larger than that for J-13 water.

The larger range of values observed in the concentrated electrolyte may have resulted from problems in reproducibility of the more concentrated electrolyte. The boil-down procedure is a batch process, and occasionally the volume reduction would proceed beyond the 1:100 stage and rehydration was necessary. This may lead to slight differences in the chemical composition of the resultant solution. The procedure for producing the concentrated electrolyte and understanding its chemical makeup is being examined with the intent of developing a formula for synthesizing concentrated groundwater in large and reproducible volumes. The data so far are instructive for the general trends they indicate.

The ranges of vaiues for the pitting potentials are given in Fig. 20. Relatively large variations in the values are obtained (especially for the concentrated electrolyte), and the ranges of values for the three temperatures investigated overlap, thus precluding any definitive statement regarding the temperature dependence of the pitting potential for any alloy. If anything. there is probably no strong temperature dependence in either $3-13$ or concentrated J-13 water. In addition to the above-mentioned difficulties in obtaining the concentrated electrolyte, the scatter in the data also results from the rather nebulous nature of pitting in copper and its alloys, where pitting can occur in a mostly uniform pattern on the surface. By contrast, in stainless steels, pitting appears to be associated more with discrete surface inhomogeneities and is thus better quantifled. What is particularly evident in $\mathrm{Fig} .19$ is that the pitting potentials are more positive in the concentrated J-13 electrolyte than in the unaltered J-13 water for each material and at each temperature. There do not appear to be great differences in the ranges of pitting potentials for the materials in J-13 water, although generally the range of values is somewhat higher for $C O A 613$. In the concentrated electrolyte, CDA 102 appears to show lower values at 23 and $55^{\circ} \mathrm{C}$. The ranges for the three materials exhibit considerable over lap at $80^{\circ} \mathrm{C}$.

With regard to susceptibility to pitting corrosion, the most important parameter is the separation of the pitting and corrosion potentials $\left(E_{p}-E_{\text {corr }}\right)$. These values are given in $F i g .21$ and show that the concentrated electralyte appears to provide a more favorable environment for 
localized corrosion (p1tting) than unconcentrated $\mathrm{d}-13$ water (the larger the difference between the two potentials, the greater the localized corrosion resistance) for each material at each temperature. This may be the result of the higher $\mathrm{pH}$ in the concentrated electrolyte $(10.1$ to 10.3 compared with 7.6 in the unaltered J-13 water). The mechanisms influencing the values for the electrochemical paraneters must be further investigated.

values for passive-state current density for the alloys are given in Fig. 22. These values are indicative of the susceptibility of the alloy to uniform corrosion at potentials positive to the corrosion potential. The values plotted in this figure represent the current density at the "mid-potential" of the passive region in each case. As expected, there is a genera 1 tendency in $3-13$ water toward increased current density (and therefore the corrosion rate) with temperature for alt the materials. The most

discernible difference occurs between 23 and $55^{\circ} \mathrm{C}$. 1150, at each temperature, the magnitude of these ranges of values appears to be generally hygher for the concentrated electrolyte than for the J-13 water.

Finally, the values of the corrosion rates for the materials are shown in Fig. 23. Generaliy, the corrosion rates for all the materials show very 11 ttle temperature dependence in $\mathrm{J}-13$ water (oniy CDA 613 appears to show any positive effect). In the concentrated electrolyte, the rates for COA 102 and 613 generally appear to increase w1th temperature. The average values and the upper end of the range of values should be particularly noted. On the other hand, in the unaltered J-13 water, CDA 715 does not appear to show any strong temperature dependency. At $80^{\circ} \mathrm{C}$ in the concentrated electrolyte, of the three materials CDA 715 generally showed the lowest values for the corrosion rates. At other temperatures. within the precision of the measurements, the corrosion rates for the three materials (considering the range of values) are quite comparable. When compared with the actual weight loss specimens at $80^{\circ} \mathrm{C}$ (Table 8), the electrochemical rates are seen to represent conservative upper bounds.

The weight loss tata were obtained from rectangular coupons of the candidate materials exposed to $\mathrm{J}-13$ water and to steam generated from the water. Some additional materiais were incorporated into this test for comparison purposes. These data are also given in lable 8. ASTM G-1 and G-31 test procedures were used. Test detalls paralleled those used for stainless steels, as reported by Mccright et a1. (1983) and Juhas et a). (1984). The 


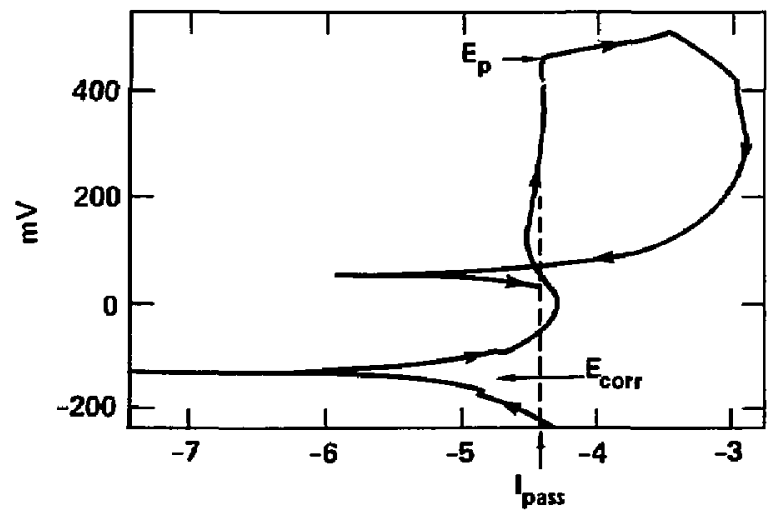

$\log I\left(A / \mathrm{cm}^{2}\right)$

F1g. 10 Polarization behavior of CDA 102 in 100-times-concentrated d-13 water at $23^{\circ} \mathrm{C}$. (Potentials in $\mathrm{mV}$, vs SCE.) Scan rate: $1 \mathrm{mV} / \mathrm{s}$. 


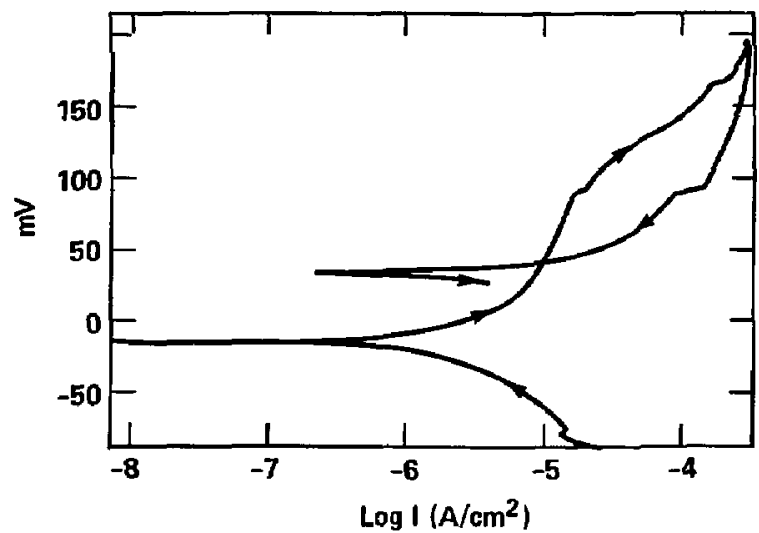

Fig. 11 Polarization behavior of CDA 102 in $\mathrm{J}-13$ water at $23^{\circ} \mathrm{C}$. (Potentials in $\mathrm{mV}$, vs SCE.) Scan rate: $1 \mathrm{~m} / \mathrm{s}$. 


\section{•}

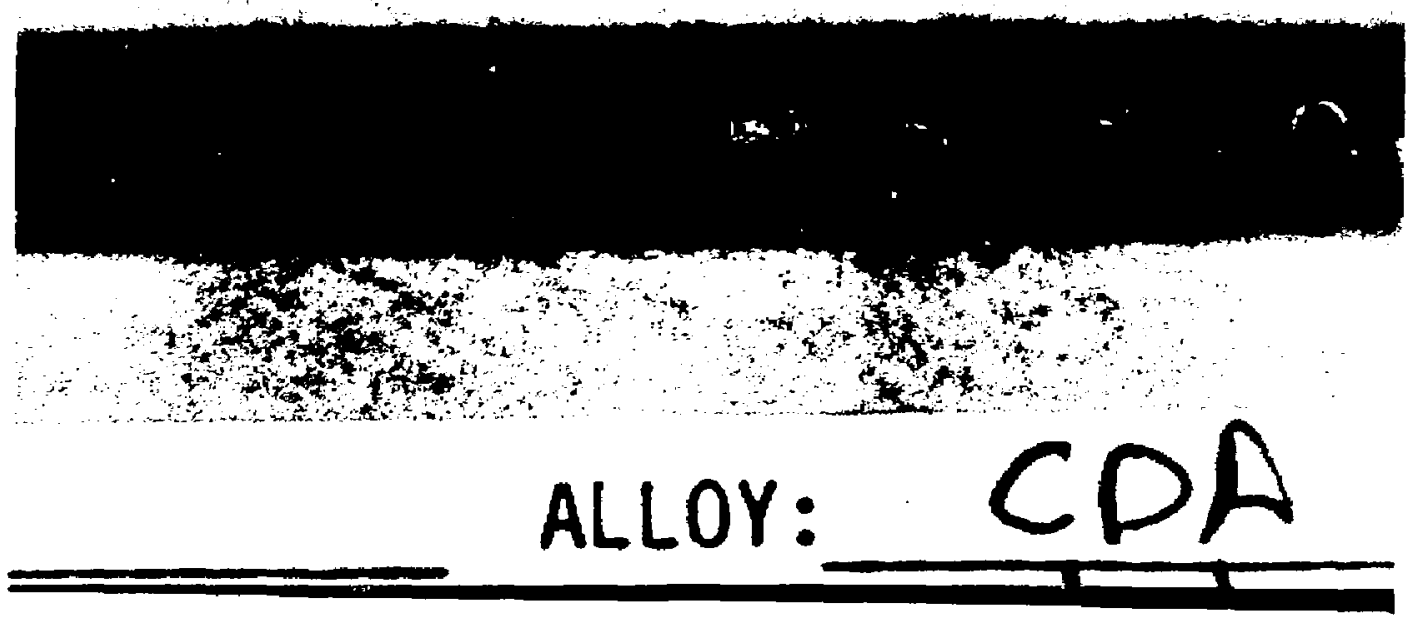

Fig. 12 Example of pit initiation on CDA 102 specimen in J-13 water. Specimen anodically polarized above the pttting potential. 


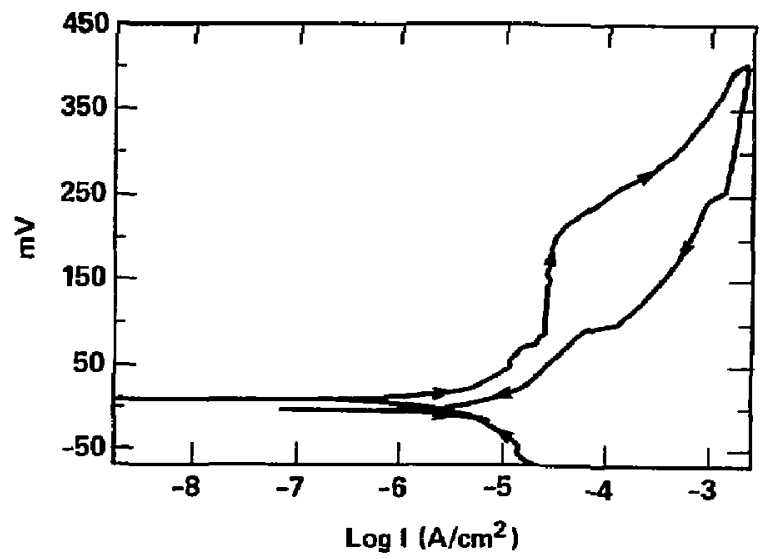

Fig. 13 Polarization behavior of CDA 102 in $\mathrm{J}-13$ water at $80^{\circ} \mathrm{C}$. (Potentials in mV, YS SCE.) Scan rate: $1 \mathrm{mV} / \mathrm{s}$. 


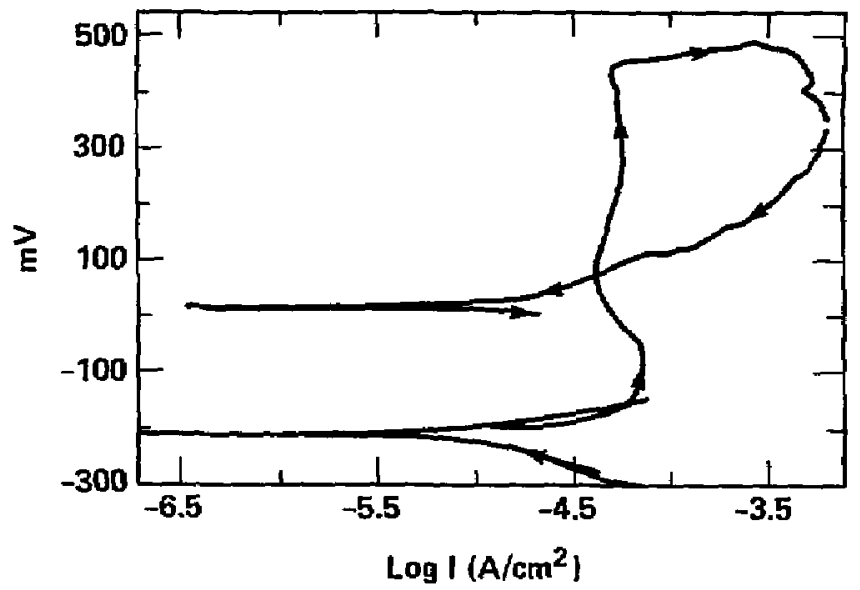

Fig. 14 Polarization behavior of CDA 102 in 100-times-concentrated $\mathrm{J}-13$ water at $80^{\circ} \mathrm{C}$. (Potentials in $\mathrm{mV}$, vs SCE.) Scan rate: $1 \mathrm{mV} / \mathrm{s}$. 


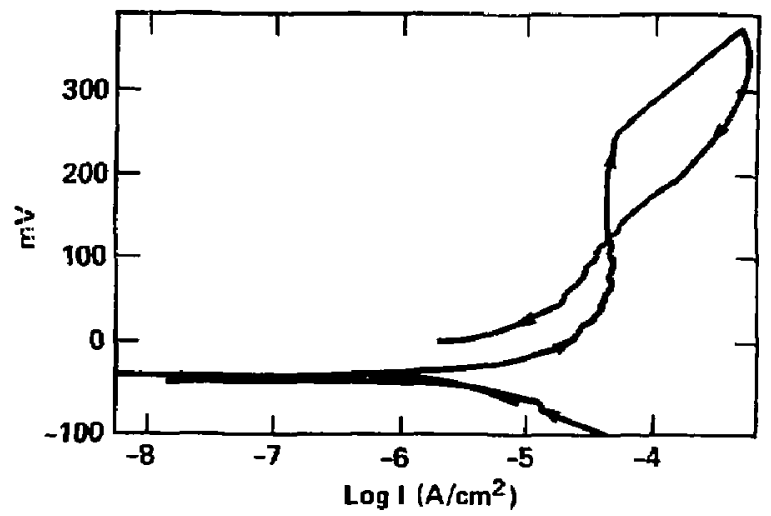

Fig. 15 Polarization behavior of CDA 613 in $\mathrm{J}-13$ water at $80^{\circ} \mathrm{C}$. 


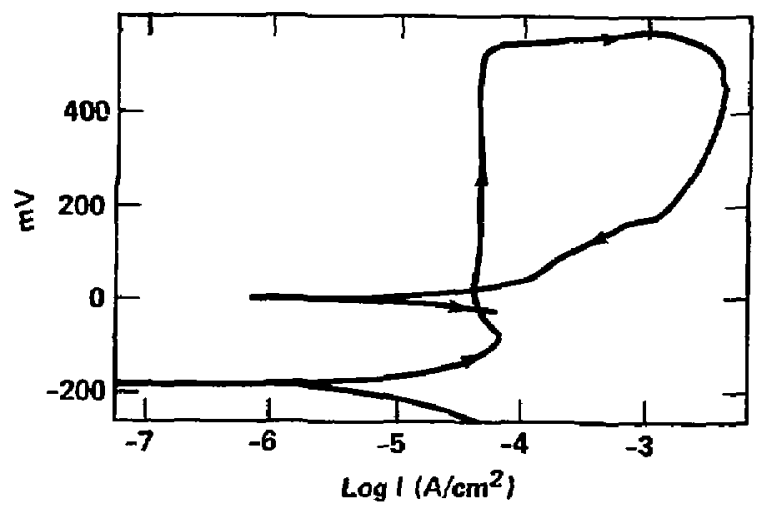

Fig. 16 Polarization behavior of CDA 613 in 100-times-concentrated J-13 water at $80^{\circ} \mathrm{C}$. (Potentials in $\mathrm{mV}$, vs SCE.) Scan rate: $1 \mathrm{mV} / \mathrm{s}$. 


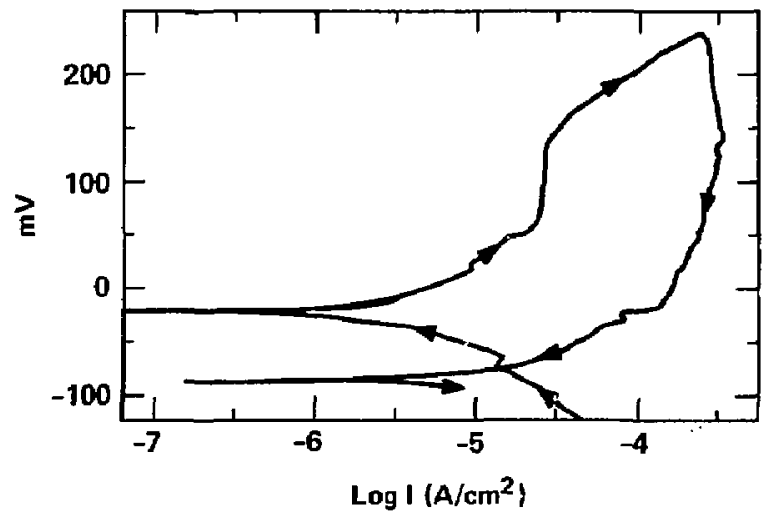

Fig. 17 Polarization behavior of CDA 715 in $\mathrm{J}-13$ water at $80^{\circ} \mathrm{C}$. 


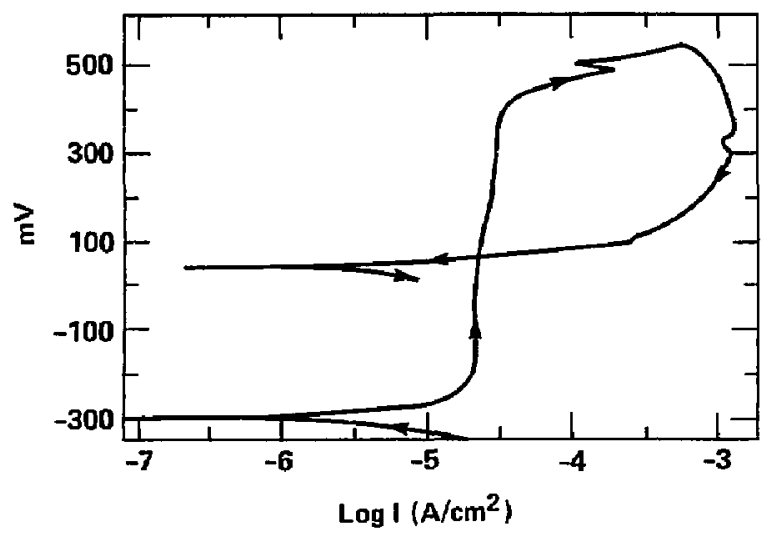

Fig. 18 Polarization behavior of CDA 715 in 100-times-concentrated J-13 water at $80^{\circ} \mathrm{C}$. (Potentials in mV, vs SCE.) Scan rate: $1 \mathrm{mV} / \mathrm{s}$. 


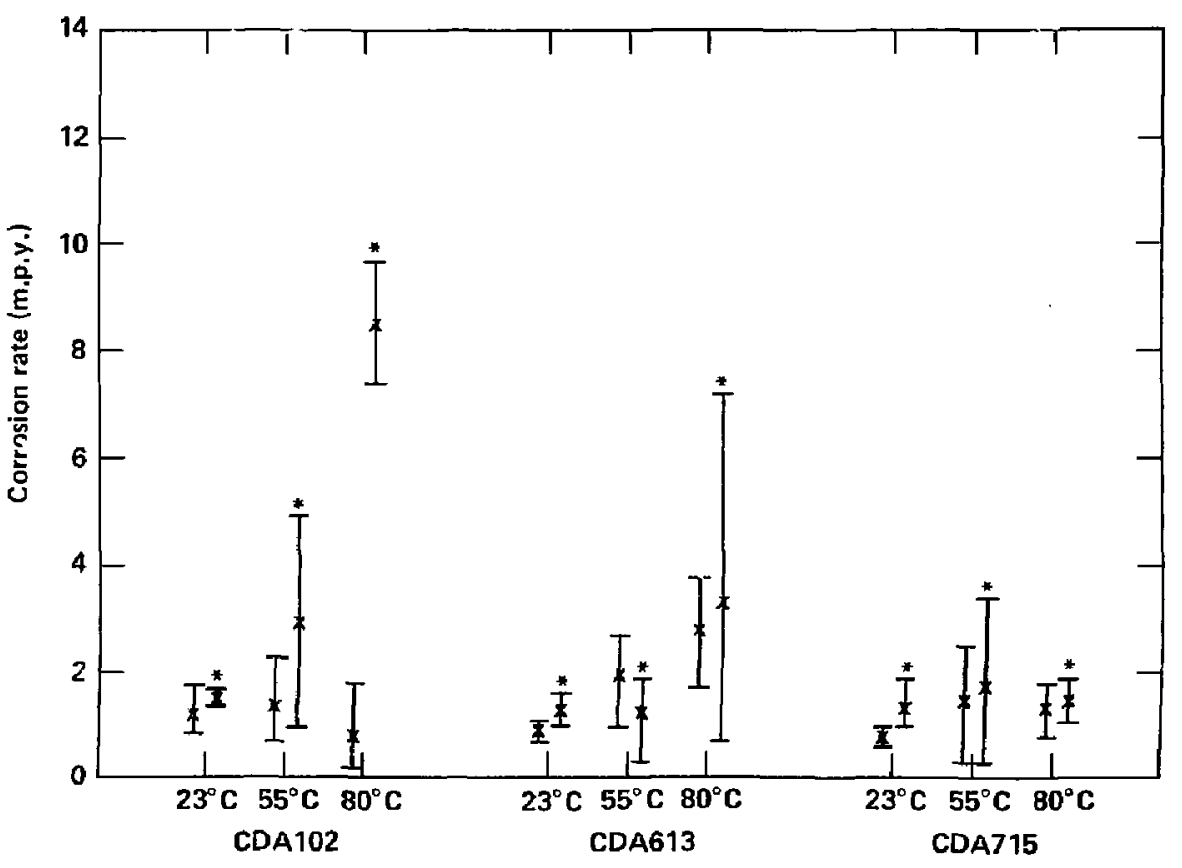

Fig. 19 Corrosion potentials in $\mathrm{J}-13$ and $100 \times$ concentrated $\mathrm{J}-13$ at different temperatures. $*=100 \times \mathrm{J}-73$. 


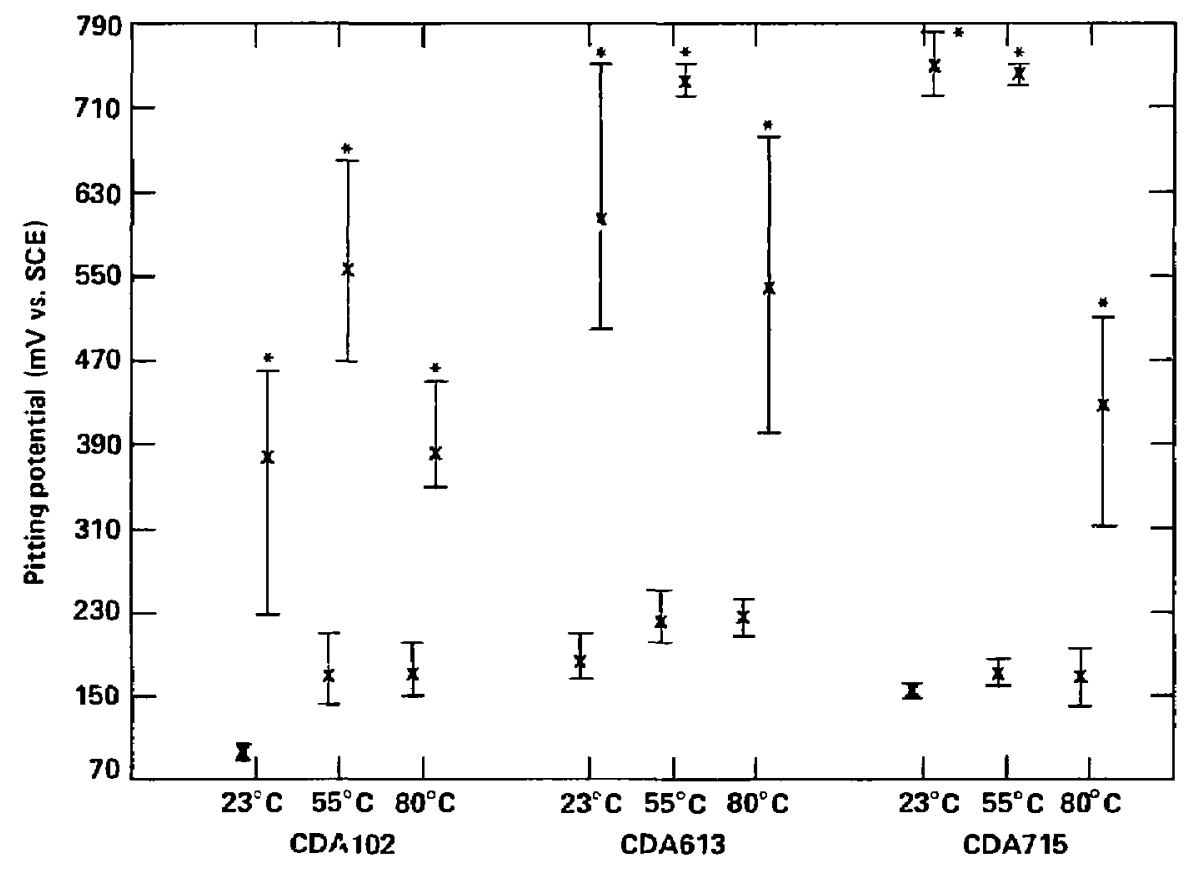

Fig. 20 Pitting potentials in $\mathrm{J}-13$ and $100 x$ concentrated $\mathrm{J}-13$ at different temperatures. $*=100 \times \mathrm{J}-13$. 


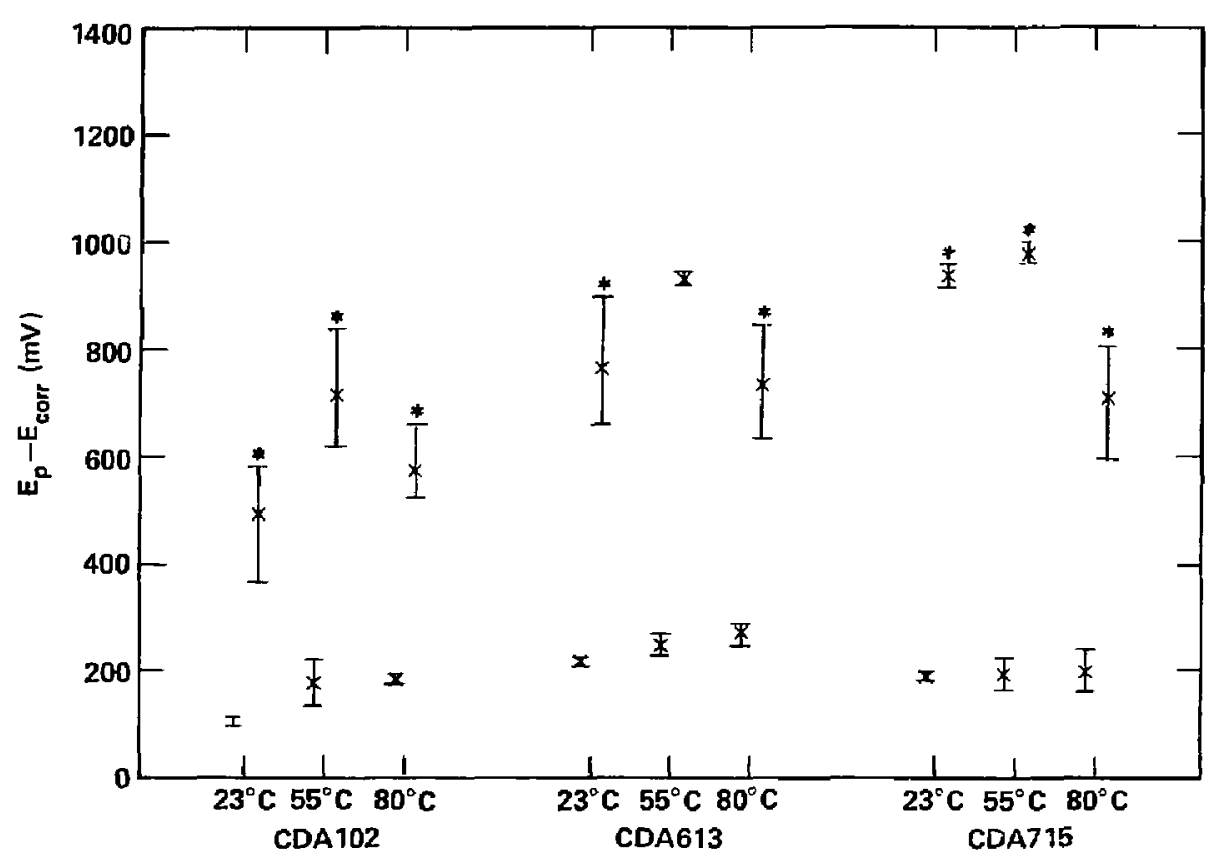

Fig. 21 Values for separation of pitting and corrosion potentials in $\mathrm{J}-13$ and $100 \times$ concentrated $\mathrm{J}-13$ at different temperatures. $*=100 \times \mathrm{J}-13$. 


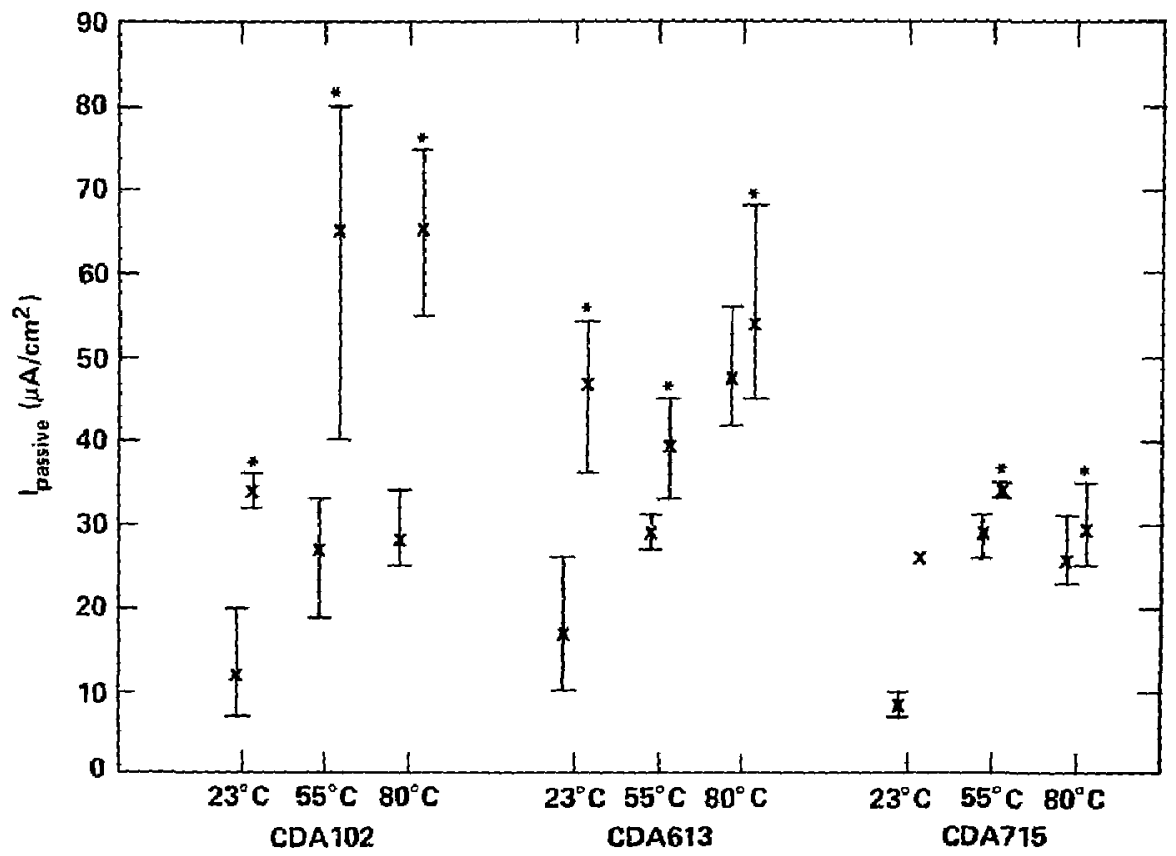

Fig. 22 Values of the passive state current density for $J-13$ and $100 x$ concentrated $\mathrm{J}-13$ at different temperatures. $=100 \times \mathrm{J}-13$. 


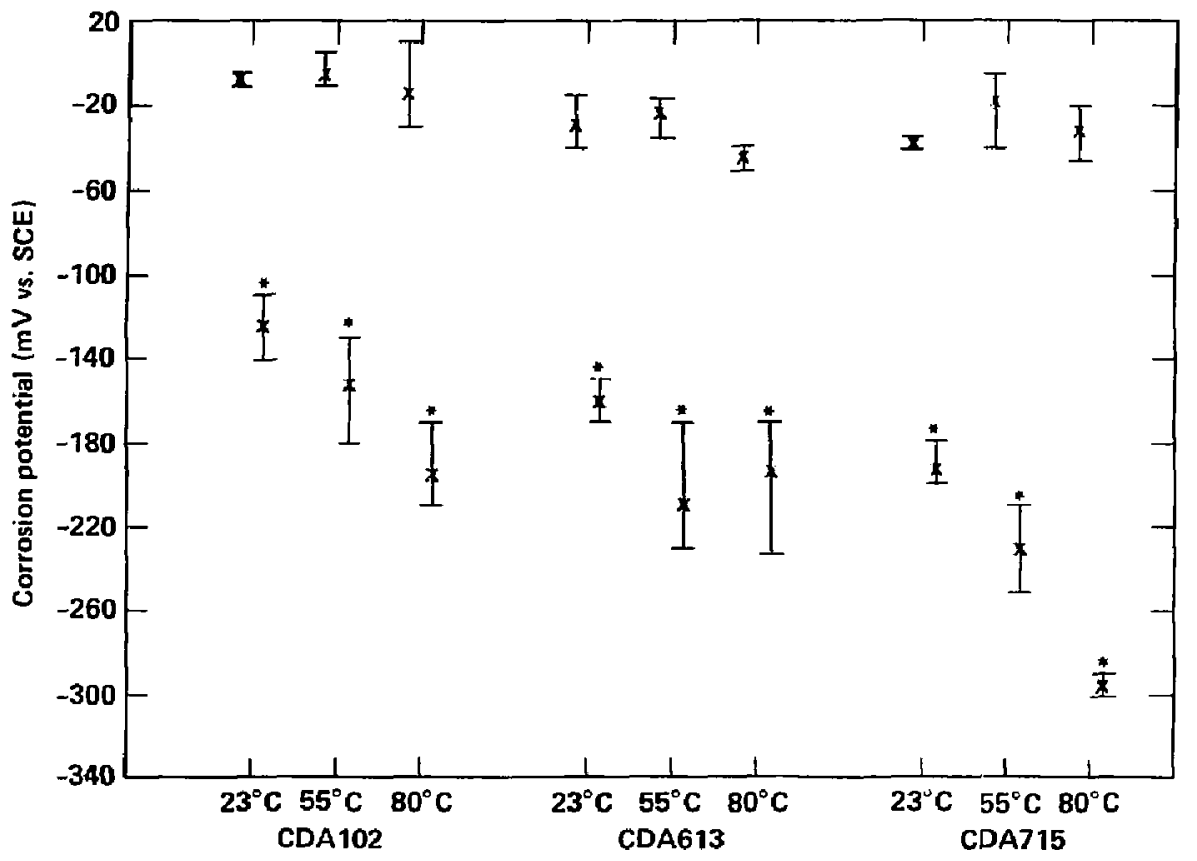

Fig. 23 Corrosion rates in $\mathrm{J}-13$ and $100 \times$ concentrated $\mathrm{j}-13$ as a function of temperature. ${ }^{*}=100 \times \mathrm{J}-13$. 
lable 8 . General corrosion penetration rates of candidate copper-base materials and other materials, for comparison, in tuff repository enviranmental conditions

\begin{tabular}{|c|c|c|c|c|c|}
\hline \multirow{2}{*}{\multicolumn{2}{|c|}{ Alloy }} & \multicolumn{4}{|c|}{ General corrosion rates $(m 115 / y)$} \\
\hline & & $\begin{array}{r}80^{\circ} \mathrm{C} J-13 \\
(3336 \mathrm{~h}) \\
\end{array}$ & $\begin{array}{l}100^{\circ} \mathrm{C} \mathrm{J-13} \\
(6000 \mathrm{~h}) \\
\end{array}$ & $\begin{array}{l}\text { Wet steam } \\
100^{\circ} \mathrm{C} \\
(6000 \mathrm{~h}) \\
\end{array}$ & $\begin{array}{c}\text { Dry steam } \\
150^{\circ} \mathrm{C} \\
(3000 \mathrm{~h}) \\
\end{array}$ \\
\hline CDA & 102 & 0.127 & 0.083 & 0.124 & 0.061 \\
\hline $\operatorname{CDA}$ & 613 & 0.172 & 0.059 & 0.090 & 0.014 \\
\hline CDA & 715 & 0.033 & 0.040 & 0.014 & 0.002 \\
\hline CDA & 110 & 0.159 & \multicolumn{3}{|c|}{ (electrolytic tough pitch copper) } \\
\hline $\operatorname{COA}$ & 706 & 0.099 & \multicolumn{3}{|l|}{ (90 Cu-10 Ni) } \\
\hline Mone 1 & 400 & 0.076 & \multicolumn{3}{|l|}{ (67 H1-32 Cu) } \\
\hline
\end{tabular}


corroston rates were obtained after four months of exposure; these rates (0.030-0.172 mpy) in $80^{\circ} \mathrm{C} \mathrm{J}-13$ water compare favorably with the general corrosion rates of copper and copper-base alloys in the natural waters discussed in Sec. 5.

In summary, in this initial study we have catalogued the electrochemical behavior for CDA 102, 613, and 715 in $\mathrm{J}-13$ and 100-times-concentrated $\mathrm{J}-13$ water at temperatures ranging from 23 to $80^{\circ} \mathrm{C}$. Some distinct differences related to $\mathrm{pH}$ and concentrattans of the anfons have been noted between the unaltered water and its concentrated form. An example is provided by the increased (positive) pitting potentials in the concentrated electrolyte, which, when coupled with the decreased (negative) corrosion potentials, produces a wider separation of these two parameters. The confunction of these two effects may actually decrease susceptiblitity to localized corrosion. The mechanisms involved in these processes are being further investigated.

\subsection{Radiation Effects on the Corrosion Processes of Copper and Copper-Base Alloys}

Both in situ electrochemical measurements and long-term testing have been initiated to determine the effects of gamma irradiation on the rates and mechanisms of corrosion of copper-base materials (CDA 102, 613, and 715). The long-term testing is being conducted at Westinghouse Hanford Engineering Development Laboratory (HEOL). The work at HEOL got underway in the sumner of 1985, and one-month results were not available for inclusion in this report. Although data are not avallable from these tests, a brief description of the experimental conditions follows.

Two environments are being examined: a two-phase system of $\mathbf{3}-13$ water and water vapor maintained at $95^{\circ} \mathrm{C}$ in one vessel, and a single-phase steam/air enviroment maintained at $150^{\circ} \mathrm{C}$ in another vesse 1 . The radiation dose in both environments is the same $\left(2 \times 10^{5} \mathrm{rad} / \mathrm{h}\right)$. Each vessel contains replicate samples of general corrosion (weight loss) coupons, stressed specimens (in the shape of a "tear drop" with a welded end), and crevice specimens (bolted coupons) of the three candidate materials.

The majority of the work performed to date has centered on In situ electrochemical measurements in gamma-trradiated environments, analogous to the work discussed previously in Sec. 6.1. Both unattered J-13 well water and concentrated $3-T 3$ water were used as electrolytes. 


\subsubsection{Aqueous Environment and Radiation Chemistry}

Before interpreting the electrochemical experiments, it is helpful to consider what is known from past work in this field about bulk radiation chemistry of aqueous solutions. Because the groundwater contains only low concentrations of solutes, most of which do not undergo high-rate reactions with radiolytic radicals, its initial radiation chemistry should be similar to that of pure water. The interaction of gamma radiation with aqueous solutions produces a host of transient radicals, fons, and stable molecular species including $\mathrm{H} \cdot, \cdot \mathrm{OH}, \mathrm{e}_{\mathrm{aq}}^{-}, \mathrm{H}_{3} \mathrm{O}^{+}, \mathrm{OH}^{-}, \mathrm{H}_{2}, \mathrm{H}_{2} \mathrm{O}_{2}, \mathrm{O}_{2}, \mathrm{O}_{2}^{-}$, and $\mathrm{HO}_{2}$. Some of these species can act as reducing agents, others as oxidizing agents. As a result of the production of such active species under gamma irradiation, one can expect alterations in the rates or mechanisms of corrosion attack modes. Hochandel (1952), Allen (1961), and Spinks and Woods (1976) discuss radiolysis in aqueous solutions.

Under radiolysis of a1r-saturated J-13 well water or its concentrated forms, we expect an oxidizing environment with oxygen and hydrogen peroxide as the dominant oxidizing species, a much smaller concentration of $0_{2}^{-}$and still smaller steady-state concentrations of $\mathrm{HO}_{2},-\mathrm{OH}_{2} \mathrm{H}_{2}, \mathrm{H} \cdot$, and $\mathrm{e}_{\mathrm{aq}}^{-}$ (Glass et al., 1985). In addition to these species, various oxides of nitrogen and nitric acid and possibly ammonia can form in a moist-air phase, if one is present, and subsequently enter the solution. Irradiation of water containing either carbon dioxide or bicarbanate ion with dissolved oxygen produces carboxylic acids (formic and/or oxalic).

\subsubsection{Potential Measurements and Electrochemical Mechanisms}

The electrochemical behavior of austenitic stainless steels in gamma-irradiated environments has been extensively discussed in a previous report (Glass et a 1., 1985). The experimental procedures and the electrochemical apparatus used to make corrosion measurements in irradtated systems were reported in that paper; the work presented below on copper used the same apparatus and procedures.

In the previous study, it was proposed that the radiolytically generated oxidant hydrogen peroxide fand also probably the transient species $\cdot \mathrm{OH}_{\text {; }}$ account for the observed electrochemical effects in irradiated systems. Most 
notably, the generation of hydrogen peroxide produces positive corrosion potential shifts for austenitic stainless steels. To compare the results obtained for copper, it will be necessary to briefly discuss representative results of irradiation on the corrosion behavior of $376 \mathrm{~L}$ stainless steel. All experiments reported below were performed at $30^{\circ} \mathrm{C}$ and at a gamma dose rate of approximately $3 \times 10^{6} \mathrm{rad} / \mathrm{h}$.

The more oxidizing environment produced under gamma irradiation shifts the corrosion potentials of austentic stainless steels in the positive direction, as shown in Fig. 24 in concentrated J-13 water. The "on" in inis figure refers to lowering of the cell into the center of the gamma sources (pencils of cobalt-60), and "off" refers to raising the cell 1.3 to $1.5 \mathrm{~m}$ above the sources, where the cell was shleided by intervening water. Several "on/off" cycles are shown. He observed similar positive potential shifts upon imposition of the gamma field for AIS1 316L in more highly concentrated groundwater (100X) and in the unaltered J-13 vell water. Similar effects were noted on irradiated specimens of 304L in these environments. The corrosion potential shifts under all of these conditions were tjpically 150-200 mV for both materlals.

In the previous study, several experiments were performed that indicated that $\mathrm{H}_{2} \mathrm{O}_{2}$ was responsible for the corrosion potential shifts shown in Fig. 25. one test, successive additions of a $30 \% \mathrm{H}_{2} \mathrm{O}_{2}$ solution were made to al, unirradiated $\mathrm{J}-13$ solution in which a freshly prepared AISI $316 \mathrm{~L}$ electrode was immersed. In this figure, a one-drop addition to the solution represents a concentration increase of approximately $0.5 \mathrm{~mA}$. which is near the 0.14-min concentration we measured for hydrogen peroxide in irradiated solution after $3.5 \mathrm{~h}$ of exposure, using the titanium oxalate method (Sellers, 1980). It can be seen that the potentlal shift observed following the addition of the first drop is near the bottom end of the range of potential shifts observed under radiolysis $(150-200 \mathrm{mV})$. Successive additions of hydrogen peroxide (at breaks in the curve) yleld smaller potential jumps than the initial addition on a per-drop basis. indicating the tendency toward an eventual saturation point. These results support the theory that the production of hydrogen peroxide under radiolysis leads to the long-term potential shifts seen in austentitic stainiess steels.

Although some of the general features (e.g., positive corrosion potential shifts) are similar, the behavior of copper in gamma-irradiated environments differs from that of stainless steel. Figure 26 shows the corrosion potential 
vs time behavior of CDA 102 in J-13 water when subjected to gamina

irradiation. Upon initiation of irradiation the corrosion potential jumped approximately $100 \mathrm{mV}$ positive, then decayed to more negative value:. If steady-state had been reached, the final potential probably would have reached nearly the same value as that attained before irradiation for at most 10-20 mV higher). This is in contrast to the much larger and longer term potential shifts observed for stainless steels in this medium. Upon termination of irradiation, the corrosion potential dropped (in the negaifue direction). which is analogous to the behavior with stainless steels. Results simtlar to those for CDA 102 were obtained for the copper alloy CDA 715, as shown in Fig. 27.

A 5 imilar corrosion potential vs time relationship was observed when hydrogen peroxide was added to unirradiated J-13 water in which a CDA 102 electrode was immersed. Results of this experiment are shown in Fig. 28. In this figure, one drop of a $30 \%$ hydrogen peroxide solution represents a resulting concentration in $\mathrm{J}-13$ water of approximately $0.5 \mathrm{~mm}$. The solution was stirred during the addition of $\mathrm{H}_{2} \mathrm{O}_{2}$.

The similarity of the potential rise and decay observed in figs. 27 and 28 for copper indicates that the radiolytic product, hydrogen peroxide, is a major determinant of the electrochemical behavior of copper in irradiated environments, as it is for AISI 316L stainless steel. The initial potential rise and the apparent steady-state potential after the decay are more positive In the ex situ case (Fig. 28), probably because the concentration of hydrogen peroxide added in the ex situ experiment was a factor of three to four $t$ imes higher than was reached in the irradiation experiment. Also, continuous stirring of the solution in the ex situ experiment increased the mass transfer of the oxidant (hydrogen peroxide) to the electrode surface. When the magneitc stirrer was turned off (see Fig. 28), the corrosion potential immediately fell to more negative values, apparently because the hydrogen peroxide in the diffusion layer next to the copper electrode was consumed by decomposition into water and oxygen, and the reaction became diffusion-limited.

The corrosion potential behavior of the copper alloys in concentrated J-13 water under gamma irradiation is currently being determined. Although all the features of the potential time curves are not yet completely understood, it appears that gamma irradiation generally has a larger effect (greater positive potential shifts) on the corrosion potential in these experiments than in the previous ones performed in unaltered $\mathrm{J}-13$ water. 
Int:lal results of the arodic polarization behavior of $\mathrm{COA} 102$ in concentrated J-13 water are showh in Fig. 29. In this figure, the curves for irradlated and unirradiated environments have been superposed; irradiation appears to produce a positive corrosion potentiai shift with respect to the unirradiated case (the values for the irradiated case are indicated by an asterisk). In contrast, there appears to be a negative shift in the pitting potential under irradiation, which produces a lower vajue for $E_{p}-E_{c o r r}$. However, in this case the increased proximity of the corrosion and pitting potentials will not lead to spontaneous pitting because the values are still widely separated.

\subsubsection{Electrochemical Mechan1sms}

It seems likely from the above findings that the radiolytically generated hydrogen peroxide and probably also the oxidizing transtent radical $\circ$ OH play important roles in the electrochemical behavior of metals in irradiated environments. The initial rapid rise of potential for CDA 102 (and that for $375 \mathrm{~L}$ stainless steel) upon initiation of jradiation most 11kely results from the production of these species in the solution layers next to the electrode surface. It has long been recognized that copper is catalytic toward the decomposition of hydrogen peroxide, whereas stainless steels are only mildly so (Reichert and Pete, 1947). In acidic media, hydrogen peroxide has been shown to increase the rate of the autodissolution process of copper by a catalytic mechanism (Molodoy et al., 1982). In this mechantsm, cupric ions are formed from the solution-phase oxidation of cuprous ions by hydrogen peroxide. The cupric lons can then act as cathodic depolarizers to acceierate the corrosion process.

Upon intiation of irradiation, the initial large positive jump in the copper corrosion potentlal indicates a rapid response to the presence of hydrogen peroxide and hydroxyl radicals. The almost immediate negative decline in potential may indicate a decreased catalytic efficiency for reduction of hytrogen peroxide and may correspond to the oxidation of the surface or alteration of the oxide f $11 \mathrm{~m}$ on copper (e.g.. by adsorption of intermediates). Visually, the surface of copper appears to be oxidized (tarnished) under irradiation. 


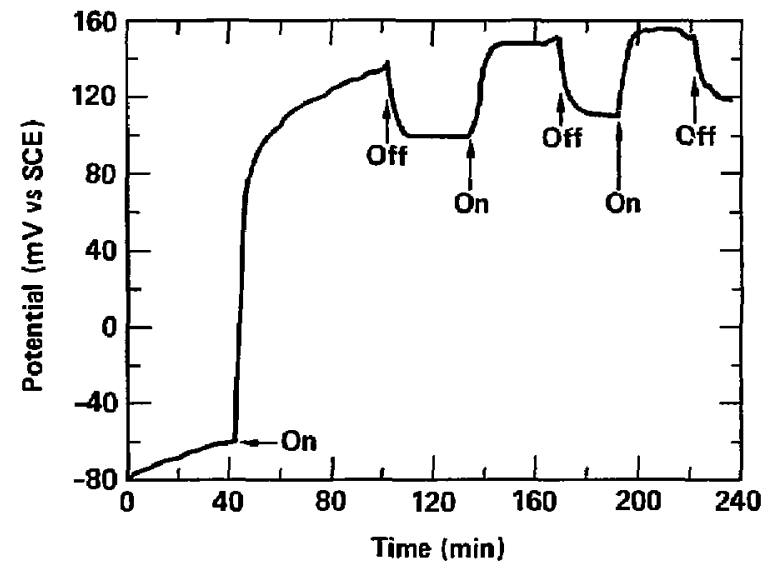

Fig. 24 Corrosion potential of CDA 316L in 100-times-concentrated J-13 water in gamma irradiation. $(0 \mathrm{n}=$ specimen lowered toward source; of $\mathrm{f}=$ specimen raised away from source.) 


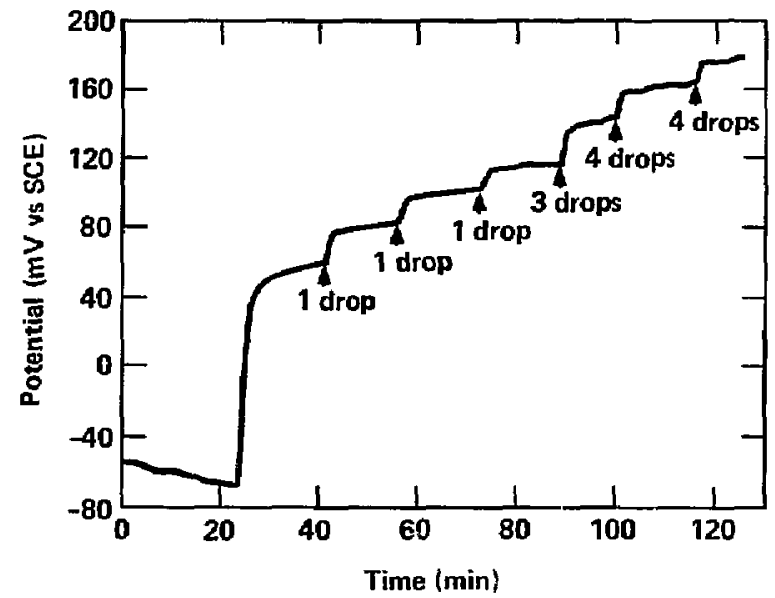

Fig. 25 Change in corroston potential of $316 \mathrm{~L}$ stainless steel in $\mathrm{J}-13$ water with addition of hydrogen peroxide ( $1 \mathrm{drop} \mathrm{H}_{2} \mathrm{O}_{2}=4.9 \times 10^{4} \mathrm{M}$ ). 


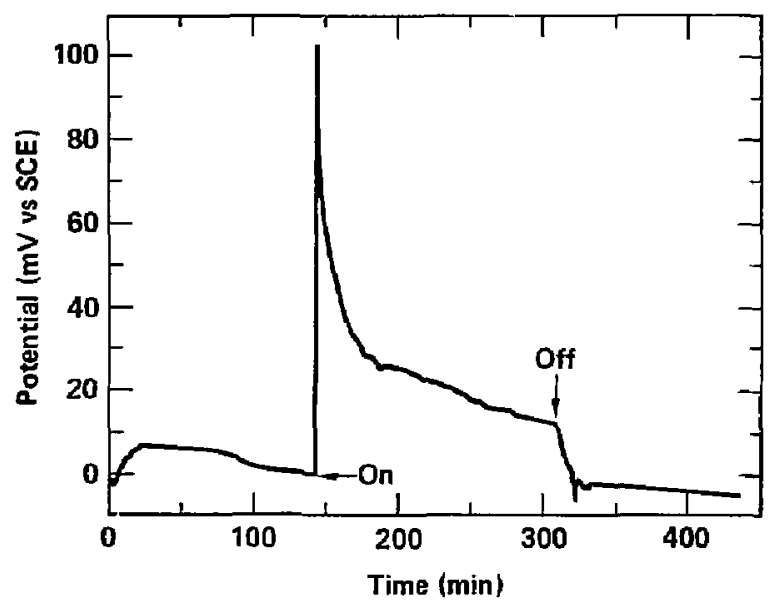

F1g. 26. Change in corrasion potential of CDA 102 in irradiated J-13 water $\left(3.3 \times 10^{6} \mathrm{rad} / \mathrm{h}\right)$. 


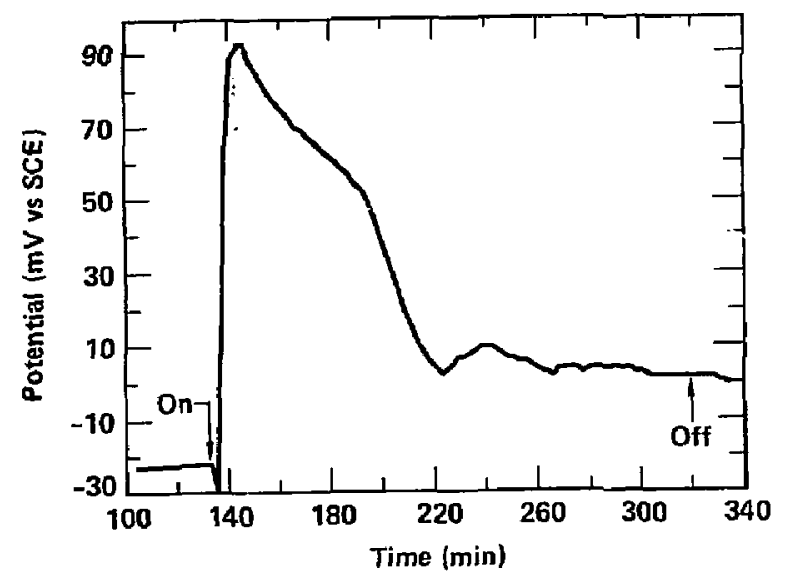

fig. 27 Change in corrasion potential of COA 715 in Irradiated J-13 water $\left(3.3 \times 10^{6} \mathrm{rad} / \mathrm{h}\right)$. 


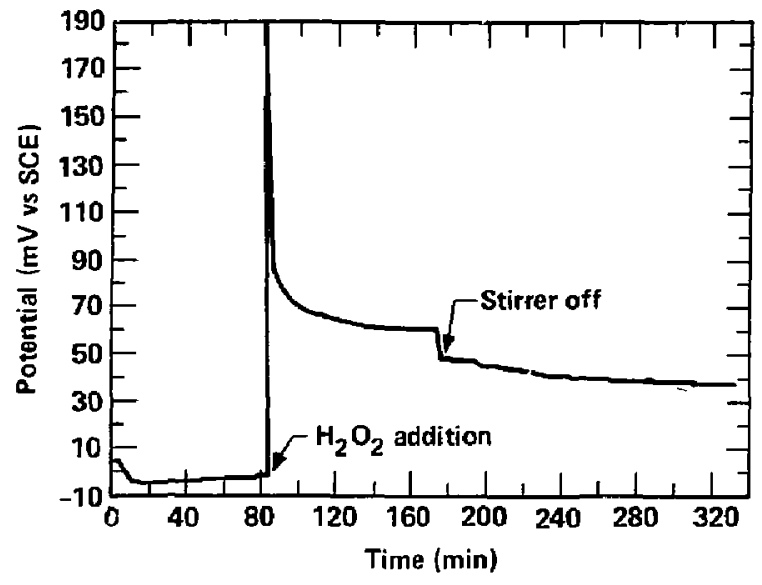

Fig. 28 Change in corrosion potential of 102715 in J-13 water with $0.5 \mathrm{~mm}$ $\mathrm{H}_{2} \mathrm{O}_{2}$ addition. 


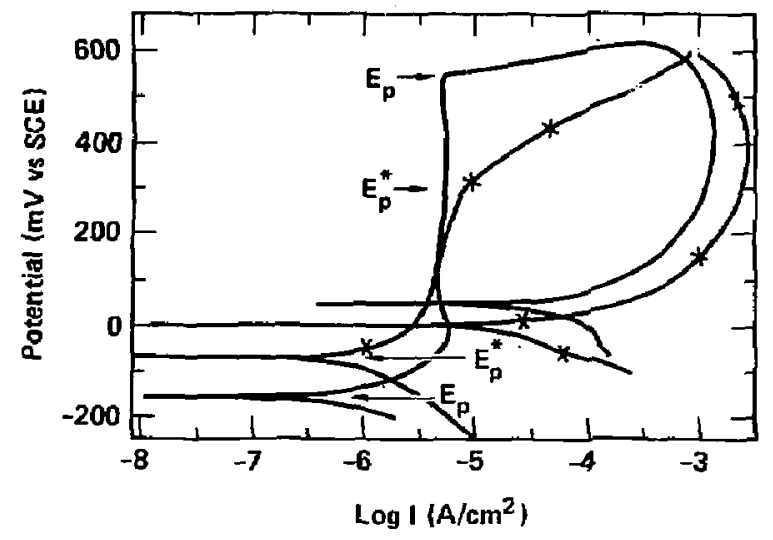

Fig. 29 Polarization behavior of COA 102 in 100x concentrated J-13 water. Scan rate $1 \mathrm{mV} / \mathrm{s}$. * = $\mathrm{rradlated}\left(3.3 \times 10^{6} \mathrm{rad} / \mathrm{h}\right)$. 
The corrosion potential under Irradiation w:11 be determined by a superposition of all the anodic (e.g., metal dissolution) and cathodic processes occurring on the surface. 0xidizing specles, such as hydrogen peroxide and hydroxyl radical, which can act as cathodic depolarizers, shift the corrosion potential in the positive direction. These specles are produced in the radiolysis of water. These reactions probably 1111 dominate under gamma irradiation of aerated aqueous systems similar to J-13 we 11 water and its concentrated forms, when the $\mathrm{pH}$ is neutral to mildly alkaline.

A mechanism for the cyclical catalytic decomposition of hydrogen peroxide on platinum that involves adsorbed species $\left(\cdot \mathrm{OH}\right.$ and $\left.\mathrm{HO}_{2}\right)$ resulting from the electrochemical discharge of hydrogen peroxide has also been advanced to account for the observed open-circuit behavior of $\mathrm{Pt}$ in aqueous $\mathrm{H}_{2} \mathrm{O}_{2}$ solutions, particularly at higher pH (Gerischer and Gerischer, 1956). In the cyclical mechanism. water and the additional cathodic depolarizer oxygen are liberated. In analogy to these studies on platinum, similar mechanisms may explain the observed results for stainless steels and, particularly. for copper and its alloys in irradiated aqueous solutions. However, the situation will surely be more complex for these materials in the J-13 environment than for $P t$ in high-purity aqueous solutions of hydrogen peroxide. This will result from the additional anodic reactions of metal dissolution and the presence of other species capable of participating in redox reactions (such as nitrate and bicarbonate ions\}. In addition, for copper and its alloys, the presence of hydrogen peroxide may catalytically accelerate the autodissolution process via the following reaction series:

$\mathrm{Cu} \rightarrow \mathrm{Cu}^{+}+\mathrm{e}-$

$\mathrm{Cu}^{+2}+\mathrm{e}_{-} \rightarrow \mathrm{Cu}^{+}$,

with $\mathrm{Cu}^{+2}$, acting as an oxidant, being generated from the solution reaction:

$\mathrm{Cu}^{+}+\mathrm{H}_{2} \mathrm{O}_{2} \rightarrow \mathrm{Cu}^{+2}+\mathrm{OH}+\mathrm{OH}^{-}$.

As mentloned above, the open circuit behavior as a function of time during irradiation is somewhat different for copper than for stainless steel. Upon inftiation of irradiation, the potentlal imediately shifts by $150-200 \mathrm{mV}$. 
The potential then declines to less positive values. This may indicate a decreased catalytic efficlency for hydrogen peroxide elther because of the oxidation of the copper surface or, perhaps, because of the adsorption of a spectes such as hydroxyl radical, which blocks surface sites.

\subsubsection{Vapor-Phase Corrosion}

We have found that copper is much more susceptlble to vapor-phase attack in irradiated environments than is stainless steel. This is likely a result of the known formation of ozone and various oxides of nitrogen, as well as nitric acid in systems containing oxygen, nitrogen, and water vapor (Lind, 1961; Burns et a 1., 1982). The praducts are corrosive to copper but much less so to stainless steel. A photograph of a sample of the vapor-phase currosion of CDA 102 is shown in $\mathrm{F} 1 \mathrm{~g}$. 30. In this case, the left half of the length of the rod was immersed in J-13 well water, and the right half was exposed to the atmosphere above it in a sealed glass tube. The irradiation lasted 15 days. Although oxidation of both the vapor-and salution-phase surfaces is apparent. much more severe oxidation has occurred in the vapor phase. The oxide that formed was identified as $\mathrm{Cu}_{2} \mathrm{O}$ by $x$-ray diffraction, as shown in $\mathrm{Fig} .31$. Previous studies of the irradiation of copper in molst air without a liquid phase have revealed formation of what appeared to be copper hydroxide nitrate, $\mathrm{Cu}_{2}(\mathrm{OH})_{3} \mathrm{NO}_{3}$ (also known as basic copper nitrate) instead of cuprous oxide (Byalobzhesk11, 1970; Primak and Fuchs, 1954).

The absence of detectable nitrate in the present case may have resulted either from the relatively small dose or from dissolution of some of the nitrogenous gases in the liquid phase, preventing their reaction with the surface of the sample in the vapor-phase region. It is known that reaction of pure $\mathrm{NO}_{2}$ with copper produces $\mathrm{Cu}_{2} \mathrm{O}$ (Park and Partington. 1924). Data obtained from our long-term corrosion testing program in irradiated air/steam environments will be very useful in mechanistic interpretation of vapor-phase attack.

\subsection{Thermodynamic Considerations}

As mentioned in the NNWS1 test plan (Sec. 4), copper can coexist thermodynamically with water under certain condttions. We felt that some 


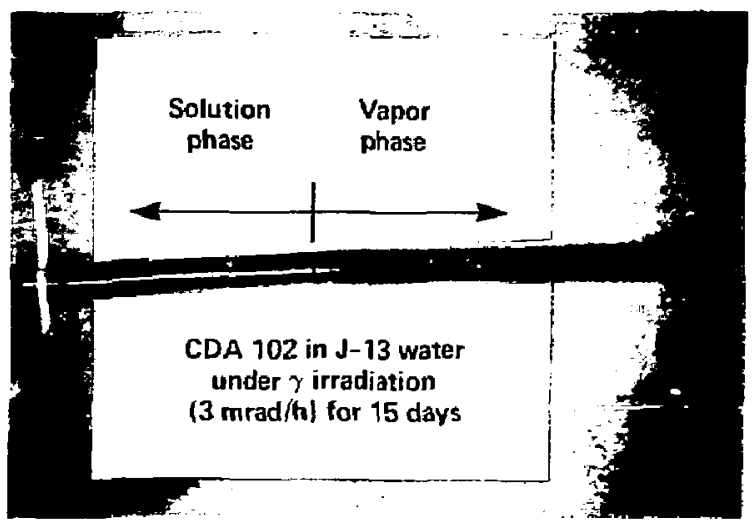

Fig. 30 Appearance of CDA 102 rod exposed to irradiated $3-13$ water and vapor for 15 days. 


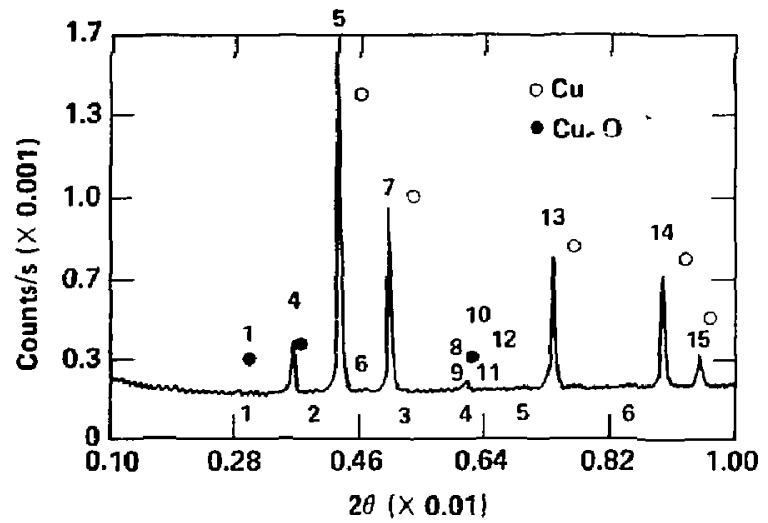

Hig. 31 X-ray diffraction spectrum of vapor-phase corrosian products on COA 102 in irradiated J-13 water. 
thermodynamic investigations might be in order, particularly in interpreting how gamma radiation would affect the phase stability of species important for determining the corrosion behavior of copper in aqueous systems.

The relevant Pourbalx diagrams (potential-pH) for copper in J-13 water and in irradiated $\mathrm{J}-13$ water are presented in Appendix $B$.

The diagrams are tentative and mist be examined in the light of experimental results and a review of the assumptions made in drawing them. Some of these are indicated in Appendix $B$. The diagram for irradiated J-13 water hows a large stability region for the basic cupric nitrate.

\subsection{Expected Test Results in Near Future}

The work discussed in Sec. 6.2 will continue into Fy 1986 unt11 there are enough data on which to decide whether copper or a copper-base alloy should be considered further as a viable container material for waste packages in a repository at Yucca Mountain. Tne fY 1986 work is focused on deriving the information required to arrive at that decision.

The planned activities for FY 1986 were discussed in Sec. 4.3.4. Since the time when the NNWSI Test Plan was formulated (December 1984), we have decfoed to place more emphasis in fY 1986 on fnteraction testing between waste package components. Speciffically, we are concerned about the interaction between copper (or copper-base alloys) and the Zircaloy cladding on spent-fue] elements.

Fesults from the phenomenological tests in radiation environments now under way at Westinghouse HEDL will be important in directing the research activitles of the copper test plan. These tests are about three months late from the scheduled plan, due to a delay in the release of funds for copper testing activities (Janliary 1985) and some experimental difficulties in installing the test vessels. The greatest uncertatnty with copper is its performance in irradiated environments. As indicated in Sec. 5, production of such species as nitrate, nitrite, and ammonia can increase the general. corrosion rate or promote stress corrosion cracking. As also discussed in Sec. 5 and again in Sec. 6, the copper-base alloys substantially improve corrosion resistance to these phenomena.

We were not aware of the intergranular-related corrosian phenomena, on either stressed or unstressed specimens, discussed in Sec. 5. Apparently some of these phenomena can develop in steam and water at temperatures above $300^{\circ} \mathrm{C}$ 
In binary (not commercial) copper-nickel alloys. Although these temperatures are beyond our immedtate range of interest, we are interested in determining whether intergranular corrosion is of concern over long time periods under our environmental conditions. The problem of selective leaching laluminum from CDA 613, nickel from CDA 715) does not appear to be relevant under our environmental conditions from our analysts of the published 11 terature.

\section{FABRICATION AND WELDING OF COPPER AND COPPER ALLOY CONTAINERS}

The different designs proposed for NWWSI waste package containers are simple geometric shapes with routine engineer ing requirements. Quality assurance requirements are likewise well known and understood among large metal parts fabricators, since these have long been a requirement in nuclear application components. Under sub-contract to LLNL, CDA has prepared some background matertal on conventional manufacturing methods for producing thinand thick-walled containers, as well as material on alternative fabrication methods. An advantage to these alternative processes is that they eliminate some or all of the welds that would be needed using convenilonal fabrication methods.

Some typical industrial fabricators are cited as exampies to show the capabilities of the metalworking industry. These firms were chosen purely on the basis of convenience, or because of the avallability of personnel for discussion during the time when this report was in preparation. No preference is intended or implied. These companies do represent the state of che art. in their flelds and are among the leaders in their respective technologies. All are aware of the DOE's container development programs and all. expressed interest in elther contributing technological expertise or taking part in actual hardware fabrication projects.

\subsection{Fabrication Methods for Container Shells}

There are three basic methods for fabricating container shells: (1) rolled and we ?ded fabrication, (2) centrifugal casting, and (3) extrusion. We will discuss each method in detail in the following paragraphs. 


\subsubsection{Rolled and Welded Fabrication}

The most cotmon (and conventiona1) comerclal method for producing Targe-diameter cylinders is to form them from plate, joined by a longitudinal weld seam. For example, container-size pressure vessels, tanks, heat exchanger shells, etc. are made by this process. It is generally accepted that this fabrication method is less costly than others. Because it is so commonly practiced, it also offers the advantage of a large cholce of potentlal suppliers.

The cylindrical shape is formed by either rolling or press-break bending. Both ferrous and nonferrous metals can be fabricated by elther method; because copper metals are more ductile than steels they can be fabricated in roughly twice the wall thickness as steel on a given capactty roll or press break. Hal1 thicknesses of several centimeters can be fabricated by this technique.

once formed into a cylinder, the plate edges are joined by a longitudinal seam weld. In conventional linepipe fabrication, this weld is made using submerged arc techniques; in copper metals it may be made using electron beams (for very thick walls) or, more 11kely, by hot-wire gas-tunsten arc (GTA) (also called tungsten-inert gas (IIG)) or, occastonally, by gas-metal arc (GMA) (also called metal-inert-gas (HIG)). Since formed and welded cylinders are rarely perfectly round, they normaliy require final sizing by bending (on a press break) or hydrostatic expansion. The standard method for making linepipe is therefore commonly known as "UOE" fabrication: "U"-bending, "O"-forming, and finally "E"-expansion.

Examples of large contatner-słzed copper products are water-cooled molds used for the vacuum-arc and electroslag reneit processes (VAR and ESR, respectively). These molds are used in the primary fabrfcation of specialty and high-performance alloys. A fabricating shop specializing in making such molds in the U.S. is Zak. Inc. (]roy, NY). Most molds are between 30 and $50 \mathrm{~cm}$ in diameter and approximately $3 \mathrm{~m}$ long. with wall thicknesses ranging from 2 to $5 \mathrm{~cm}$. Larger molds have been produced.

Welding is frequently performed using aluminum bronze or other copper-base flller wire. The GTA process is preferred because it permits better control and results in higher joint qualtty (less opportunity for oxidation). GMA welding is also used, although not for critical joints. Seam welds are made

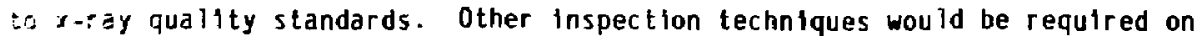


nuclea: waste containers. As-welded cylinders are not round but assume a slightly irregular shape caused by shrinkage stresses near the longitudinal c am weld. Distortion appears to total no more than a centimeter. Held seams are straightened on a press break. In some cases, cylinders are brought to finished roundness tolerances by explosive expansion.

The type of waste package conta'ners envistoned for the NNWSI conceptual designs could be manufartured in much the same manner as VAR and ESR cructbles, standard industrial items with approximately the same overall dimensions. Shops spectalizing in this type of copper metal fabrication are not now numerous.

\subsubsection{Centrifugal Castịng}

Simple, hollow, cylindrical metal parts have long been produced by centrifugal casting. For example, many thousands of tons of cast-iron water mains are made by this process every year. Holten metal is poured into a spinning mold, which may be oriented vertically or horizontally depending on the aspect ratio of the part at hand. The spinning action creates a centrifingl force that holds the metal against the mold wall until solidification is complete. The mold normally is made of steel, and its inner surface is given a ceramic mold wash for protection and for ease of removal of the finished casting. Centrifugal castiny molds are always sightly tapered; this drafting also facilitates separation.

The outstanding characteristic of centrifugal casting is its cleanliness compared with ordinary sand castings. Most impurittes (inclusions, slag, bits of refractories, etc.) are less dense than molten metal. As the metal is held against the mold wall, these are trapped as the metal solidifies. The inrer surface of centrifugal castings therefore forms a bullt-ta riser which, like a conventional riser, is discarded, in this case by machining it away by boring or turning. This leaves only the sound, clean metal of the finished casting.

Centrifugal castings do not have the total soundness of wrought metal. That is not to imply that they are porous; indeed, many such castings are used as high-pressure hydraulic cylinders and catalytic reforming tubes. Never theless, the question of whether the microshrinkage found in all castings, including centrifugals, wlll permit the permeation of fission gases (as could arise from a ruptured fuel rod) renatins to be answered. Microshrinkage volds can be sealed by forging or by hot 1sostatic pressing. 
Centrifugal casting foundries can be found in most parts of the country, but many of them cast ferrous parts (water mains, etc.) and are not equipped to cast copper allays. Wisconsin Centrifuga' Inc. (Waukesha, WI) regularly casts steels and copper alloys in about equal quantities. Two of their most frequently called for allays are aluminum bronze and copper-ntckel. The inner surfaces of such castings need not be cylindrical (although most centrifugal castings are) but may be cast to net and near-net shape through use of cores. This process could be used to produce containers with integrally cast internal structures such as racks, spacers, stiffeners or partitions to separate fuel assemblies.

Centrifugal casting appears we 11 sutted to the manufacture of container shells in copper alloys. High-purity copper would be difficult to cast, but dilute alloys such as COA 815 (1\% chromium) could be produced. Patential disadvantages of the process involve soundness or mechanical property requirements placed on the products, atthough it should be noted that the mechanica? properties of quality centrifugal castings closely approach those of wrought products. Some subsequent forging or HIPping may be required to ensure gas tightness; however, this polnt must be addressed by experiment. If the slight taper necessary on all centrifugal castings is objectionable, removing it will require incremental added expense.

\subsubsection{Extrusion}

Extrusion of tubular products is a standard industrial proces5; great quantities of smali-to-medium-diameter extruded pipe and tube are produced throughout the world. The proposed container designs are essentially large-diameter closed-end pipes, and extrusion is therefore also a potential method for their production.

Extruded hollows as large as the conceptual design containers are not common since the equipment needed to $;$;oduce them is very large and specialized. However, such equipment is available in the U.S. and has been used to manufacture large-diameter copper alloy piping. An example is the 32,000-metric-ton extrusion press lacated at the Cameron Iron Works plant in Cypress. 1x. Cameron's extrusion press can extrude tubes of the diameters, lengths, and thlcknesses proposed in the NNWSI conceptual designs. 
An interesting option is the possibility of producing one-end-closed impact extrusions. This process is already being used to produce bomb cases tiut has not as yet been used on cylinders of the size and wall thickness required for the NNWSI containers. Cameron engineers belleve such a scale-up is possible. If so, production of container pre-forms wosld be stralghtforward. The cost compared with other manufacturing options would have to be evaluated.

Extrusion of pre-forms for copper-base waste package containers is feasible from the technological viewpoint. Simtlar shapes have been commerclally produced in quantity. It is likely that one-end-closed cylinders can also be produced, and this holds the advantage of eliminating some velds. A disadvantage is that, at present, to our knowledge, Cameron has the only press large enough in the U.S.

\subsection{Fabrication Methods for Finished Containers}

The following discussion focuses on sealing the container that has been formed by one of the three processes described above and filled with spent-fuel rods or vitrified waste-form canisters. The filling and sealing operations must be performed remotely. An alternative process to the separate forming and sealing operations is to produce a fully metallic structure by means of HIPping.

\subsubsection{Conventional Welding}

Automatic welding processes must be considered because of the high gamma fields produced by the waste form. Such processes are numerous and have advanced much in the past few years, especlally with the growth of robotics.

As noted previously, automatic GTA welding is used to fabricate VAR and ESR crucibles. Thts practice would require the installation of suitable optical (1V) or infrared (weld pudi?e) scanning instrumentation to adapt it to the remote environment needed for container fabrication. GTA welding of statnless steel contalners has been performed remotely in this manner by Westinghouse EMAD at the Nevada Test Site. The welding parameters and the feed wire would have to be changed to perform the identical operation on copper containers. 
Advanced technologies are avallable through such suppliers as Linde (Florence, SC): Hobart Brothers (Troy, $\mathrm{OH}$ ); Lincoln Electric (Cleveland, $\mathrm{OH}$ ); and Miller Electric (Appleton, WI). If the final closure weld is made circumferentially, the operation will closely resemble the joining of adjacent sections of linepipe: Most linepipe today is joined automatically, and several established companies specialize in the process: CRC Automatic Welding (Houston, TX); McDermott, Inc. (New Or leans, LA): Evans Automatic Helding (Houston, TX); and Astro ATc Co. (Sun Valley, CA).

\subsubsection{Electron Beam Welding}

The Swedish SKQF/KBS container development program considered, in its final reports, only the fabrication of very thick-walled vessels $(10 \mathrm{~cm})$. Conventlonal GTA welding of such vessels would not be practical. It would be time-consuming, making it difficult to control quality, and would require inordinately large amounts of filler wire. The Swedish investigation. therefore, constdered electron beam (EB) welding.

Since thick-walled weld joints had never been made in copper using EB welding. SKBF/KBS contracted with The Welding Institute in Cambridge, England* to establish the necessary parameters. The results of that investigation are detalled in Sanderson et al. (1983). The only problem remaining unresolved at the conciusion of the work centered on column collapse during the perlod of beam fade-out at the completion of a weld pass. This problem is normally circumvented in industrial practice by including a run-out tab. For containers, The Welding Institute felt, that with additional work, the problem could be overcome.

EB welding is a very clean process since it is normally carried out in a vacuum. However, it can aiso be performed in air. The process is used for welded assemblies demanding the higiest structural integrity: alrcraft engine components, gas steam-turbine rotating members, nuclear reactor fuel pins, etc. Because it is usually done under vacuum, however, sophisticated techniques have been worked out to manipulate and control the electron beam and the workpiece remotely. Inis technology would have to be extended to permit sealing of waste package containers.

* The Helding Institute now has a working relationship with the Edison Welding Institute in Columbus, $\mathrm{OH}$. 
High-powered EB welding is a logical choice for joining relatively thick sections under conditions where contamination must be minimal. EB weld joints use no flller metals; the two surfaces to be joined are brought into contact. and the electron beam is run along the line where they touch. The resulting weld seam may be only a few millimeters wide. lts depth wlll depend on the material being welded, the power applied, and other welding parameters.

Ontario iydro has also studied EB welding of both electrolytic tough pitch and oxygen-free copper for nuclear waste disposal for Atomic Energy of Canacis. The oxygen-free copper proved to be superfor in terms of weld penetration and porosity. Sound welds at penetrations of more than 25 mn were obtained using a wide range of weld parameters.

Two U.S. companies supplying EB welding equipment are Sciacky Brothers (Chicago, IL) and Leybold Heraeur: Vacuum Systems, Inc. (Enfteld, CT). Current equipment would be capable of manipulating and seal-welding solid copper containers of the size envisioned by the SKBF/KBS program. The equipment would have to be downscaled for the smaller, thin-walled contalners envisioned for the NNWSI program. Smaller equipment has been on the market for years.

EB welding is an established process able to produce joints of the highest metaliurgical quality. With regard to the container development program it is not without disadvantages. It is cumbersome, requiring highiy specialized manipulating equipment, remote maintenance of the source and manipulating equipment, time for pumping down to acceptable vacuum levels, and considerable operator ski11. In addition, it may not be possible to use this technique on containers filled with an inert gas.

\subsubsection{Hot Isostaic Pressing}

An innovative alternative among the varlous fabrication methods propased by the SKBF/KBS researchers was to place intact spent-fuel elements in thick-walled copper canisters, fill the canisters with copper powder, emplace the canister end pieces, seal the unit, deoxidize the contents with wet hydrogen, evacuate and seal the entire assembly, and hot isostatically press (HIP) at $1500 \mathrm{~atm}$ and $550^{\circ} \mathrm{C}$. This process results in a solld block of copper. cully densified, surrounding the fuel elements. 
This process has been demonstrated using a slightly sub-scale canister and fuel elements containing stainless steel pins in place of uranium oxide pellets. Detalls of the program are contained in Lonnerberg et al. (1983). The work was performed by ASEA CERAMA, a division of the large Swedish electromechanical equipment supplier.

HIPping is widely used in the U.S. to densify high-quality castings, such as those for aircraft engine components. It is also used to form near-net-shape compacts from high-performance alloy and refractory metal powders and to clad base metal structures with wear-or corrosion-resistant metalilic coatings.

There are numerous press installations in the U.S., many having ASEA presses of the type and size used in the SKBF/KBS program. 1wo such companies are Howmet Pechiney (Greenwich, $\mathrm{CT}^{7}$ ) and Wyman Gordon (Horcester, MA). Both of these companies have the capability to HIP pllot-scale containers of the type and stze demonstrated by the swedes. Because their unfts are customarlily used to densify high-performance alloy castings, the HIPping of copper powders would require Tower temperatures and shorter times than normally used. Another company provides HIPping as a toll service and also designs and butlds HIP equipment (Industrial Materials lechnology, Inc., Andover, MA).

Serious questions exist regarding the safety aspects of a process that takes place at very high pressures $(1500 \mathrm{~atm})$ and elevated temperatures $\left(550^{\circ} \mathrm{C}\right)$. Adequate precautions have been established and are practiced in industry for non-nuclear applications. The process is carried out in pits or in secure sections of the plant. The transition from industrial practice to hot cell operation involving highly radioactive waste will require the resolution of numerous safety-related issues. Additionally, a copper-filled container HIPped to full density would be a very heavy item requiring high-capacity handling equipment. Quality assurance procedures for this process will reilíre extensive development.

\subsubsection{0ther Fabrication lechniques}

other, less common techniques may be worthy of consideration. High-energy, flash-butt welding asing homopolar generators, under development at the University of Texas at Austin, has been considered for the instantaneous joining of pipeline sections and rallroad ralls (the latter are 
conventionally joined using standard flash-butt techniques). The McDermott Corp. (New 0rleans, LA) has licensed the Russian flash-butt welding technology for linepipes. Friction welding has also been performed on copper-base alloys; it is fast and requires no filler metals. Diffusion bonding requires the use of fillers, although not in the conventional sense. In this process, the "filler" provides a diffusion bond between two mating metals. It is usially carried out under vacuum, elevated temperature, and high mechanical force.

Laser welding has been suggested, but the absorption characteristics of copper to wave lengths emitted by $\mathrm{CO}_{2}$ lasers (the type used for welding) are not fayorable. If a laser welding process for copper were developed, it would offer several advantages as a container closure-weld technique: lack of filler wire, air or inert gas operation, and high speed. INCRA is currently studying the laser welding of copper.

\section{SUMMARY}

lhis report completes the first year of a two-year investigation on the feasibllity of copper and copper-base alloys for waste package containers in a tuff repository. Several important activities that will help to determine the feastbility are not yet finished. Because we have so little data on the corrosion performance of copper and its alloys in the appropriate geochemical environments, even a tentative conclusion on the suttability of copper as a container material wauld be premature at this time. The testing performed so far indicates that copper and copper-base alloys do have attractive features that merit continuing at tention.

Although we are not prepared to make a comparison between the copper-base alloy system and austenitic stainless steels (the reference materials for NNWSI conceptual design containers), we emphasize that copper and its alloys are an alternative alloy system to the stainless steels. This statement is predicated on the basis that the environmental conditions that can lead to devastating attack on stainless steels do not produce the same devastation on copper. Chloride ton, for instance, in concentrations exceeding several hundred ppm can inttiate pitting, crevice atlack, and transgranular stress corrosion cracking on many grades of stainless steel by destroying its protective passive film. On the other hand, whereas chloride ion 
concentration may increase the general corrosion rate on copper imainly because of an increase in electrolyte concentration), the devastating inltiation of severe localized or stress-assisted attack does not occur. The $11 \mathrm{mited}$ test data that we have so far generated appear to substantiate this statement--that concentrating the electrolyte content of J-13 water does not appear to invoke localized attack on the copper-base materials.

Copper does have vulnerabilities, particularly in the presence of chemical species whose formation would be favored in irradiated environments where water (and probably wet steam) and air are present. Radlalysis and hydrolysis effects to produce nitrate, nitrite, ammonia, and hydrogen peroxide are potentlally damaging. In work performed so far, we have found that hydrogen peroxide is the dominant species formed from irradiated J-13 water. However. the corrosion rates of copper appear to be $11 \mathrm{mited}$ by the catalytic decomposition of the peroxide, and the peroxide does not bulld up to damaging concentrations. Normally, these species are not particularly damaging to austenitic stainless steels except when the stainless steel is in the sensitized condition.

Austenitic stainless steels are subject to sensitization and resulting intergranular attack (including stress corrosion cracking along grain boundaries) after certain thermomechanical treatments. There is concern that the lengthy times at moderately elevated temperatures in the repository may provoke a low-temperature sensitization on susceptible grades. The corrosion performance of copper-base alloys is not usually as sensitive to the thermal and mechanical process histary as are the stainless steels. Intergranular phenomena do exist in copper-base alloys although the causative conditions appear to be different.

Copper corrodes at a higher general corrosion rate than austenitic stainless steels in water and in wet vapor environments. This result was expected. Of the alloys tested, the 70Cu-30Ni (COA 715) corroded at a rate comparable to that of the austenitic stainless steels. There is usually some "comfort" in tolerating modestly high general corrosion rates when they preclude (as they usually do) catastrophic localized and stress corrosion forms of attack. Hodestly high, but tolerable, general corrosion rates in the context of waste package contalners are clearly in the range around 0.1 mpy. Higher rates can be tolerated for thicker containers. 
In copper-base alloys, further alloy additions loften at 5mall concentrations) can achieve quite remarkable improvements in the corrosion performance in otherwise aggresstve environments. Examples are tin additions to aluminum bronze and 1ron to copper-nickels. Greater technical conservatism in ensuring containment may be gained by thorough analysis of the benefit of alloying effects. This approach is also being pursued in our assessment of the austenitic stainless steels. The candidate copper-base alloys, aluminum bronze or 70 copper $\mathbf{- 3 0}$ nickel, may be more suftable container materials than high-purity copper because of their better corrosion and oxidation resistance in the environments expected in a tuff repository.

Both the copper/copper alloys and austenitic stainless steels are readily fabricated by a number of methods. This does not appear to be a limiting factor. Furthermore, welding does not appear to be any more limiting for cr, per than for other metals. These processes will have to be further investigated for any potential metaliurgical factors that will degrade performance.

\section{ACKNOWLE DGMENTS}

It is a pleasure to acknowledge the efforts of several people who made major contributions to the preparation of this report. Stuart Lyman of the Copper Development Assoctation (Greenwich. CT) and Dale Peters of the International Copper Research Association (New York, NY) organized and co-ordinated the information supplied by the copper industry and tts consultants. Jim Myers, consultant (Frank 1 ir, $\mathrm{OH}$ ), surveyed and analyzed the 1iterature on copper corrosion and oxidation (Sec. 5). Konrad Kundig. consultant (Randolph, NJ), complled the information on fabrication and welding processes and vistted many of the plants and installations discussed in the text (Sec. 7). Ellis Verink, consultant (Gainesville, $F L$ ), developed the potential-pH diagrams (Sec. 6.3 and Appendix B). Art Cohen (COA) helped to comptle much of the information on physical and mechantcal properties of copper and copper-base alloys (Appendix A).

Within LLNL, Robert Glass directed much of the work and wrote much of the material on corrosion test results (Sec. 6). Richard Van Konynenburg collected the thermomechanical data used for deviloping the potential-pH 
d1agrams (Sec. 6 and Appendix B). Barbara Bryan processed the draft text and its several revisions. Maureen Donohue and Mary Ann Esser edited the text and expedited the timely delivery of the report.

The following people revlewed the draft of this status report and contributed valued comments and suggestlons: Mark Frei and Naomi Abraham (DOE/HQ); Evelyn Gause (Roy Weston, Inc.); Donald Schweitzer and Daniel van Rooyen (Brookhaven National Laboratory); Donald Vieth and Michael Valentine (DOE/NV); Denny Jones (University of Nevada, Reno); John Griess (0ak Ridge National Laboratory); and Lynden Ballou and Lawrence Ramspott (LLNL). 


\section{REFERENCES}

A. 0. Allen. The Radiation Chemistry of Hater and Aqueous Solutions,

(Princeton, NJ: D. Van Nostrand and Co., Ine., 1961).

ASM Committee on Corrosion of Copper, Metals Handbook. 1. "Propertles and Selection of Metals." pp. 983-1005 (Metals Park, OH: American Society for Meta1s, 1961).

J. Benard, F. Gronlund, J. Oudar, and M. Duret, Z. Elektrachem., 63, p. 799 (1959)

L. A. Benjamin, D. Hardle, and R. N. Parkins, University of Newcastleupon-Tyne, England, Report No. 83-06/SKBF/KBS (1983).

E. G. Brush and H. L. Pear 1, Corros10n, 25, p. 99 (1969).

W. G. Burns, A. E. Hughes, J. A. C. Marples, R. S. Nelson, and A. M. Stonenam, Nature, 295, p. $130(7982)$.

A. V. Byalobzheskil, Radiation Corrosion, Israel Program for Sclentific Translations, Jerusalem (1970).

H. S. Campbe11, "A Review: Pitting Corrosion of Copper and its Aliays," Localized Corrosion. NACE-3. National Association of Corrosion Engineers. Houston, TX (1974).

W. E. Campbe 11 and U. B. Thomas, Trans Electrochemical Soctety, 9], p. 623 (1947).

R. Gerischer and H. Gerischer, Z. Phys. Chem_, E, p. 178 (1956).

R. S. Glass, G. E. Overturf III, R. A. Van Konynenburg, and R. D. McCright, Gamma Radiation Effects on Corrosion: I Electrochemical Mechanisms for the Aqueous Corrosion Processes of Austentic Stainless Steels, Lawrence Livermore National Laboratory, Livermore, CA, UCRL-92311 (1985). 
F. Gronlund, Jour. Chim. Phys.. 53, p. 660 (1956)

A. P. C. Hallowes and E. Voce, Hetallurgla Manchr., 34, p. 95 and p. 119 (1946).

C. J. Hochande 1, J. Physical Chemistry, 56, p. 587 (1952).

J. N. Hockman and W. C. O'Nea 1. Ihermal Modeling of Nuclear Haste Package Designs for Disposal in Tuff, Lawrence Livermore National Laboratory Livermore, CA, UCRL-89820 \{1983\}.

8. E. Hopkinson, Corroston, 20, p. 80 t (1964).

3. K. Johnstone, R. R. Peters, and P. F. Gnirk, Unit Evaluation at Yucca Mountain. Mevada Test Site: Summary Report and Recommendation, Sandia National Laboratorles, Albuquerque, NH, SANO 83-0372 (1984).

J. K. Johnstone and K. Holfsberg. Evaluation of luff as_a Medium for a Nuclear Waste Repository: Interim Status Report on the Properties of Tuff. Sandia Natlonal Laboratorles, Albuquerque, NM, SAND 80-1464 (1981).

M. C. Juhas, R. D. McCright, and R. E. Garrison, Behavior of Stressed and Unstressed 304L Specimens in luff Repository Environmental Conditions, Lawrence Livermore National Laboratory. Livermore, CA, UCRL-91804 (1984).

J. F. Klement, R. E. Maersch, and P. A. Tul1y, Metal Progress, 75 (2), p. 83 (1959).

0. Kubaschewski and B. E. Hopkins. Oxidation of Metals and Alloys, pp. 249-253 (London: Butterworths, 1962).

F. L. Laque, Corrosion, 10, p. 391 (1954).

5. C. Lind, Radiation Chemistry of Gases, (New York: Reinhold Publishing Corp., 19611. 
B. Lonnerberg, H. Larker, and L. Ageskog, Encapsulzt an and Handling of Spent. Nuclear Fuel for Final 01sposal, KBS 83-20 (1983).

B. Lustman and R. F. Mehl, Iransactions AIME. 143, p. 246 (1941).

R. D. McCright, H. Weiss, M. C. Juhas, and R. W. Logan, Selection of Candidate Canister Matertals for High Level Huclear Waste Containment in a luff Repository. Lawrence Livermore National Laboratory. Livermore, CA, UCRL-89988 (1983).

R. J. Mckay and R. Worthington, Corrosion Resistance of Metals and Alloys. p. 409 (New York: Reinhold Publishing Corporation, 1936).

A. I. Molodov, G. N. Markos'yan, and V. V. Losev, Elektrokhimiya, 18, p. 1186 (1982).

P. Montazer and W. E. Wilson, Conceptual Hydrologic Model of Flow in the Unsaturated Zone, Yucca Mountain, Mevada, U.S. Geological Survey-Water Resources Investigations report, USGS-HRI-84-4345 (1984).

J. R. Myers and M. F. Obrecht, Matertals Performance, 12 (4, 17) (1973).

H. Mishimura, Jour. Min. Metall., Kyoto, g, p. 655 (1938).

NRC (U.S. Nuclear Regulatory Comission). D1sposal of High-Level Radioactive Wastes in Geologic Repositorles, Technical Criterla, Findl Rule 10 CFF 60 , NRC, Federal Register 48 (120) (1983).

W. C. O'Neal, D. W. Gregg, J. N. Hockman, E. H. Russe11, and W. Stein, Preclosure Analysis of Conceptual Haste Package Designs for a Nulcear Waste Repository in luff, Lawrence Livermore National Laboratory, Livermore, CA, UCRL-53595 (1984).

J. R. Park and J. R. Partington, J. Chem. Soc., 125, p. 72 (1924). 
N. B. Pilling and R. E. Bedworth, Industrial Engineering Chemtstry, 17, p. 372 (1925).

W. Primak and L. Fuchs, Physics Today, 2. p. 15 (1954).

H. S. Rawdon and E. C. Groesbeck, National Bureau of Standards, Hashington, OC, Technical Paper No 367. p. 409 \{1928\}.

J. S. Reichert and R. H. Pete, Chemical Engineering, 54, p. 213 (1947).

A. Ronnquist and H. Fischmeister, Journal Institute of Metals, 昂, D. 65 $(1960-61)$.

L. Sanderson et al., Feasibility Study of Electron Beam Welding of Spent Nuclear Fuel Canisters, KBS 83-25 (1983).

M. O. Sanderson and J. C. Scully, Oxidation of Metals, 3, (1), p. 50 (1971).

S. Sato, Sumitomo Light Metal Technical Reports. $\underline{5}$ (4), p. 242 (1964).

S. Sato and K. Nagata, Boshoku Gijutsu, 23, p. 125 (1974).

R. M. Sellers, Analyst, 105, p. 950 (1980).

J. W. T. Spinks and R. J. Woods, An Intraduction to Radiation Chemistry. 2nd Edition (New York: John Wiley and Sons, 1976).

Y. Suzukt. Y. Hisamatsu, and S. Mor ish1ma, Boshoku Gijutsu, 23, p. 477 (1974).

D. H. Thampson and A. H. 1racy, Trans. AIME, 185, p. 100 (1944).

E. A. T1ce and C. P. Ven1zelos, Power, $107(11,64),(1963)$.

J. Tobin, General Dynamics Corporation, San Diego, CA, Report No GA-3349, (1963). 
R. F. Tylecote, Journal Institute of Metals, 78, p. 259 (1950-51).

H. H. Uhilg, Corrosion and Corrosion Control, pp 797-198 (New York: John Wiley and Sons, Inc., 1971\}.

G. Valens1, Revue de Metallurgie, 45, p. 10 (1948). 
FY 1985 SIATUS REPORT ON FEASIBILITY ASSESSMENT

OF COPPER-BASE HASTE PACKAGE CONTAINER MATERIALS

IN A TUFF REPOSITORY

\section{ABSIRACT}

This repari discusses progress made during the first year of a two-year study on the feasibllity of using copper or a copper-base alloy as a container materlal for a waste package in a potential repository in tuff rock at the Yucca Mountain site in Nevada. The expected corrosion and oxidation performances of oxygen-free copper, aluminum bronze, and $70 \%$ copper-30\% nickel are presented; a test plan for determining whether copper or one of the alloys can meet the containment requirements is out lined. Some preliminary corrosion test data are presented and discussed. Fabrication and joining techniques for forming waste package containers are described. Preliminary test data and analyses indicate that copper and copper-base alloys have several attractive features as waste package container materials, but additional work is needed before definitive conclusions can be made on the feasibility of using copper or a copper-base alloy for containers. Plans for work to be undertaken in the second year are indlcated. 
Table A-1. Copper metals under consideration for nuclear waste disposal canister.

\begin{tabular}{|c|c|c|c|c|c|c|}
\hline \multirow{2}{*}{$\begin{array}{c}\text { Copper or } \\
\text { copper alloy No. }\end{array}$} & \multirow[b]{2}{*}{ Description } & \multicolumn{5}{|c|}{ Nominal composition } \\
\hline & & $\mathrm{Cu}$ & $\underline{p}$ & $\mathrm{re}$ & A] & $\mathbf{N}$ \\
\hline Cro200 & of copper & 99.95 & & & & \\
\hline$c 80100^{a}$ & & 99.95 & & & & \\
\hline $\mathrm{C} 12200$ & DHP copper & 99.95 & 0.025 & & & \\
\hline $\cos 1100^{\circ}$ & & 99.90 & & & & \\
\hline$C 61300$ & aluminum bronze & 90 & & 3 & 7 & \\
\hline$C 95200^{\mathrm{a}}$ & & 88 & & 3 & 9 & \\
\hline c70600 & $90 \mathrm{Cu}=10 \mathrm{Ni}$ & 88.6 & & 1.4 & & 10 \\
\hline$c 96200^{a}$ & & 88.6 & & 1.4 & & 10 \\
\hline C71500 & $70 \mathrm{Cu}-30 \mathrm{Nt}$ & 69.5 & & .5 & & 30 \\
\hline $\operatorname{cg} 6400^{a}$ & & 69 & & 1 & & 30 \\
\hline
\end{tabular}

a Cast material. 
Taple A-2. Density

\begin{tabular}{|c|c|c|}
\hline \multirow[b]{2}{*}{$\begin{array}{c}\text { Copper or } \\
\text { copper alloy No. }\end{array}$} & \multicolumn{2}{|c|}{ Density } \\
\hline & $\mathrm{g} / \mathrm{cm}^{3}$ & $1 \mathrm{~b} / \ln ^{3}$ \\
\hline C70200 & 8.9 & 0.321 \\
\hline $\cos 100^{\mathrm{a}}$ & 8.94 & 0.323 \\
\hline C12200 & 8.9 & 0.321 \\
\hline $\cos 1100^{\circ}$ & 8.94 & 0.323 \\
\hline C67300 & 7.8 & 0.280 \\
\hline $\operatorname{cg} 5200^{a}$ & 7.64 & 0.276 \\
\hline $\cos 800^{a}$ & 7.64 & 0.276 \\
\hline$c 70600$ & 8.90 & 0.320 \\
\hline $\operatorname{cg6200^{\circ }}$ & 8.94 & 0.323 \\
\hline C71500 & 8.95 & 9.325 \\
\hline$c 96400^{a}$ & 8.94 & 0.323 \\
\hline
\end{tabular}

a

Cast materia 1. 
Table A-3. Coefflctent of Inear thermal expansion.

\begin{tabular}{|c|c|c|c|c|c|c|}
\hline $\begin{array}{l}\text { Copper or } \\
\text { copper alloy No. }\end{array}$ & $25-100^{\circ} \mathrm{C}$ & $\frac{\text { Coefficte }}{\frac{77-212^{\circ} \mathrm{C}}{}}$ & $\begin{array}{r}\text { of } 1 \text { inear } \\
20-200^{\circ} \mathrm{C}\end{array}$ & $\begin{array}{l}\text { termal expar } \\
68-392^{-1} \\
\end{array}$ & 10n & 68-572'F \\
\hline c1020E & 0.0000168 & 0.00000933 & 0.0000173 & 0.00000961 & 0.0000177 & 0.00000983 \\
\hline $\operatorname{coc} 100^{a}$ & --- & -- & --- & --- & 0.0000169 & 0.0000094 \\
\hline C1z200 & 0.00000168 & 0.00000933 & 0.0000173 & 0.00000961 & 0.0000177 & 0.00000983 \\
\hline $\cos 100^{\circ}$ & -- & -- & $\cdots$ & $\cdots$ & 0.0000169 & 0.000009 \\
\hline C61300 & 0.000016 & 0.000009 & --- &.-- & 0.000017 & 0.000009 \\
\hline C95200 & -- & -- & -.- & $\cdots$ & 0.0000162 & 0.000009 \\
\hline $\operatorname{c9} 5800^{\circ}$ & -- & $\ldots$ & $\cdots$ & $\cdots$ & 0.0000162 & 0.000009 \\
\hline C70600 & $\ldots$ & -- & --- & -.- & 0.000017 & 0.000009 \\
\hline$C 96200^{\mathrm{a}}$ & -- & $\cdots$ & $-\cdots$ & -- & $0.0000173^{\prime}$ & 0.0000095 \\
\hline C71500 & --- & --- & -- & $\cdots$ & 0.000016 & 0.000009 \\
\hline$C 96400^{a}$ & $\cdots$ & $\cdots$ & -- & - & 0.000016 & 0.000009 \\
\hline
\end{tabular}

a Cast material. 
Table A-4. Thermal conductivity.

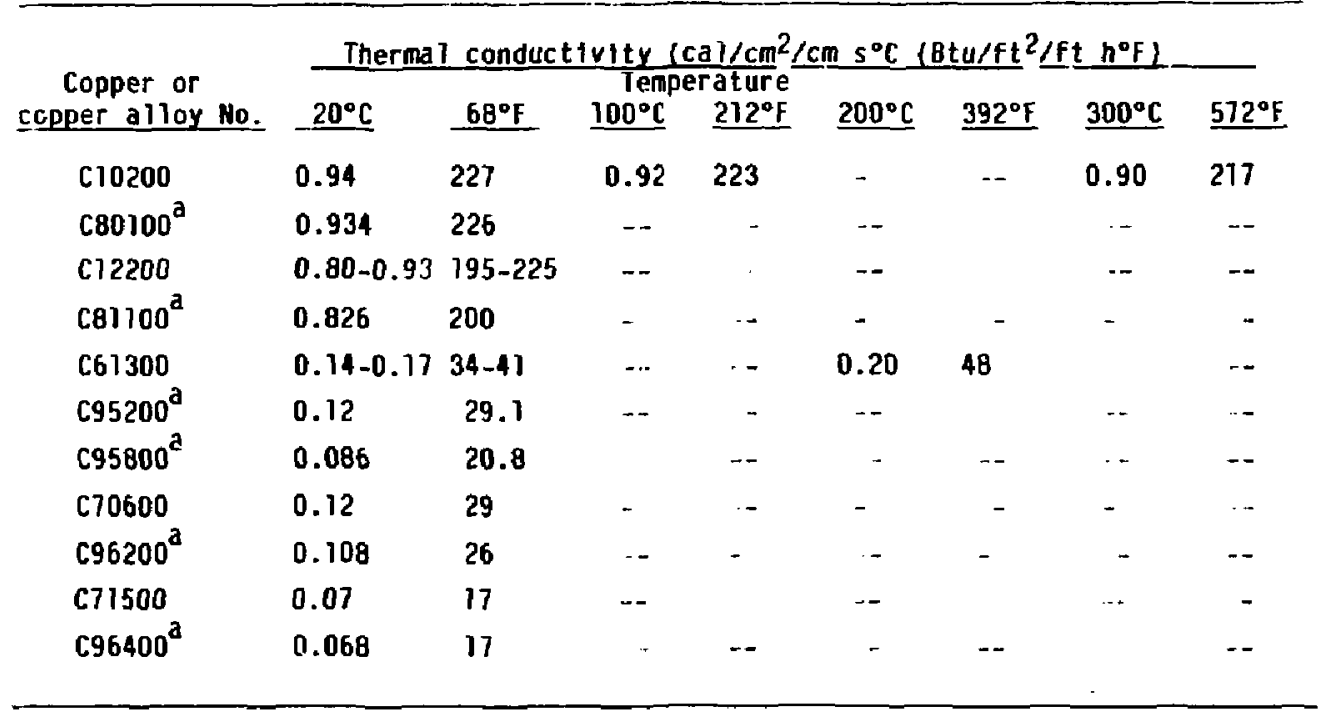

a Cast mater\{a\}. 
Table A-5. Modulus of elasticity

\begin{tabular}{|c|c|c|}
\hline \multirow{2}{*}{$\begin{array}{c}\text { Copper or } \\
\text { copper alloy No. }\end{array}$} & \multicolumn{2}{|c|}{ Modulus of elasticity (annealed) } \\
\hline & $\mathrm{N} / \mathrm{mm}^{2}$ & ksi \\
\hline 010200 & 117,200 & 17,000 \\
\hline $\operatorname{csol} 100^{a}$ & 117,000 & 17.000 \\
\hline C12200 & 117,200 & 17.00 \\
\hline (8) $100^{\mathrm{a}}$ & 117,000 & 17.000 \\
\hline$C 61300$ & 120,000 & 17,400 \\
\hline $\operatorname{c95200^{\circ }}$ & 103.000 & 15.000 \\
\hline$c 95800^{\mathrm{a}}$ & 114,000 & 16.500 \\
\hline C70600 & 135,100 & 19,600 \\
\hline$C 96200^{\mathrm{a}}$ & 124,000 & 18,000 \\
\hline C71500 & 151.700 & 22,000 \\
\hline $\operatorname{c96400^{a}}$ & 145,000 & 21,000 \\
\hline
\end{tabular}

Cast material. 
Tablo A-6. Tensile sirength (extrapolated walues in parentheses).

\begin{tabular}{|c|c|c|c|c|c|c|c|c|c|c|c|c|c|c|c|c|c|c|c|c|c|}
\hline \multicolumn{22}{|c|}{ 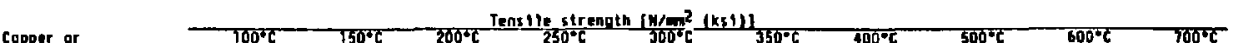 } \\
\hline$C 10200$ & (221) & $(32.1)$ & (193) & $(20.1)$ & $(104)$ & $(23.8)$ & 164 & $(23.8)$ & (145) & $(21,0)$ & & & & & & & & & & & \\
\hline $\cos 100^{\circ}$ & 172 & 25 & & & & & & & & & & & & & & & & & & & \\
\hline c1220n & 234 & 33.9 & 216 & 31.3 & 198 & 28.0 & 189 & 27.5 & 116 & 25.5 & & & & & & & & & & & \\
\hline $\operatorname{col} 100^{\circ}$ & 172 & 25 & & & & & & & & & & & & & & & & & & & \\
\hline $\cos 1300$ & 507 & 73.5 & 411 & 59.6 & & & 301 & 43.7 & & & 231 & $30 / 9$ & & & 165 & 22.9 & 113 & 16.4 & 11 & 10.3 & 35 \\
\hline $\operatorname{c95200^{\circ }}$ & 574 & 03.2 & & & 530 & 76.9 & & & & & & & & & & & & & & & \\
\hline $\operatorname{cgs} 800^{\circ}$ & 638 & 9.25 & & & & & 549 & 79.6 & 325 & 76.1 & 500 & 72.5 & 176 & 69.0 & & & & & & & \\
\hline 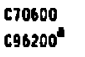 & 323 & 16.0 & & & & & 276 & 10.0 & & & 263 & 38.1 & 255 & 37.0 & 251 & 36.6 & & & & & \\
\hline C71500 & 301 & 53.2 & & & & & 322 & 46.7 & & & סוכ & 45.0 & 302 & 43.0 & 290 & 12.1 & & & & & \\
\hline $696400^{\circ}$ & 469 & 68 & & & & & & & & & & & & & & & & & & & \\
\hline
\end{tabular}

Cast aterial. 
Table A-7. Yoid strength lextrapolated values in parentheses)

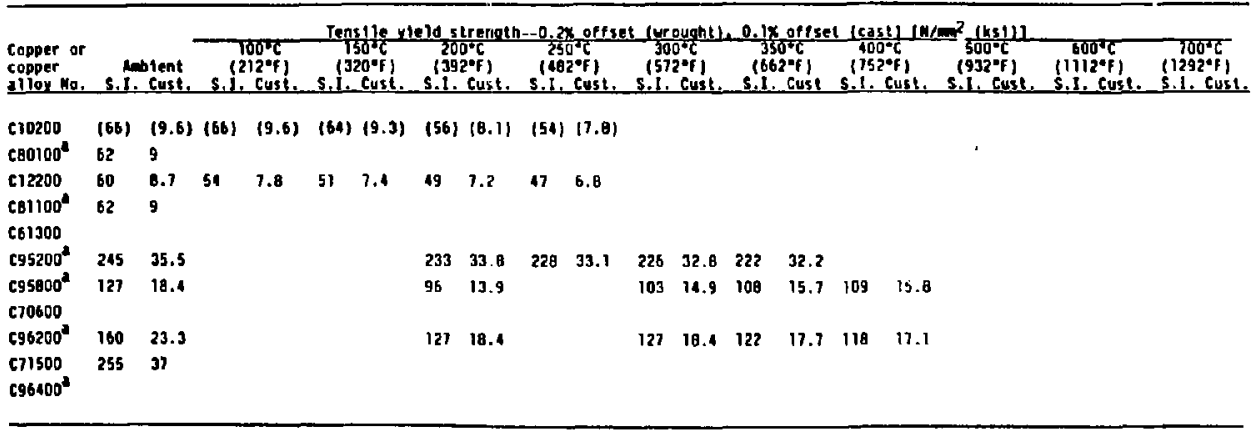

Cast material. 
Table A-B, Elongat Ion.

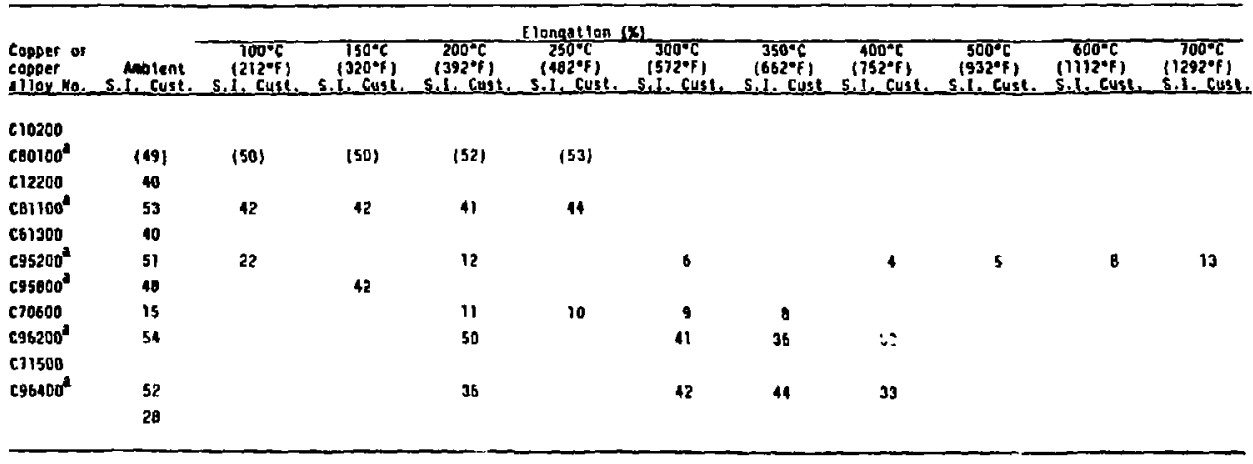

ast material. 
Table A-9. 10,000-h creep strength (extrapolated values in parentheses).

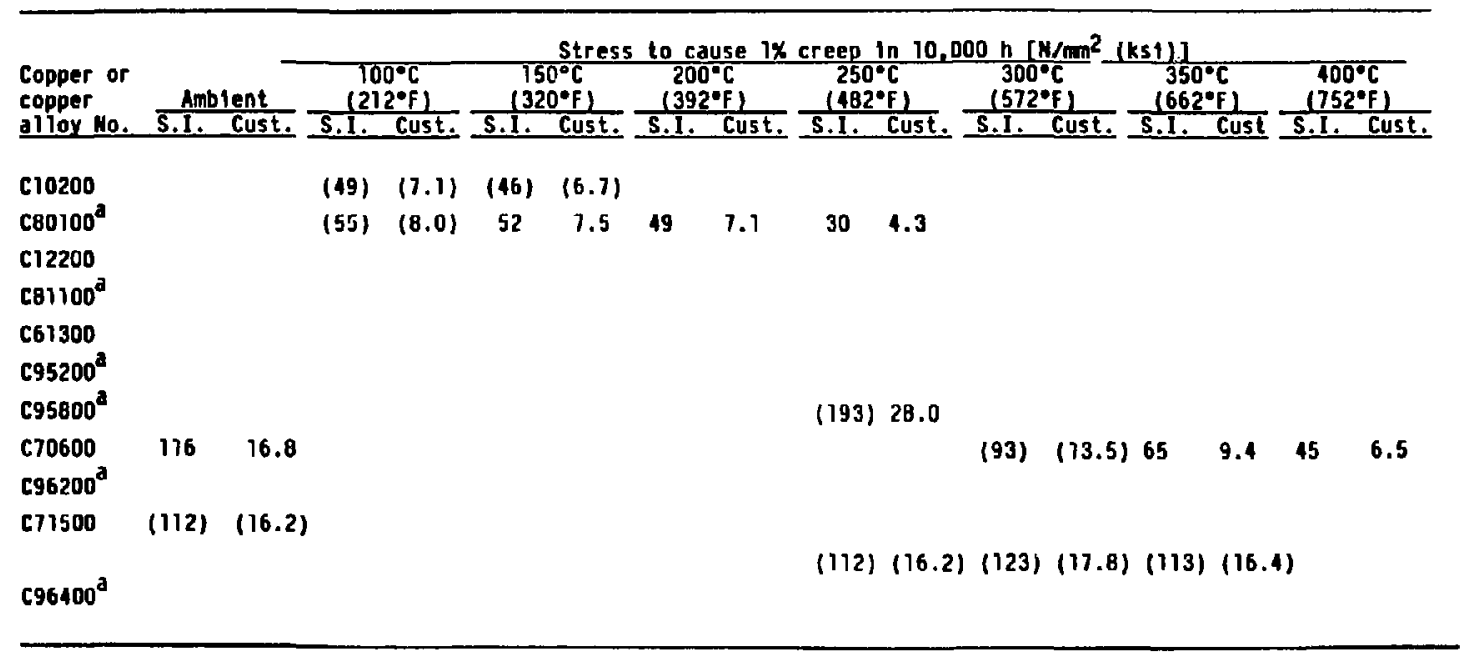

a cast mater 1 al. 
Table A-10. 100,000-h creep strength (extrapolated values in parentheses).

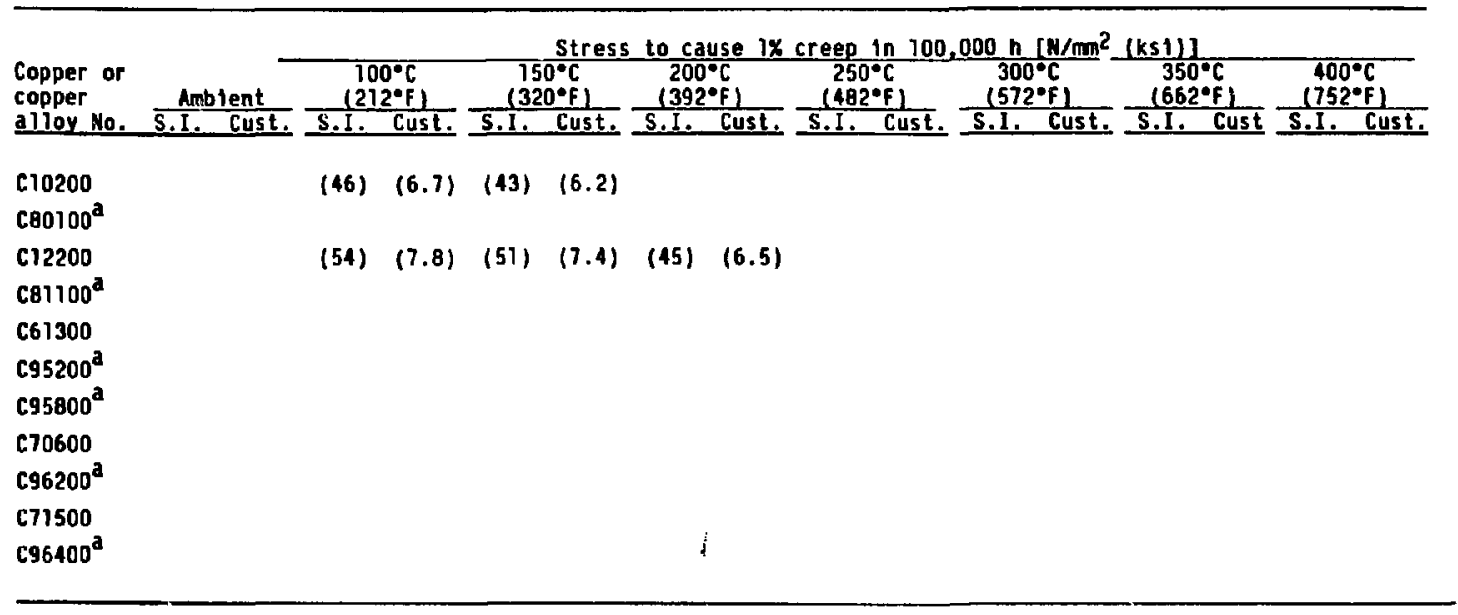

a Cast material. 
Table A-11. 10,000-h rupture strength (extrapolated values in parentheses).

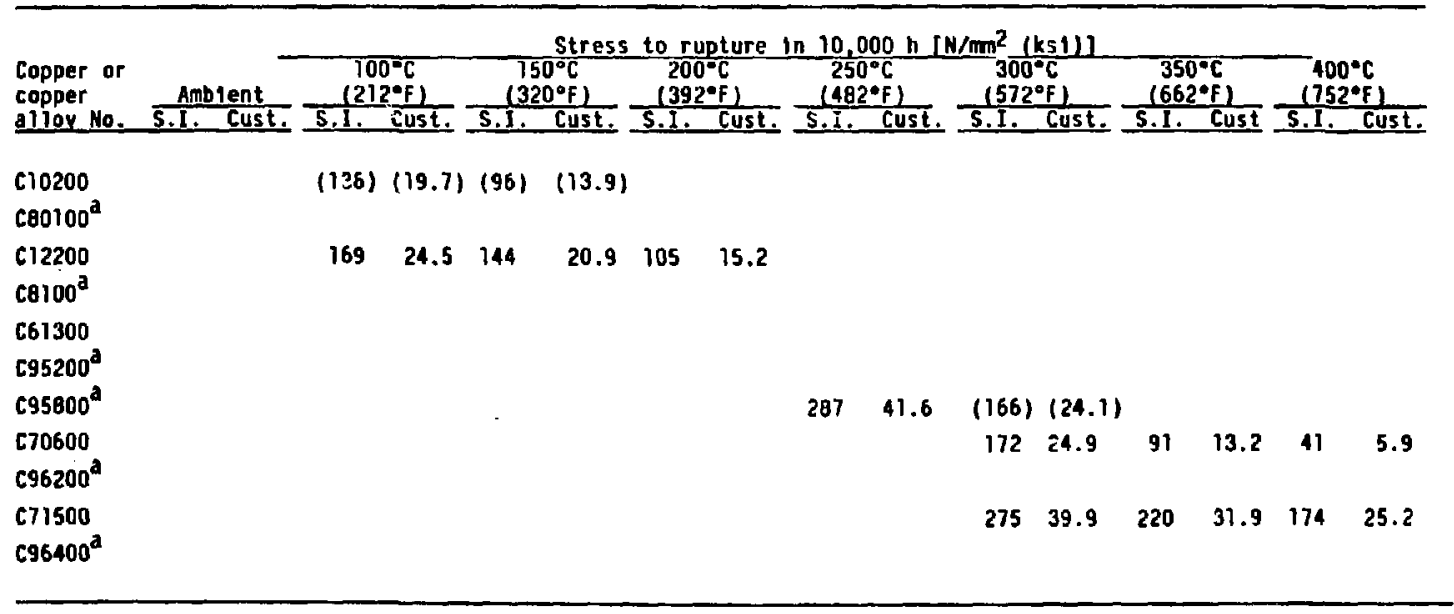

a Cast material. 
Table A-12. 100,000-h rupture strength.

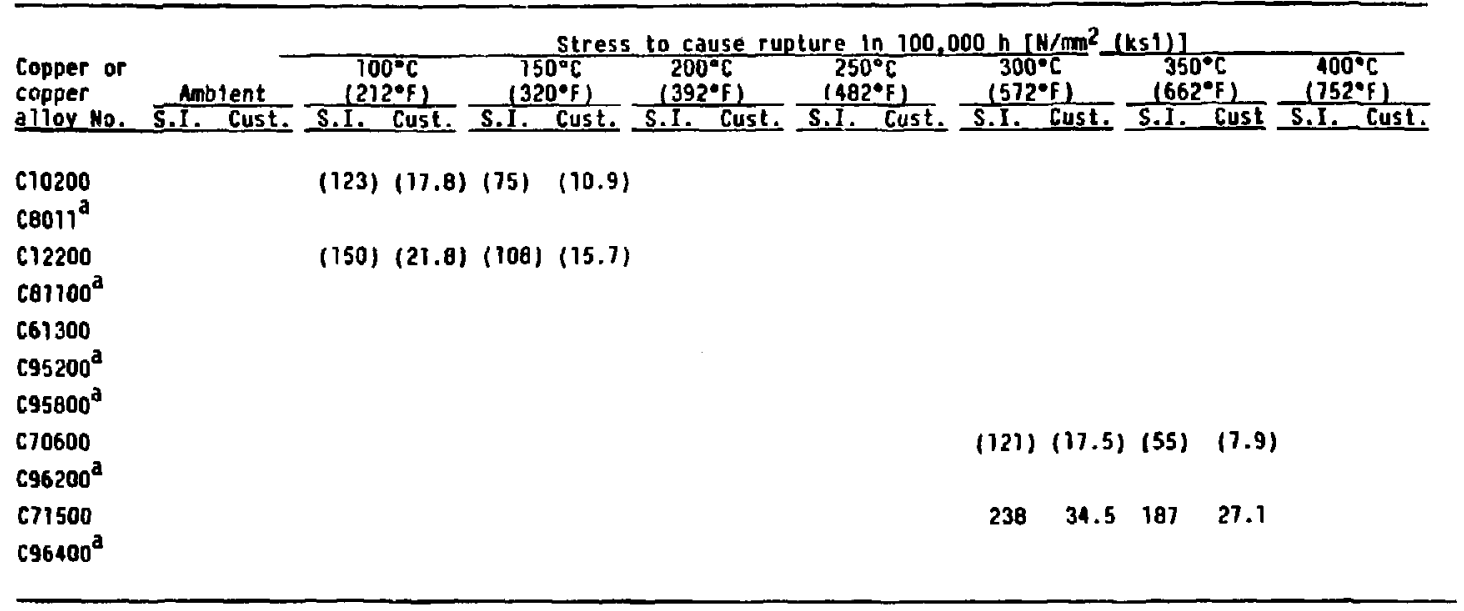

\section{a cast matertal.}


Preliminary studies were conducted in an effort to predict stable species that may be formed on copper exposed to irradiated $3-13$ water at temperatures up to $95^{\circ} \mathrm{C}$ in the presence of Nevada tuff rock. It was recognized that this investigation would necessarlly be a preliminary study to determine whether the thermodynamic lechniques involved had promise for use in later stages of the investigation of copper as a containment material for nuclear waste.

A computer program developed at the University of florida is avallable for calculation of Pourbaix diagrams of complex systems. Input information is the thermodynamic data (free energy of formation at temperature and assumed activity for each specles). Free energy data for $25^{\circ} \mathrm{C}$ are readily avallable for normal solid and ionic corrosion products and for most ionic species in the water. Room-temperature thermodynamic data also are avallable for some but not all of the complexes expected to be found in waters subject to radiolysis (Table B-1).

The present preliminary study was organized around three thrust areas:

1. Influence of varying the irradiated water composition on the features of the $\mathrm{Cu}-\mathrm{H}_{2} \mathrm{O}$ Pourbalx diagram at $25^{\circ} \mathrm{C}$.

2. Influence of added tons (not 115ted in Table 8-1) an the features or the $\mathrm{Cu}-\mathrm{K}-\mathrm{H}_{2} \mathrm{O}$ diagrams (where " $\mathrm{K}$ " is the added species at $25^{\circ} \mathrm{C}$.

3. Influence of increased temperatures on 1 and 2 above. 


\section{RESULTS}

\section{Study Area 1}

Table B-1 gives the estimated steady-state concentratians of species in oxygen-saturated $\mathrm{J}-13$ water irradiated at $3.3 \times 10^{6} \mathrm{rad} / \mathrm{h}$. The dose rate is expected to be about one order of magnitude less than this rate. The primary radiolytic species expected from the influence of gamma radiation on triple-distilled water in a noncorrosive container are listed in Table B-2.

Pourbatx diagrams were calculated by computer assuming fonic activities (assumed equal to concentrations) of $10^{-6}$ (for a 11 spectes of activity $10^{-6}$ and less) and the tabulated activity for the other fonic species shown in Table B-l for which thermodynamic data were avallable. The selection of $10^{-6}$ as the minimum caricentration was dictated by the computer program and was constdered to be a conservative error. A second Pourbaix diagram assumed all activities were $2 \times 10^{-3}$. The features of the $\mathrm{Cu}-\mathrm{H}_{2} \mathrm{O}$ Pourbalx diagrams calculated for each of these levels of ionic activity (concentration) were identical dt room temperature (the graphs superimpose). These are shown in Figure B-1. Thus, it is reasonable to cnnclude that the water itself introduces no unexpected corrosion products of copper at room temperature even If the radiolytic species are present at levels several orders of magnitude above the expected steady-state values. It is emphasized that this study made use of thermodynamic data at $25^{\circ} \mathrm{C}$.

\section{Study Area 2}

A special condition could result at $95^{\circ} \mathrm{C}$ (the bolling point) if irradiated 3-13 water in contact with Nevadi iuff rock were exposed also to atmospheric air. The gaseous phase would cons. st of $\mathrm{CO}, \mathrm{CO}_{2}, \mathrm{~N}_{2}$ and water vapor. The mixed llquid-plus-gas phase would have oxides of nttrogen (notably $\mathrm{HNO}_{2}$ and $\mathrm{HNO}_{3}$ ) that would dissolve in the water. If the buffering effect of the surrounding rock is insufficlent. $\mathrm{NO}_{3}^{-}$would be favored over $\mathrm{NO}_{2}^{-}$, and in any event $\mathrm{H}_{2} \mathrm{O}_{2}$ present would oxidize $\mathrm{NO}_{2}^{-}$to $\mathrm{NO}_{3}^{-}$at $\mathrm{pH}=8$. 
Van Konynenburg's calculations indicate that the $\mathrm{NO}_{3}^{-}$concentration could reach 0.1 mol/l for a $10^{10}-$ rad total dose. Normally $\mathrm{HCO}_{3}^{-}$would be expected to be a dominant species; however, at elevated temperatures the $\mathrm{HCO}_{3}^{-}$goes to $\mathrm{CO}_{3}^{-}$and then slowly forms oxalate ion. Hence. $\mathrm{HCO}_{3}^{-}$is not considered important at the elevated temperature.

A Pourbalx diagram was calculated assuming the following activities:

$\begin{array}{ll}\text { Spectes } & \text { Activity } \\ \mathrm{O}_{2} & 1 \times 10^{-4} \\ \mathrm{H}_{2} \mathrm{O}_{2} & 1 \times 10^{-4} \\ \mathrm{H}^{+} & 1 \times 10^{-6} \\ \mathrm{NO}_{3}^{-} & 1 \times 10^{-1}\end{array}$

At $25^{\circ} \mathrm{C}$ the resulting Pourbalx diagram shows a large domain of stabl11ty for $\mathrm{Cu}\left(\mathrm{NO}_{3}\right)_{2} \cdot 3 \mathrm{Cu}(\mathrm{OH})_{2}$. This diagram is shown in Figure $\mathrm{B}-2$. Thus, a high concentration of $\mathrm{NO}_{3}^{-}$would aiter the features of the Pourbaix diagram from those exhibited by the $\mathrm{Cu}-\mathrm{H}_{2} \mathrm{O}$ diagram at $25^{\circ} \mathrm{C}$.

\section{Study Area 3}

It is important to examine the influence of temperature (up to $95^{\circ} \mathrm{C}$ ) on the expected reactions. Unfortunately, few thermodynamic data are available in this temperature range. Criss and Cobble (1964) have suggested a method for estimating thermodynamic data for lons that seems to be reasonably reliable up to about $200^{\circ} \mathrm{C}$. Antlcipating the need for elevated temperature diagrams, we have beon revising the Pourbalx diagram program to make it capable of estimating elevated-temperature thermodynamic data using the Criss and Cobble technique. We are now testing the revised program, but there has not been time to apply it to the present study. We would expect to to so in later stages of the research program. 


\section{COMHENTS}

The studies based on room temperature data indicate that no change in the features of the $\mathrm{Cu} \rightarrow \mathrm{H}_{2} \mathrm{O}$ Pourbaix diagram should be expected at room temperature even with large (orders of magnitude) increases in concentrations over those shown in Table B-1. Simllar studies should be carried out at $95^{\circ} \mathrm{C}$ together with a review of data on the stability of solid reaction products as a function of temperature.

If estimates of $\mathrm{HO}_{3}^{-}$concentration $=0.1 \mathrm{M}$ are accurate, this poses important questions regarding the passive behavior of copper. Present studies assumed formation of $\mathrm{Cu}\left(\mathrm{NO}_{3}\right)_{2} \cdot \mathrm{Cu}(\mathrm{OH})_{2}$ as a stable spectes. The domain of stability is significant at room temperature. He have not examined the protectiveness of this species at room temperature nor at $95^{\circ} \mathrm{C}$ and have not determined whether it is stable or protective at $95^{\circ} \mathrm{C}$. Future studies should include examination of these important questions.

It would be highiy desirable to perform experiments in the laboratory to determine the kinetics of corrosion of copper at $95^{\circ} \mathrm{C}$ in the presence of $0.1 \mathrm{H} \mathrm{NO}_{3}^{-}$. Analysis of actual corrosion products would be helpful in vertfying the stable species.

Van Konynenburg suggested another mechanism that also should be explored. If air inleakage had established a concentration of nitrogen species in the water so that a "liner" were to develop that excluded fur ther atr, the oxygen would be depleted, forming $\mathrm{Cu}_{2} \mathrm{O}$ (for example), and the $n i t$ trogen might react with hydrogen to form ammonia, which in turn might promote cracking. The work of Parkins et al. (1983) in connection with KBS-III suggests that repository conditions considered by the Swedish investigators would favor very low concentrations of $\mathrm{NO}_{2}^{-}$(well below the reported cracking range for pure copper in $\mathrm{NaNO}_{2}$ ) rather than $\mathrm{NH}_{3}$ (or $\mathrm{NO}_{3}^{-}$). However, the Swedes w111 store spent fue 1 in ponds for 50 years before burlal, so the temperatures will be different. 
References

C. M. Criss and J. N. Cobble, J. American Chemical Soctety, 86, pp. 5385-5401 (1964).

R. N. Parkins, L. A. Benjamin, and D. Hardie, Investigations of the Stress Corrosion Cracking of Pure Copper. SKBF/KBS Report 83-06 (1983). 
Table B-1. Estimated steady-state concentrations of species in oxygen-saturated $\mathrm{J}-13$ water irradiated at $3.3 \times 10^{6} \mathrm{rad} / \mathrm{h}$

(Data from LLNL and the National Bureau of Standards.)

\begin{tabular}{|c|c|c|c|}
\hline & cies & $\begin{array}{c}\text { Estimated } \\
\text { Concentration } \\
\text { moles/l } \\
\end{array}$ & $\begin{array}{r}\Delta G_{f}^{\circ} \begin{array}{l}(298 \mathrm{~K}) \\
\mathrm{ca} 1 / \mathrm{mo})\end{array} \\
\end{array}$ \\
\hline $\mathrm{HCO}_{3}^{-}$ & measured value & $2 \times 10^{-3}$ & $-140,260$ \\
\hline $\mathrm{O}_{2}$ & (air-saturated solution) & $3 \times 10^{-4}$ & - \\
\hline $\mathrm{H}_{2}^{2} \mathrm{O}_{2}$ & (1/3 of $\mathrm{O}_{2}$ concentration) & $1 \times 10^{-4}$ & $-28,780$ \\
\hline $\mathrm{OH}^{-}$ & (assuming $\mathrm{pH}=8$ ) & $1 \times 10^{-6}$ & $-33,670$ \\
\hline $0_{2}^{-}$ & (assumed ordose rate) & $1 \times 10^{-7}$ & N.O. ${ }^{a}$ \\
\hline $\mathrm{HO}_{2}$ & $\left.I=\left[H^{+}\right]\left[0_{2}^{-}\right] / 10^{-4.88}\right)$ & $1 \times 10^{-10}$ & N.D. \\
\hline $\mathrm{H}^{+\infty}$ & (assuming $\mathrm{pH}=8$ ) & $1 \times 10^{-B}$ & 0 \\
\hline $\mathrm{OH}$ & (assumed ardose rate) & $2 \times 10^{-9}$ & $+8,180$ \\
\hline $\mathrm{H}_{2}$ & (assumed ardose rate) & $3 \times 10^{-9}$ & 0 \\
\hline$e_{a q}^{-}$ & (assumed ordose rate) & $3 \times 10^{-11}$ & N.D. \\
\hline$H^{-}$ & (assumed ordose rate) & $2 \times 10^{-71}$ & $+48,581$ \\
\hline $\mathrm{HO}_{2}^{-}$ & (as sumed ordose rate) & $4 \times 10^{-16}$ & $-16,100$ \\
\hline
\end{tabular}

a Not determined. 
Table B-2. Primary radiolytic species resulting from degassified, triple-distilled water in a nonreactive container using gamma radiation (LLNL data).

\begin{tabular}{|c|c|c|}
\hline & Ees. & $\begin{array}{l}\text { Yield expected } \\
\text { (number of radicals/loo Ev of } r_{a b} \text {. }\end{array}$ \\
\hline $\mathrm{OH}$ & hydroxy 1 radical & 2.72 \\
\hline$e_{a g}^{-}$ & aqueous electron & 2.63 \\
\hline$H^{04}$ & monatomic hydrogen & 0.55 \\
\hline $\mathrm{H}_{2}$ & molecular hydrogen & 0.45 \\
\hline $\mathrm{H}_{2} \mathrm{O}_{2}$ & hydrogen peroxide & 0.68 \\
\hline $\mathrm{HO}_{2}$ & hydroperoxyl radical & 0.026 \\
\hline
\end{tabular}

Note 1. The radicals react with the molecular species, and at steady state the predominant species are $\mathrm{H}_{2} \mathrm{O}_{2}, \mathrm{H}_{2}$ and some $\mathrm{O}_{2}$.

Note 2. If oxygen is present, it dominates the reaction by interacting with the aqueous electrons to form $\mathrm{O}_{2}^{-}$, which ultimately ties up the $\mathrm{H}_{2}$. 
Tentative

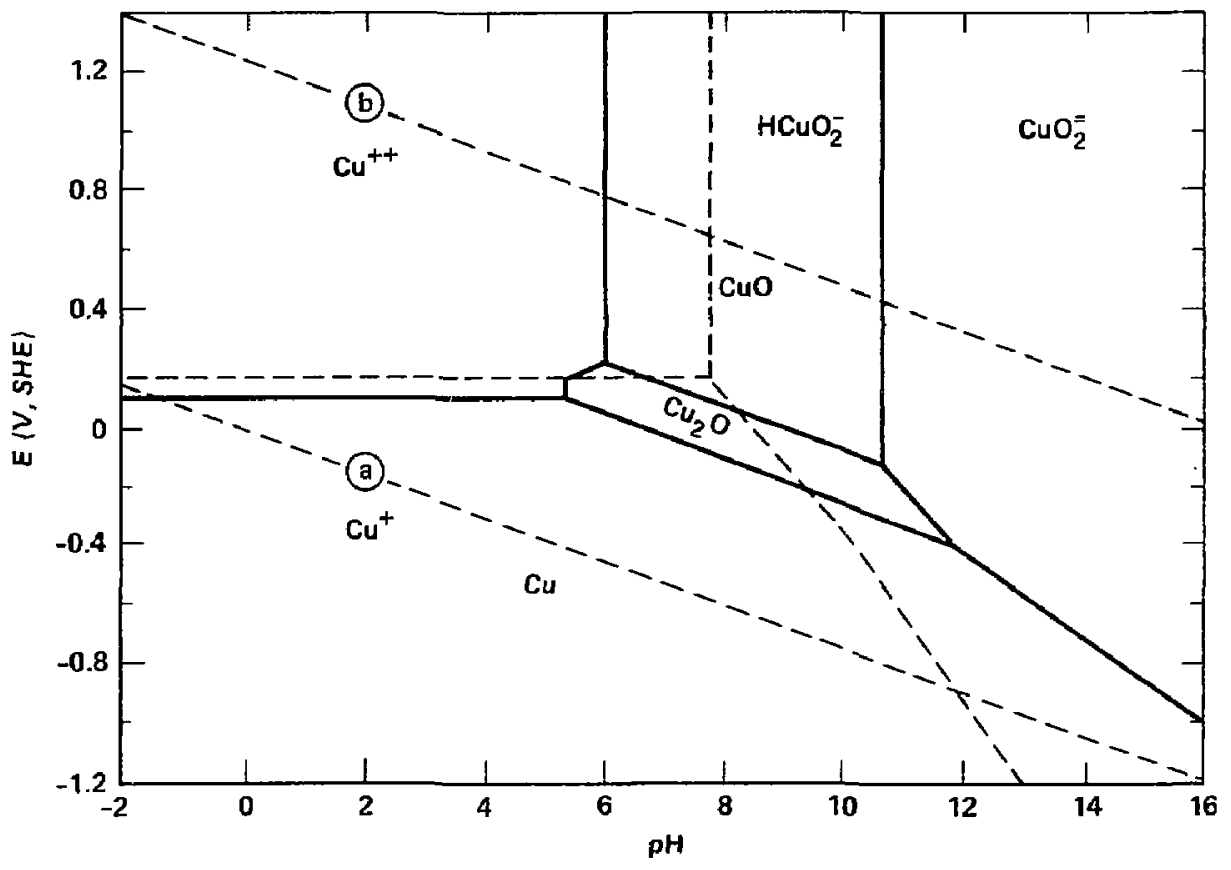

Fig. B- $\mathrm{Cu}-\mathrm{H}_{2} \mathrm{O}$ system, $\mathrm{I}=95^{\circ} \mathrm{C}, \mathrm{J}-13$ water.

B-8 
The following 16 tables identify 11 copper metals under consideration for use as container materlals in the U.S. program for civilian nuclear waste disposal (lable $A-1$ ) and present their physical and mechanical properties (Tables A-2 through A-12).

Mechanical property data at elevated temperature are somewhat sparse. The data presented represent well-estab71shed property values. Additional specific data sources are being evaluated, and some gaps will be filled in a new draft of tables to be sent shortly.

The data represent the thickest section and softest candtions for which data are avallable for the wrought products. Cast data represent separately cast test bars. 


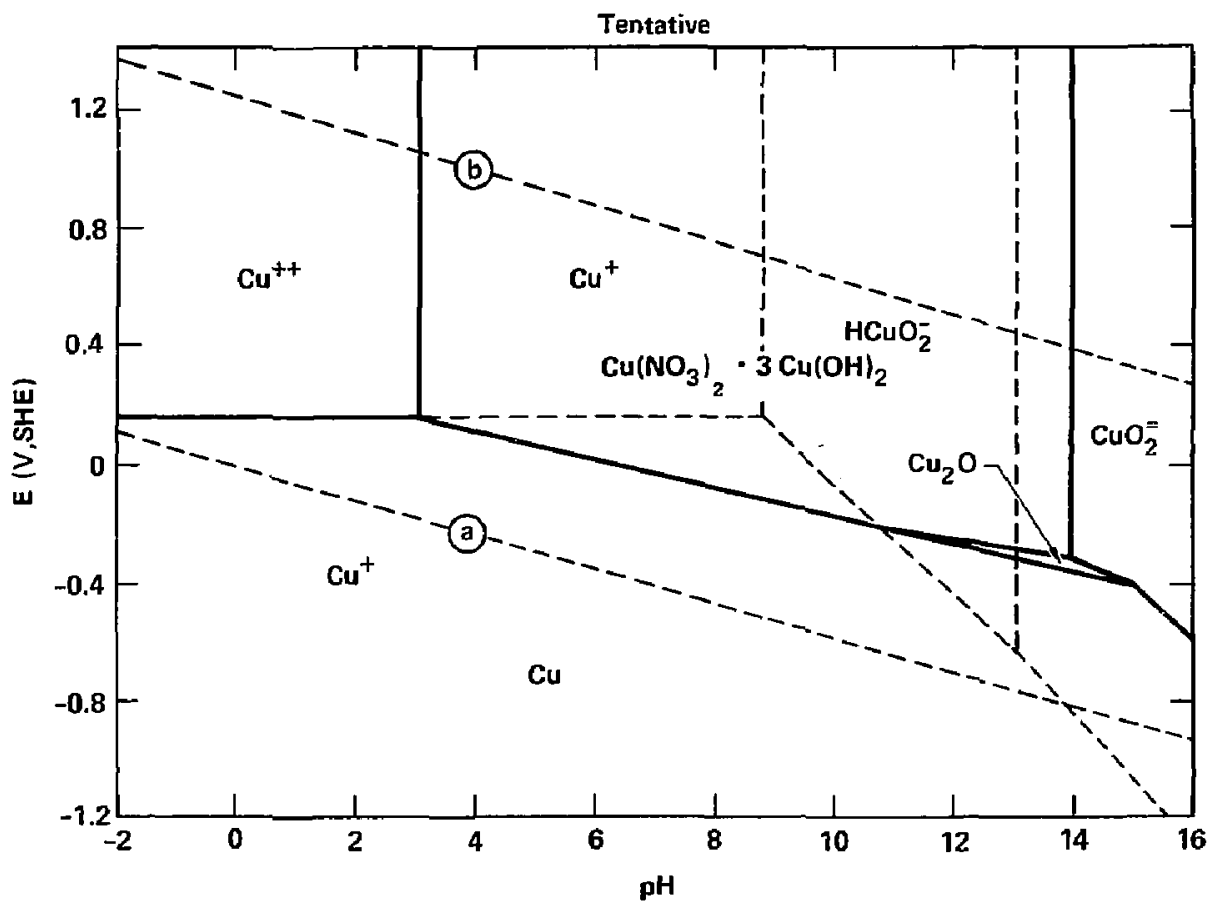

Fig. B-2 $\mathrm{Cu}-\mathrm{H}_{2} \mathrm{O}-\mathrm{O} . \mathrm{IM} \mathrm{NO}_{3}, \mathrm{~T}=25^{\circ} \mathrm{C}$, irradiated $\mathrm{J}-73$ water. 